\title{
MAIN REGULARITIES OF FAULTING IN LITHOSPHERE AND THEIR APPLICATION (BASED ON PHYSICAL MODELLING RESULTS)
}

\author{
S. A. Bornyakov ${ }^{1,2}$, K. Zh. Seminsky ${ }^{1}$, V. Yu. Buddo ${ }^{1}$, A. I. Miroshnichenko ${ }^{1}$, \\ A. V. Cheremnykh ${ }^{1}$, A. S. Cheremnykh ${ }^{1}$, A. A. Tarasova, ${ }^{1,2}$ \\ ${ }^{1}$ Institute of the Earth's Crust of SB RAS, Irkutsk, Russia \\ ${ }^{2}$ Irkutsk State University, Irkutsk, Russia
}

\begin{abstract}
Results of long-term experimental studies and modelling of faulting are briefly reviewed, and research methods and the-state-of-art issues are described. The article presents the main results of faulting modelling with the use of non-transparent elasto-viscous plastic and optically active models. An area of active dynamic influence of fault (AADIF) is the term introduced to characterise a fault as a 3D geological body. It is shown that AADIF's width (M) is determined by thickness of the layer wherein a fault occurs $(\mathrm{H})$, its viscosity $(\eta)$ and strain rate $(\mathrm{V})$. Multiple correlation equations are proposed to show relationships between AADIF's width (M), $\mathrm{H}, \eta$ and $\mathrm{V}$ for faults of various morphological and genetic types. The irregularity of AADIF in time and space is characterised in view of staged formation of the internal fault structure of such areas and geometric and dynamic parameters of AADIF which are changeable along the fault strike. The authors pioneered in application of the open system conception to find explanations of regularities of structure formation in AADIFs. It is shown that faulting is a synergistic process of continuous changes of structural levels of strain, which differ in manifestation of specific selfsimilar fractures of various scales. Such levels are changeable due to self-organization processes of fracture systems. Fracture dissipative structures (FDS) is the term introduced to describe systems of fractures that are subject to self-organization. It is proposed to consider informational entropy and fractal dimensions in order to reveal FDS in AADIF. Studied are relationships between structure formation in AADIF and accompanying processes, such as acoustic emission and terrain development above zones wherein faulting takes place.

Optically active elastic models were designed to simulate the stress-and-strain state of AADIF of main standard types of fault jointing zones and their analogues in nature, and modelling results are reported in the article. A good correlation is revealed between the available seismological, structural geological and geodetic data.
\end{abstract}

Key words: lithosphere, faults, physical modelling, similarity theory, equivalent materials, synergetics, quantitative parameters.

Recommended by K.G. Levi

Citation: Bornyakov S.A., Seminsky K.Zh., Buddo V.Yu., Miroshnichenko A.I., Cheremnykh A.V., Cheremnykh A.S., Tarasova A.A., 2014. Main regularities of faulting in lithosphere and their application (based on physical modelling results). Geodynamics \& Tectonophysics 5 (4), 823-861. doi:10.5800/GT-2014-5-4-0159. 


\title{
ОСНОВНЫЕ ЗАКОНОМЕРНОСТИ РАЗЛОМООБРАЗОВАНИЯ В ЛИТОСФЕРЕ И ИХ ПРИКЛАДНЫЕ СЛЕДСТВИЯ (ПО РЕЗУЛЬТАТАМ ФИЗИЧЕСКОГО МОДЕЛИРОВАНИЯ)
}

\author{
С. А. Борняков ${ }^{1,2}$, К. Ж. Семинский ${ }^{1}$, В. Ю. Буддо ${ }^{1}$, А. И. Мирошниченко ${ }^{1}$, \\ А. В. Черемных ${ }^{1}$, А. С. Черемных ${ }^{1}$, А. А. Тарасова ${ }^{1,2}$ \\ ${ }^{1}$ Институт земной коры СО РАН, Иркутск, Россия \\ ${ }^{2}$ Иркутский государственный университет, Иркутск, Россия
}

\begin{abstract}
Аннотация: В краткой обзорной форме освещаются достижения многолетних комплексных экспериментальных исследований. Описаны их методология и современное состояние. Представлены наиболее важные результаты моделирования процессов разломообразования на непрозрачных упруговязкопластичных и на упругих оптически-активных моделях. Для характеристики разлома как трехмерного геологического тела введено понятие «область активного динамического влияния разлома» (ОАДВР). Показано, что ее ширина М определяется мощностью вмещающего разлом слоя (H), его вязкостью (П) и скоростью деформирования (V). Предложены формализованные выражения связи между М ОАДВР разломов разного морфолого-генетического типа с $\mathrm{H}, \eta$ и V в виде уравнений множественной корреляции. Охарактеризована временная и пространственная неравномерность ОАДВР, выражающаяся в стадийноэтапном формировании их внутренней разрывной структуры, с ее меняющимися по простиранию разлома геометрическими и динамическими характеристиками. Впервые для объяснения закономерности структурообразования в ОАДВР привлечена концепция открытых систем. Показано, что разломообразование представляет собой синергетический процесс последовательной смены структурных уровней деформации с характерным для каждого из них набором разномасштабных разрывных нарушений, обладающих свойствами самоподобия и что определяющая роль при смене структурных уровней принадлежит процессам самоорганизации систем разрывных нарушений. Для характеристики систем разрывов, вовлеченных в самоорганизацию, введено понятие «разрывные диссипативные структуры» (РДС). Для выделения РДС в ОАДВР предложено использовать информационную энтропию и фрактальную размерность. Исследована связь со структурообразованием в ОАДВР сопутствующих процессов, таких как акустическая эмиссия и рельефообразование над зонами формирующихся разломов.

Представлен комплекс результатов моделирования напряженно-деформированного состояния в ОАДВР основных эталонных типов зон сочленения разломов и их природных аналогов в оптически-активных упругих моделях. Показана хорошая согласованность с данными сейсмологических, геолого-структурных и геодезических исследований.
\end{abstract}

Ключевые слова: литосфера, разломы, физическое моделирование, теория подобия, эквивалентные материалы, синергетика, количественные параметры.

\section{1. ВВЕДЕНИЕ}

Физическое моделирование тектонических процессов и структур является неотъемлемой методологической частью тектонофизики. За более чем вековую историю становления и развития оно оформилось как метод исследования, опирающийся на теоретическую основу - теорию подобия [Hubbert, 1937; Gzovsky, 1975; Ramberg, 1981; Shemenda, 1983; Sherman, 1984; u dp.]. О его современном состоянии и востребованности можно судить по серии обзорных работ и материалам проходящей с 2002 г. с двухлетней периодичностью международной конференции по физическому и математическому моделированию в геологических науках «GEOMOD» [Dooley, Schreurs, 2012; Graveleau et al., 2012; Bornyakov, 2012; u dp.].

Использование физического моделирования для исследования процессов разломообразования в ИЗК СО
РАН началось в 1974 г. и было представлено экспериментами, эпизодически выполняемыми в лаборатории неотектоники и геоморфологии на непрозрачных упруговязкопластичных эквивалентных материалах. С 1979 г. эти эксперименты имеют «постоянную прописку» в созданной лаборатории тектонофизики, со временем расширились по своему целевому содержанию и дополнились экспериментами на упругих, оптически-активных материалах.

Становлению и быстрому развитию экспериментальных работ способствовали, во-первых, административная и финансовая поддержка дирекции института в лице Н.А. Логачева и О.В. Павлова и, вовторых, стажировки начинающих молодых экспериментаторов у известных мастеров эксперимента, таких как Д.Н. Осокина, А.В. Михайлова, О.Г. Шамина в ИФЗ РАН, В.Г. Гутерман в ИГ УАН, П.М. Бондаренко в ИГиГ СО РАН. 
Отличительной чертой проводимых в лаборатории тектонофизики экспериментов всегда была и остается их постоянная тематическая направленность, ориентированная на изучение основных структурно-динамических закономерностей разломообразования в литосфере и связанных с ним процессов, с акцентом на методы количественного анализа при обработке получаемого экспериментального материала.

В настоящей обзорной статье в краткой форме освещаются основные результаты выполненных в ней многолетних комплексных экспериментальных исследований большого коллектива экспериментаторов.

\section{2. ОСНОВНЫЕ РЕЗУЛЬТАТЫ ФИЗИЧЕСКОГО МОДЕЛИРОВАНИЯ ПРОЦЕССОВ РАЗЛОМООБРАЗОВАНИЯ НА УПРУГОВЯЗКОПЛАСТИЧНЫХ МОДЕЛЯХ}

\section{1. МЕТОДИКА МОДЕЛИРОВАНИЯ}

\subsection{1. Условия подобия}

Из пяти выделенных М.В. Гзовским основных принципов моделирования процессов формирования тектонических структур первым и наиболее важным является принцип подобия модели и природного объекта [Gzovsky, 1975]. Существует два кардинально отличающихся подхода к реализации этого принципа. По мнению сторонников первого, достаточно достижения подобия модели и ее природного аналога на качественном уровне (В.В. Белоусов, М.А. Гончаров, В.Г. Гутерман и др.), тогда как сторонники второго подхода убеждены в том, что такое подобие должно осуществляться на количественной основе. Второй подход развит М.В. Гзовским [Gzovsky, 1975] с учетом ранее имеющегося опыта использования условий подобия при моделировании тектонических (Г. Кенинсберг, Е.Н. Люстих, О. Морат, М. Хабберт, Б.Л. Шнеерсон) и физических (А.А. Гухман, В.Л. Кирпичев, М.В. Кирпичев, Л.С. Эйгенсон и др.) процессов. Позднее предпринимались неоднократные попытки его совершенствования [Shemenda, 1983; Sherman, 1984; Babichev, 1987; и дp.]. Время подтверждает правомерность и современный приоритет второго подхода. Сегодня в подавляющем большинстве зарубежных публикаций, посвященных результатам моделирования, теория подобия является неотъемлемой частью их методического раздела.

В лаборатории тектонофизики ИЗК СО РАН физическое моделирование процессов формирования крупных разломных зон в литосфере проводилось и проводится с использованием количественного критерия подобия для определения граничных условий эксперимента:

$$
\eta / \rho g L T=\text { const, }
$$

где $\eta$ - вязкость, Па·с; $\rho$ - плотность, кг $/ \mathrm{M}^{3}$; g - ускорение свободного падения, м/ $\mathrm{c}^{2} ; \mathrm{L}-$ линейные размеры, м; Т - время, с [Sherman, 1984; Gzovsky, 1975; Babichev, 1987]. Этот критерий позволяет вычислить масштабные коэффициенты для каждого из использованных в нем физических параметров. При моделировании крупных разломов, соизмеримых по масштабу с межплитными границами, принято использовать масштабные коэффициенты подобия вязкости $\mathrm{C}_{\eta} \sim 10^{17}$, плотности $\mathrm{C}_{\rho} \sim 0.5$, линейных размеров $\mathrm{C}_{\mathrm{l}} \sim 10^{6}$ и времени $\mathrm{C}_{\mathrm{t}} \sim 5 \cdot 10^{11}$. При таких значениях коэффициентов подобия 1 мм в модели соответствует 1 км в ее природном аналоге, а 1 мин эксперимента эквивалентна 1 млн лет природного процесса.

\subsection{2. Модельный материал}

Выбор модельного материала осуществлялся с учетом упруговязкопластичного поведения литосферы при длительно действующих на нее нагрузках [Sherman, 1977]. В рамках временной длительности эксперимента при используемых скоростях нагружения моделей сходные с литосферой реологические свойства имеют водные пасты глин. Нами выбрана водная паста монтмориллонитовой глины, правомерность использования которой в качестве модельного материала обоснована специально проведенным исследованием [Seminsky, 1986]. Она представляет собой малопрочную твердообразную структурированную систему, которой присущи следующие реологические свойства: предел текучести; частичные обратимые и необратимые деформации, обусловленные наличием в материале мгновенной и замедленной упругости; ступенчатый вид снижения эффективной вязкости с возрастанием напряжения, что свидетельствует о характерных значениях вязкости, остающихся постоянными в определенных интервалах значений напряжения и соответствующих разной степени нарушенности структуры; уменьшение значений основных количественных параметров по мере увеличения нарушенности структуры материала; наличие релаксации напряжений. Перечисленные свойства глинистой пасты проявляются и в литосфере при ее деформации, что позволяет говорить о их реологической сопоставимости [Seminsky, 1986].

\subsection{3. Экспериментальное оборудование, техника подготовки и проведения экспериментов}

При подготовке и проведении экспериментов использовался комплекс оборудования, включающий в себя вискозиметры, установку «Разлом», фото- и видеоаппаратуру. Установка «Разлом» позволяет воспроизводить в моделях процессы формирования зон разломов в условиях растяжения, сжатия, сдвига или их комбинаций, при скоростных режимах деформирования $10^{-5}, 10^{-4}$ и $10^{-3} \mathrm{M} / \mathrm{c}$ (рис. 1). Модельный матери- 


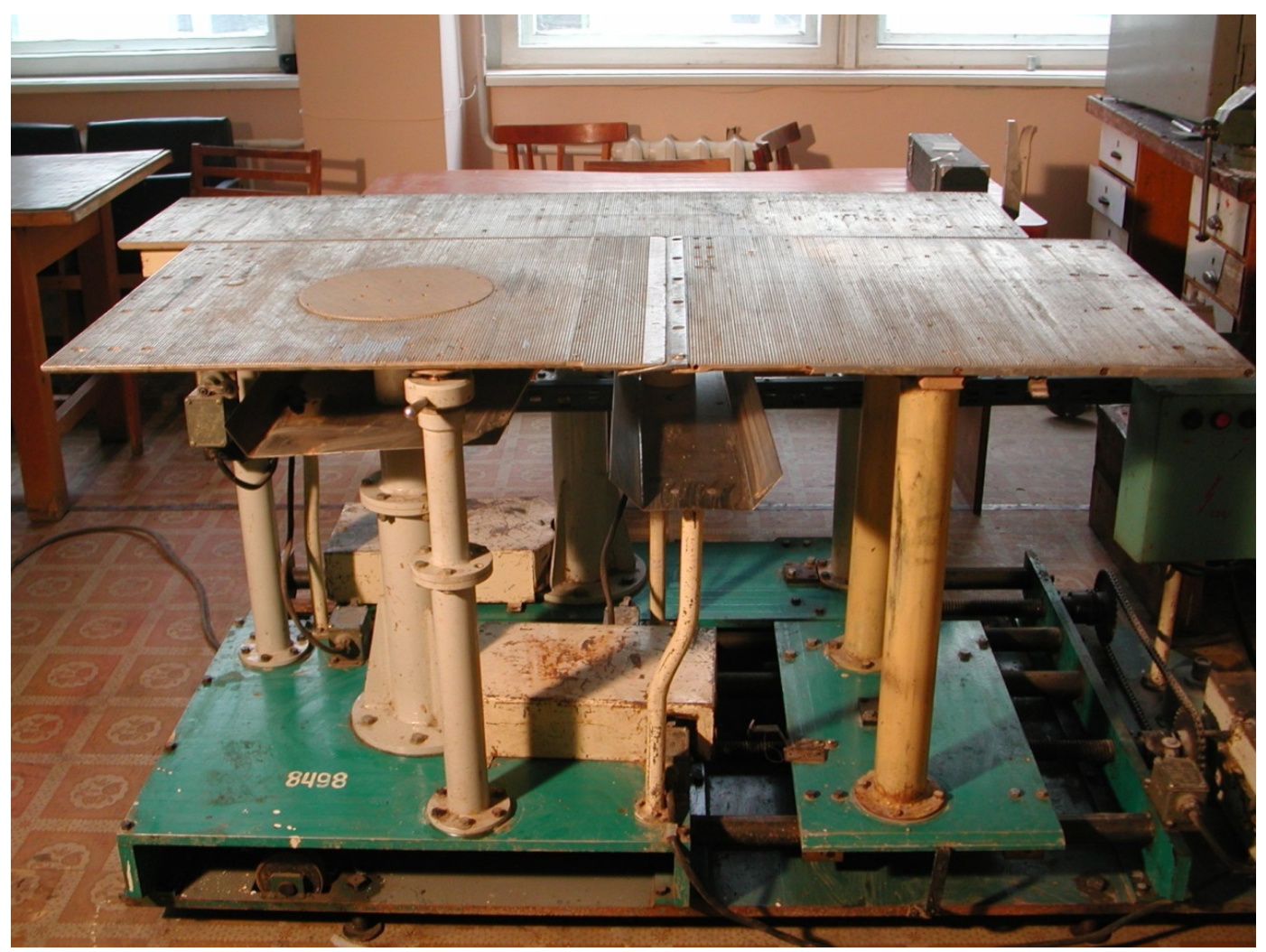

Рис. 1. Общий вид установки «Разлом» для моделирования процессов разломообразования в упруговязкопластичных моделях литосферы.

I Fig. 1. RAZLOM installation for simulation of faulting in the lithosphere in elasto-visco-plastic models.

ал после инструментального контроля вязкости прибором ПДС-10, конструкции М.В. Гзовского и Д.Н. Осокиной, или реовискозиметром Гепплера ровным слоем размещался на рабочей поверхности экспериментальной установки. До эксперимента на плановую поверхность модели наносилась реперная сетка из колец или прямых линий, по формоизменению которой впоследствии производилась количественная оценка деформаций и перемещений. Развивающийся в модели процесс структурообразования в зоне формирующегося разлома детально фотографировался через выбранный временной интервал. В зависимости от решаемой задачи временная дискретность съемки варьировалась от 1 с до 1 мин. Полученные фотоматериалы составляли основу для построения необходимых структурных схем, с которых снималась качественная и количественная информация с последующей ее обработкой и анализом. Для каждого морфолого-генетического типа разломной зоны проводился самостоятельный комплекс экспериментов, в рамках которого, с учетом принципа раздельного моделирования существенных факторов, оценивалось влияние на формирующуюся внутреннюю структуру и характеризующие ее количественные параметры мощности разрушаемого слоя, ее вязкости и скорости деформирования. С фотографий моделей получены десятки тысяч замеров разных количествен- ных параметров, между которыми установлены парные и многомерные корреляционные связи.

\section{2. ОСНОВНЫЕ ЗАКОНОМЕРНОСТИ ФОРМИРОВАНИЯ КРУПНЫХ РАЗЛОМОВ ЛИТОСФЕРЫ, ВЫЯВЛЕННЫЕ ПО РЕЗУЛЬТАТАМ ФИЗИЧЕСКОГО МОДЕЛИРОВАНИЯ}

При описании основных экспериментально установленных закономерностей формирования крупных разломов литосферы акцент чаще делается на результатах моделирования сдвиговых зон. Их распространенность в природе и относительная простота воспроизведения в моделях делают сдвиговые зоны своеобразным структурным эталоном для моделирования. Все выявленные для них основные закономерности в большей части будут правомерны и для других морфолого-генетических типов разломных зон.

\subsection{1. Крупные разломы и составляющие их внутреннюю структуру разрывы как трехмерные тела}

Наблюдения за развитием процессов разломообразования в моделях стимулировали введение нового понятия - «область активного динамического влияния разлома» (ОАДВР). Под ним понимается окружающее разлом в трех измерениях пространство, в котором 


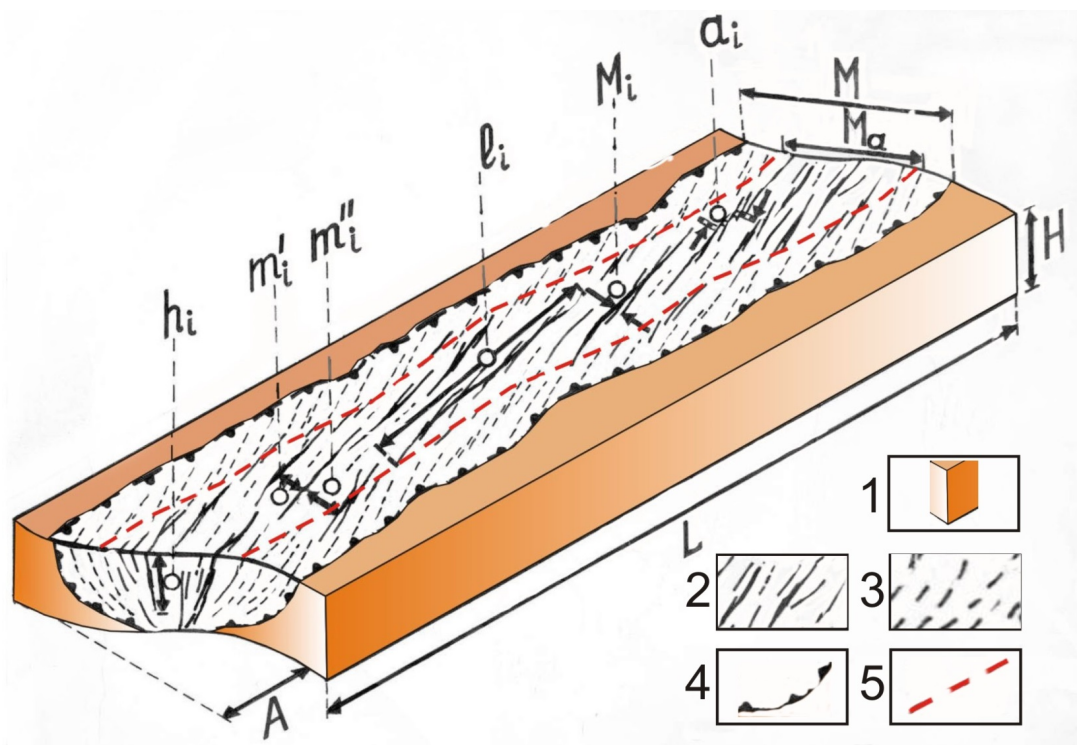

Рис. 2. Структурная схема ОАДВ сдвиговой зоны в модели и ее параметры.

$\mathrm{L}$ - длина и $\mathrm{H}$ - толщина модели; А - амплитуда смещения крыльев сдвиговой зоны; $\mathrm{M}$ - ширина ОАДВ; $\mathrm{M}_{\mathrm{a}}-$ ширина ОАС; $\mathrm{l}_{\mathrm{i}}-$ длина и $\mathrm{h}_{\mathrm{i}}$ - глубина проникновения единичного разрыва и $\mathrm{a}_{\mathrm{i}}$ - амплитуда смещения на единичном разрыве; $\mathrm{m}_{\mathrm{i}}$ и $\mathrm{m}_{\mathrm{i}}{ }^{\prime}-$ ширина смежных блоков, контактирующих по единичному разрыву. 1 - модель; 2 - активные разрывы; 3 - пассивные разрывы; 4 - граница ОАДВ; 5 - граница AOC.

Fig. 2. Structural scheme of AADIF in a simulated shear zone.

L - model length; $\mathrm{H}$ - model thickness; A - amplitude of displacement of wings of the shear zone; M - AADIF width; $\mathrm{M}_{\mathrm{a}}$ - width of acoustic signal area; $l_{i}-$ singular fault's length; $h_{i}-$ singular fault's depth; $a_{i}$ - displacement amplitude at the singular fault; $m_{i}^{\prime}$ and $m_{i}$ " - widths of adjacent blocks separated by the singular fault. 1 - model; 2 - active faults; 3 - passive faults; 4 - AADIF boundary; 5 - boundary of the acoustic signal area.

проявляются пластические и разрывные деформации, вызванные формированием разлома и последующими подвижками по нему [Sherman et al., 1983]. В проведенном комплексе экспериментов с моделей были собраны замеры ширины (M) формирующихся в моделях зон разломов (рис. 2) [Sherman et al., 1983, 1991]. Эксперименты выполнялись при варьирующихся значениях толщины модели Н (от 0.01 до 0.10 м), вязкости $\eta$ (от $10^{4}$ до $10^{8} \mathrm{~Pa} \cdot \mathrm{s}$ ) и скорости деформирования V (от $10^{-5}$ до $\left.10^{-3} \mathrm{M} / \mathrm{c}\right)$, что позволило получить формализованную зависимость ширины ОАДВР от перечисленных параметров. В общем виде эта зависимость описывается уравнением:

$$
\mathrm{M}=\mathrm{C}_{1} \cdot \mathrm{H}+\mathrm{C}_{2} \cdot \lg \eta+\mathrm{C}_{3} \cdot \lg \mathrm{V}-\mathrm{K}
$$

Для каждого морфолого-генетического типа ОАДВР характерны свои значения коэффициентов $\mathrm{C}_{1}$, $\mathrm{C}_{2}, \mathrm{C}_{3}$ и свободного члена K [Sherman et al., 1983, 1991, 1992, 1994]. Выполненные оценки показали, что ширина зоны разлома главным образом определяется толщиной разрушаемого слоя и связана с ней прямой зависимостью. К аналогичному выводу в разное время приходили и другие экспериментаторы [Gzovsky, 1975; Stoyanov, 1977; Courtillot et al., 1974; Naylor et al., 1986; Tchalenko, 1970; Wilcox et al., 1973; Atmaoui et al., 2006]. Существенно меньший вклад в параметр М вносят вязкость и скорость деформирования. При этом увеличение первой способствует заложению в ней более широких разломных зон, тогда как увеличение второй приводит к обратному эффекту [Bornyakov, 1990; Sherman et al., 1991, 1992, 1994].

Параметр М отражает максимальную ширину ОАДВР, характерную для конца первой стадии его развития [Sherman et al., 1983, 1991]. При дальнейшей эволюции зоны разлома процесс структурообразования локализуется во все более узкой области. Эта область названа нами «областью активного структурообразования» (ОАС). В дополнительно проведенных сериях экспериментов был собран необходимый цифровой материал, позволивший сделать количественную оценку ее ширины $\left(\mathrm{M}_{\mathrm{a}}\right)$ (рис. 2). Для сдвиговой зоны она имеет вид [Bornyakov, 1990]:

$$
\begin{aligned}
& M_{a}=0.9525 H-0.02701 A-0.0758 \lg \eta+ \\
& +0.4161 \lg V+4.4924
\end{aligned}
$$

Из приведенного уравнения видно, что $\mathrm{M}_{\mathrm{a}}$ ОАС в основном определяется толщиной разрушаемого слоя (Н) и амплитудой смещения (А) ее крыльев, при незначительном влиянии $\eta$ и V. При этом Н и А выполняют разные функции. Если первый из них определяет 
максимально возможное значение параметра $\mathrm{M}_{\mathrm{a}}$, в пределе равное М, то второй контролирует его последующие изменения по мере развития деструктивного процесса.

Внутреннее строение сдвиговой зоны как объемной трехмерной структуры первого порядка представлено системами разноранговых разрывных нарушений и вычленяемых ими блоков. Каждый разрыв тоже имеет свою сложно построенную более мелкими разрывными нарушениями зону деструкции, представляя, таким образом, так же как и материнская структура, объемное трехмерное тело, меньшего по отношению к ней масштабного ранга. Геометрия ОАДВ таких разрывов характеризуется тремя параметрами: длиной $\mathrm{l}_{\mathrm{i}}$, шириной $\mathrm{M}_{\mathrm{i}}$ и глубиной проникновения $\mathrm{h}_{\mathrm{i}}$ (рис. 2). Ширина $\mathrm{M}_{\mathrm{i}}$ в общем виде описывается уравнением [Bornyakov, 1990]:

$$
\begin{aligned}
& M_{i}=C_{1} \cdot l_{i}+C_{2} \cdot m_{b 1}+C_{3} \cdot m_{b 2}+C_{4} \cdot \lg \eta+ \\
& +C_{5} \cdot \lg V-K,
\end{aligned}
$$

где $\mathrm{m}_{\mathrm{b} 1}$ и $\mathrm{m}_{\mathrm{b} 2}$ - ширина смежных с разрывом блоков, с которыми $\mathrm{M}_{\mathrm{i}}$ связана прямой зависимостью. Выполненные оценки показали, что ширина ОАДВ единичного разрыва в основном определяется его длиной, при осложняющем действии других параметров. При этом коэффициент $\mathrm{C}_{1}$ не остается постоянным и нелинейно убывает с увеличением длины разрыва.

\subsection{2. Временная и пространственная неравномерность развития крупных разломов}

На основе результатов моделирования установлено, что внутренняя разрывная структура крупных разломов эволюционирует в рамках трех стадий однонаправленно, от многочисленных мелких разрывов, через избирательное разрастание одних и переход в пассивное состояние других при межстадийных перестройках, к единому магистральному шву (рис. 3) [Bornyakov, 1981; Sherman et al., 1983, 1991; Seminsky, 2003]. Количественный анализ ряда параметров, характеризующих внутреннюю разрывную структуру разломных зон, показал, что в пределах стадий деформационный процесс развивается так же периодически и неравномерно, проявляя автомодельность на более низком пространственно-временном масштабном уровне. Так же как весь эволюционный процесс структурообразования подразделяется на стадии, каждая отдельная стадия, в свою очередь, подразделяется на три качественно повторяющихся этапа. Принципиальное отличие структурных перестроек между этапами и стадиями заключается в том, что первые способствуют дискретно эволюционному разрастанию существующей системы разрывов, тогда как вторые приводят к заложению новой системы более высокого масштабного ранга [Bornyakov, Semenova, 2011].

Временная неравномерность развития деструктив- ных зон по стадиям и этапам дополняется пространственной неравномерностью. Она проявляется в вариациях по простиранию и в крест простирания формирующегося разлома интенсивности протекания деструктивного процесса, что находит отражение в плотности составляющих его внутреннюю структуру активных разрывов и ряда других характеризующих их параметров [Seminsky, 2003]. На рис. 3 показана пространственная дифференциация зоны по степени нарушенности. Локализованные участки высокой плотности активных разрывов дискретно распределены по ее простиранию, чередуясь с участками низких значений этого параметра. В индивидуальном развитии разных участков зоны разлома имеются элементы несогласованности. В пределах одних участков процесс деструкции, варьируясь, протекает более интенсивно, чем в других, и фазы высокой активности у первых могут быть смещены по времени.

Детальный анализ вариаций амплитуд смещений во времени по отдельным разрывам показал, что их эволюционная динамика закономерна и подчиняется общему этапно-стадийному сценарию развития. В начале стадий и этапов новообразованный масштабный ранг разрывов обладает максимальной свободой перемещения своих крыльев, реализующегося в виде ускоряющихся или замедляющихся криповых смещений, с остановкой или без них, и дискретных импульсных подвижек, соответствующих известной модели «stickslip» [Brace, Byerlee, 1966]. По мере приближения к моменту очередной структурной перестройки эволюционирующей системы активных разрывов в конце этапов или стадий усиливаются стесненные условия на фоне роста напряжений, что сказывается на подвижности их крыльев. Криповые смещения в этом динамическом состоянии зоны разлома имеют минимальное проявление, тогда как дискретные импульсные подвижки, наоборот, преобладают, причем для последних характерно существенное увеличение во времени их количества на фоне снижения средних значений амплитуд. Возникающий дефицит смещений на внутриразломных разрывах в конце этапов и стадий частично компенсируется усилением пликативных деформаций разделяющих разрывы блоков.

\subsection{3. Нелинейная динамика деформационного процесса в деструктивной зоне}

Деформационный процесс в разломной зоне реализуется за счет упругой и пластической деформации блоков и их перемещений относительно друг друга по системам разрывам. Динамика последних отчетливо прослеживается по временным и пространственным вариациям амплитуд смещения (а) и ее приращениям за контрольный интервал времени $\left(\Delta \mathrm{a}_{\mathrm{i}}\right)$. На рисунке 4 показан фрагмент сдвиговой зоны с системой хорошо развитых протяженных разрывов и узких линейно вытянутых блоков. Результаты мониторинга приращения 

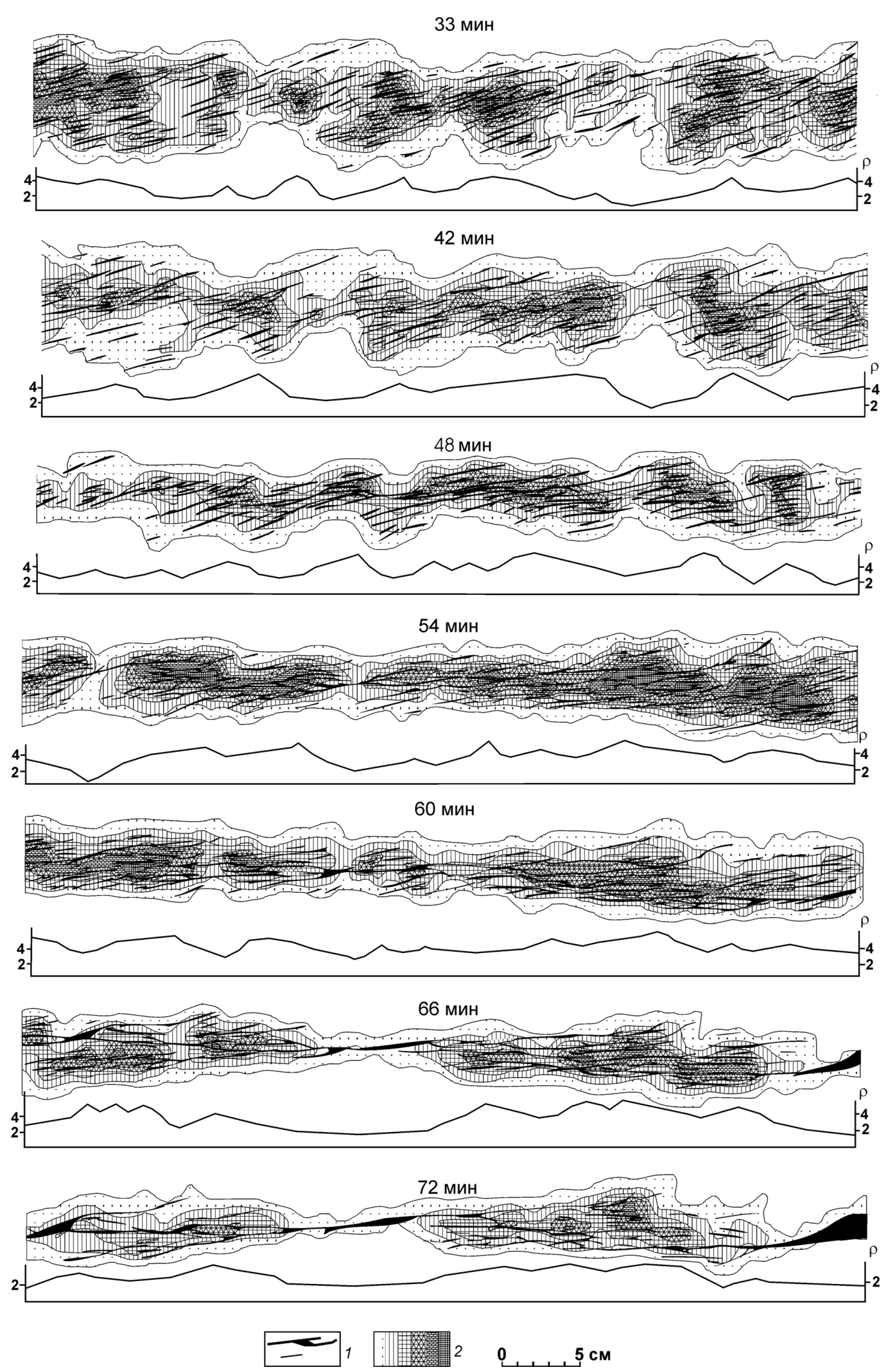

Рис. 3. Структурные схемы активных разрывов в сдвиговой зоне, графики и карты распределения их плотности в изолиниях, соответствующие отдельным этапам формирования сдвиговой зоны в упругопластичной модели.

1 - разрывы; 2 - области с различным количеством разрывов в единице площади (интенсивность штриховки пропорциональна плотности).

Fig. 3. Structural schemes of active faults in the shear zone, and curves and maps showing density patterns in isolines, which correspond to shearing stages. Elasto-plastic model.

1 - faults; 2 - areas with different numbers of faults per area unit. Higher density is shown by denser hatching. 


\section{A}

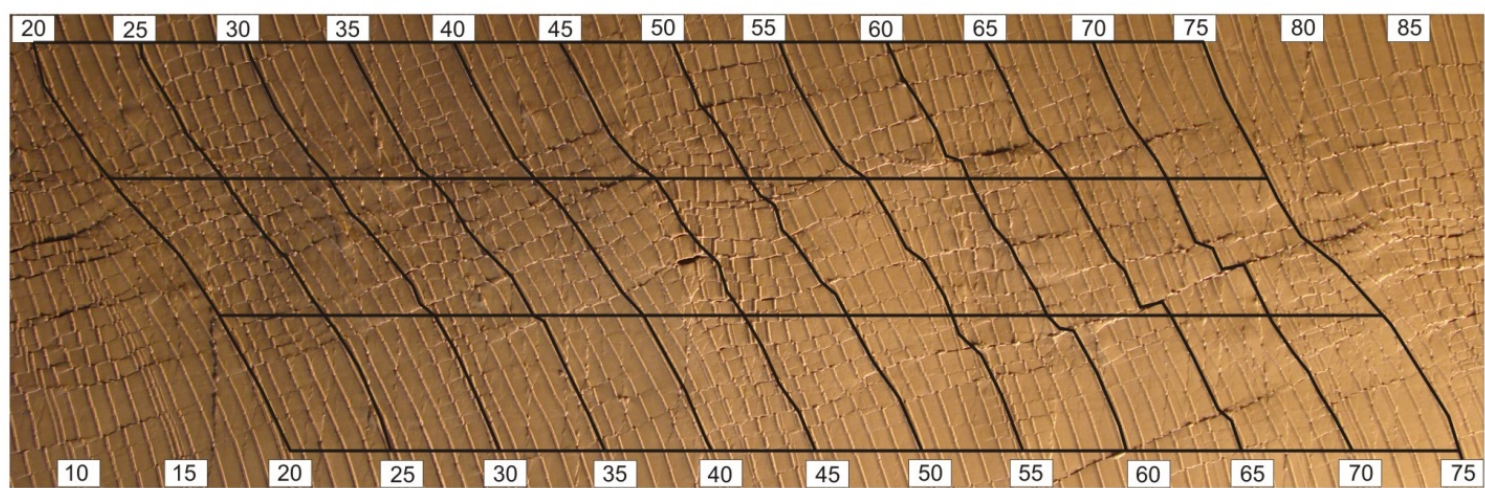

Б

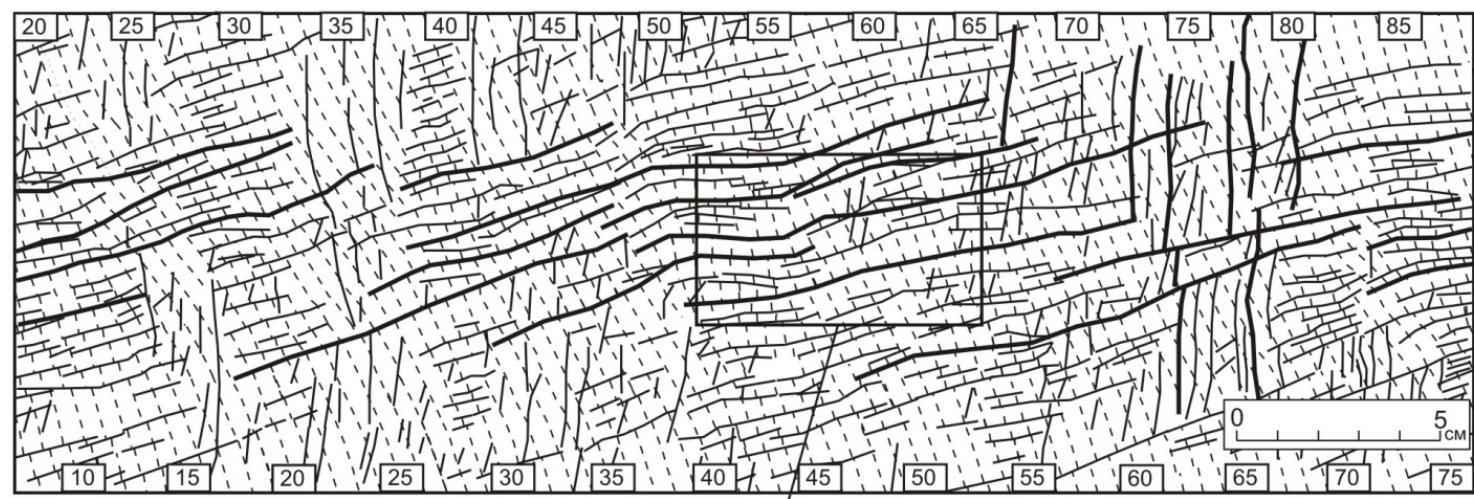

B

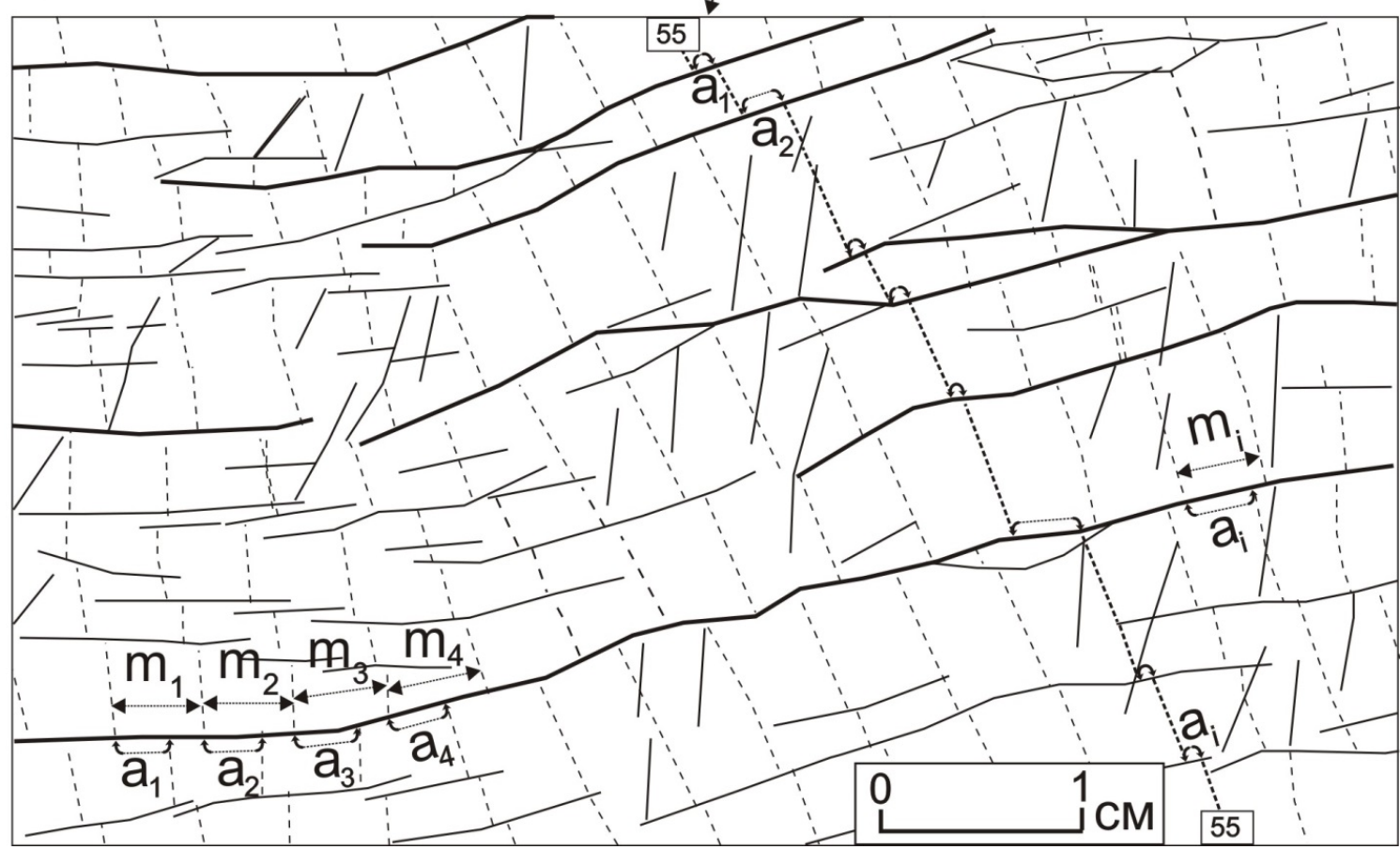

Рис. 4. Фрагмент сдвиговой зоны на модели (вид в плане) (А), ее структурная схема (Б) и увеличенный фрагмент структурной схемы (B). Расшифровка параметров $\mathrm{a}_{1} \ldots . \mathrm{a}_{\mathrm{i}}, \Delta \mathrm{m}_{1} \ldots \Delta \mathrm{m}_{\mathrm{i}}$ дана в тексте.

1 - реперная сетка линий; 2 - разрывы; 3 - нумерация реперных линий.

Fig. 4. Fragment of the simulated shear zone (plan view) $(A)$, its structural scheme $(\bar{b})$, and zoomed-up fragment of the structural scheme $\left((B)\right.$. Parameters $\mathrm{a}_{1} \ldots . \mathrm{a}_{\mathrm{i}}, \Delta \mathrm{m}_{1} \ldots \Delta \mathrm{m}_{\mathrm{i}}$ are described in the text.

1 - reference grid; 2 - faults; 3 - numbers of reference lines. 
$\mathrm{T}_{1}$

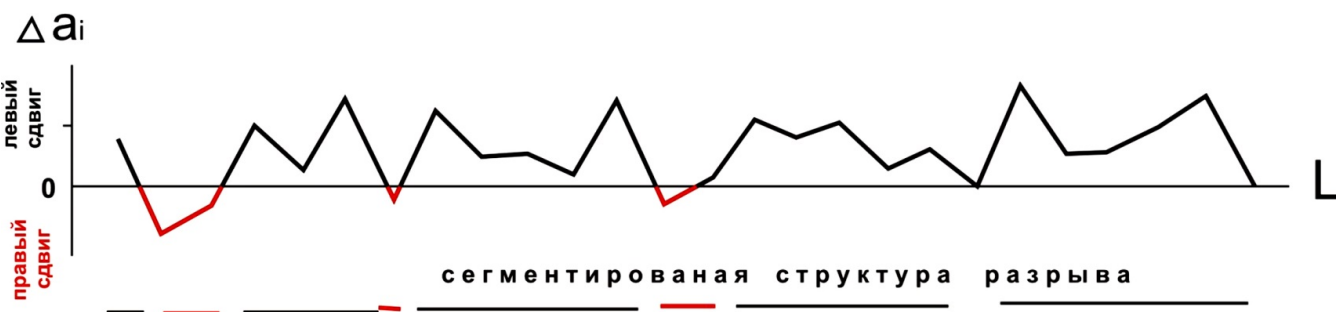

$\mathrm{T}_{2}$

$\Delta \mathrm{ai}$

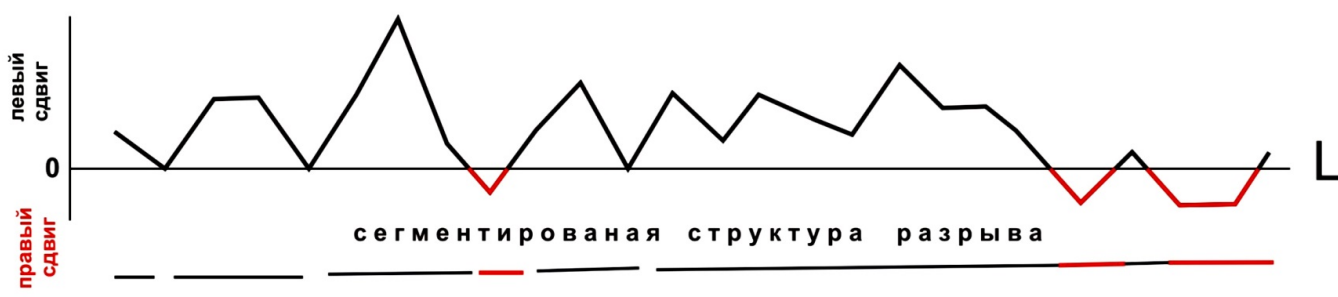

$\mathrm{T}_{3}$
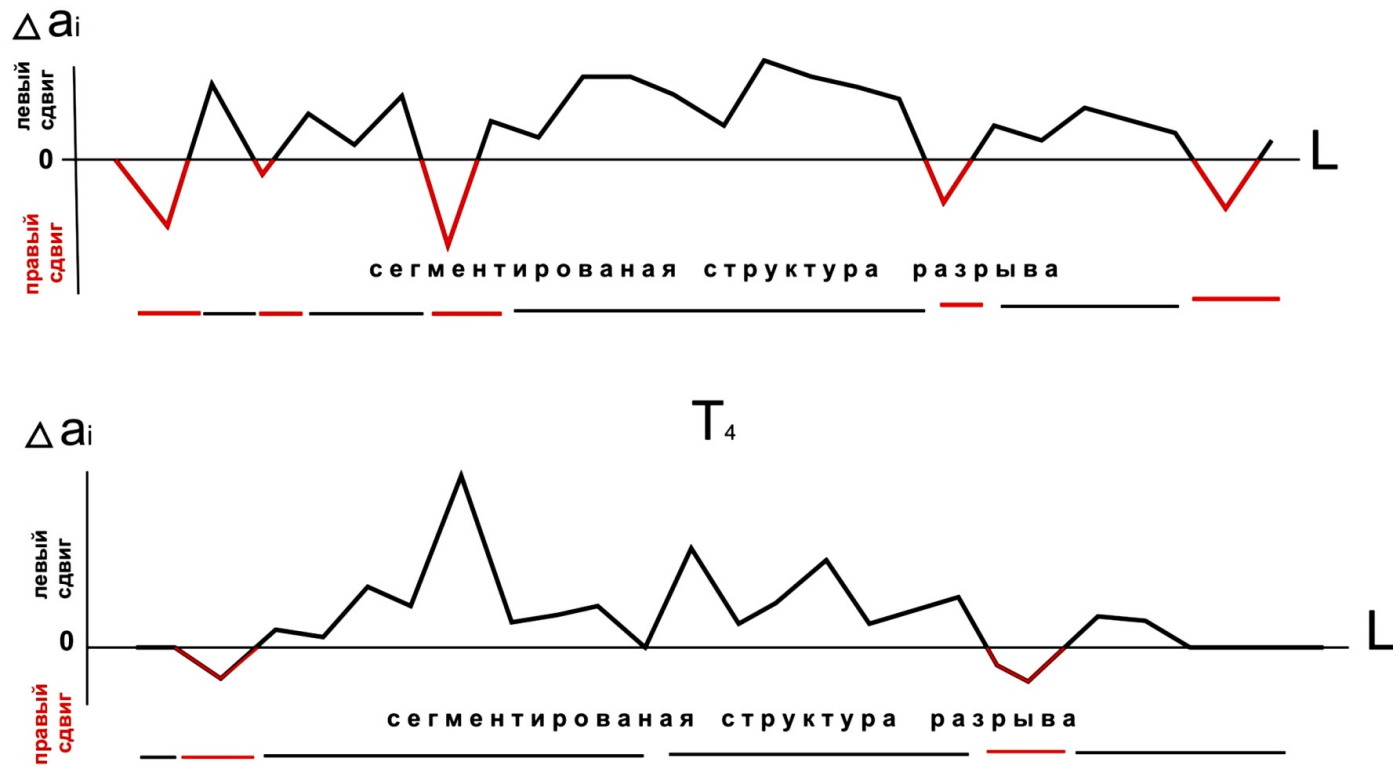

Рис. 5. Вариации приращения амплитуды смещения $\mathrm{a}_{\mathrm{i}}$ по простиранию единичного разрыва $\mathrm{L}$ в формирующейся зоне сдвига в модели, зафиксированные во время $\mathrm{T}_{1}, \mathrm{~T}_{2}, \mathrm{~T}_{3}, \mathrm{~T}_{4}$ с дискретностью 30 секунд.

Fig. 5. Variations of incremental displacement amplitude, $a_{i}$ along the strike of singular fault, $L$ in the shear zone in the model, which are recorded at time points T1, T2, T3, T4 with discreteness of 30 seconds.

амплитуды смещения $\left(\Delta \mathrm{a}_{\mathrm{i}}\right)$ на одном из таких разрывов, представленные на рисунке 5 в виде временной последовательности графиков, наглядно отражают пространственно-временную динамику изменения этого параметра. Его вариации указывают на разную степень активности разрыва по простиранию. По этому показателю разрыв в каждый фиксированный момент времени может быть представлен совокупностью разновеликих активных и пассивных сегментов. Сегмен- ты характеризуются пространственно-временной мобильностью и отличаются не только по величине амплитуды, но и по ее знаку. Наличие отрицательных значений приращения амплитуды свидетельствует о том, что на некоторых отдельных сегментах разрыва за контрольный интервал времени накопленная амплитуда не увеличилась, а, наоборот, уменьшилась за счет появления на них смещений обратного знака, противоположных направлению движения крыльев сдвиго- 

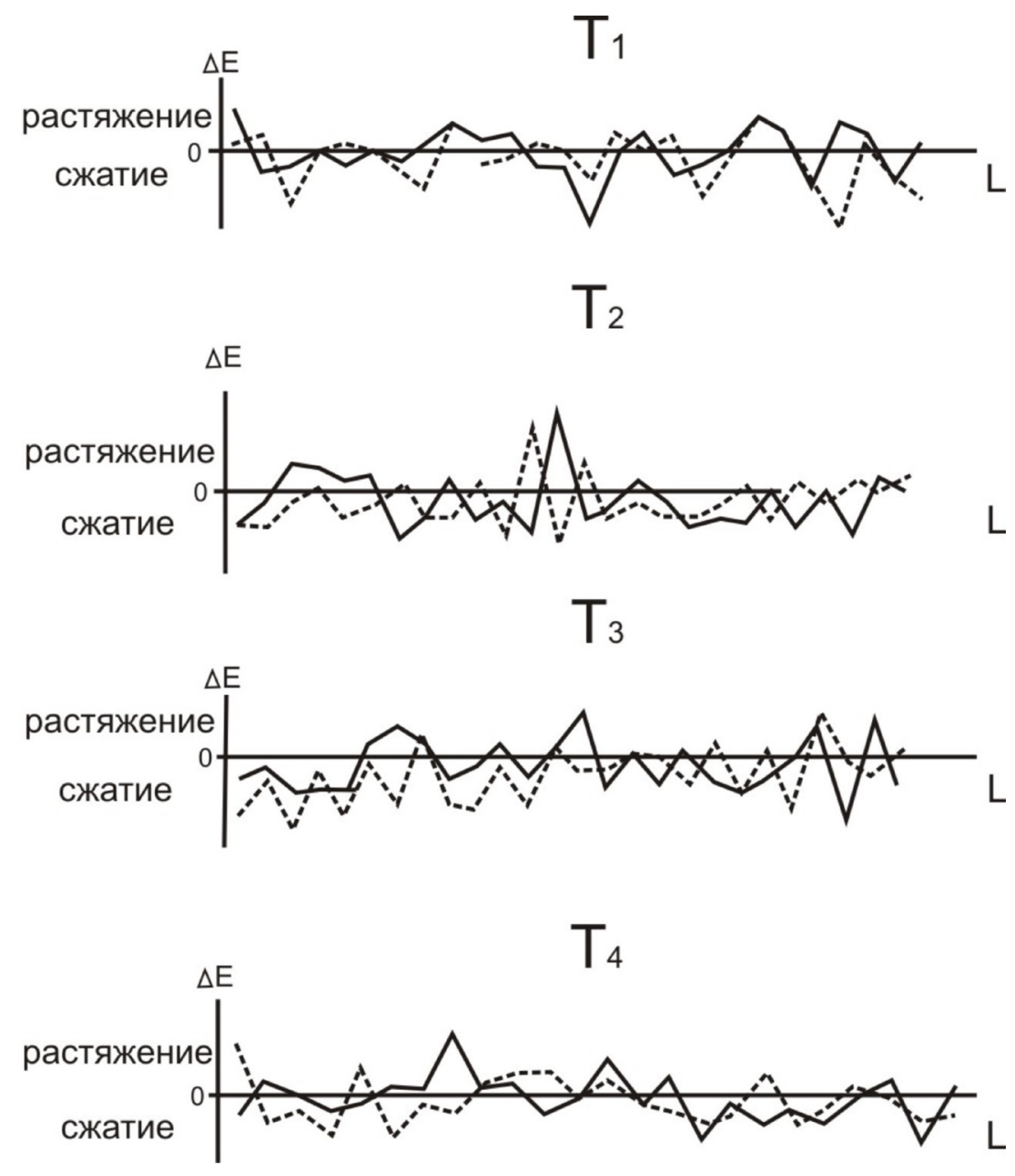

Рис. 6. Приращение деформации смежных $\Delta$ Е блоков в приконтактной области вдоль простирания разделяющего их разрыва.

| Fig. 6. Incremental stain of adjacent blocks, $\Delta \mathrm{E}$ in the near-contact zone along the strike of the fault between the two blocks.

вой зоны. Процесс сегментации приводит к тому, что в каждый момент времени реальной активностью обладают лишь отдельные участки протяженных разрывов, отнесенных к категории активных (рис. 5).

Для выяснения причин проявления на сегментах смещений обратного знака был проведен мониторинг деформации $\left(\mathrm{m}_{\mathrm{i}}\right)$ в приконтактных частях каждого из блоков с оценкой величины их приращения $(\Delta \mathrm{E})$ во времени (см. рис. 4):

$$
\Delta \mathrm{E}=\mathrm{m}_{\mathrm{i}+1}-\mathrm{m}_{\mathrm{i}}
$$

Построенные по результатам измерений графики показывают весьма неоднородную деформационную картину (рис. 6). Смежные блоки по их простиранию, по типу деформации в приконтактной области в каждый контрольный интервал времени могут быть разделены на области сжатия (отрицательные значения $\Delta \mathrm{E}$ ) и области растяжения (положительные значения $\Delta \mathrm{E}$ ), весьма мобильные во времени. Их перемещение вдоль блока в первом приближении напоминает волновой процесс. Примечателен тот факт, что деформационная обстановка на отдельных участках смежных блоков, расположенных друг против друга и контактирующих между собой по плоскости разрыва, чаще всего отличается как по абсолютным значениям деформаций, так и по их знаку. Нередки ситуации, когда в одном крыле единичного сдвигового разрыва в некоторый момент времени существует сжатие, а в симметрично расположенной точке другого крыла фиксируется растяжение (рис. 6). При определенном сочетании таких деформаций в смежных блоках на разделяющем их разрыве реализуются смещения обратного знака.

Анализ смещений по всей совокупности активных разрывных нарушений в пределах тестовой площадки в формирующейся сдвиговой зоне показал, что процесс их реализации имеет сложный, на первый взгляд неупорядоченный характер. Накопление амплитуд смещения идет в основном дифференцированно и неодинаково в разных крыльях зоны, однако в отдельные временные интервалы хаотичная волновая картина преобразуется и становится упорядоченной и квазипе- 
риодической. Такие динамические состояния блочной среды в формирующейся деструктивной зоне отмечены перед межстадийными структурными перестройками.

\subsection{4. Разломы как открытые неравновесные динамические системы}

В последние десятилетия под влиянием идей неравновесной термодинамики [Prigozhin, Kondepudi, 2002], синергетики [Haken, 1980, 1985] и фрактальной геометрии [Mandelbrot, 1982] представления о линейности, континуальности и детерминированности геологических систем меняются на представления о их нелинейности и масштабно-иерархической дискретности со сложными взаимоотношениями хаоса и порядка. В геодинамике это отражает тенденцию к формированию новой геодинамической концепции, показывающей, что литосфера в целом и все ее структурные элементы представляют собой открытые неравновесные динамические системы, процесс эволюции которых закономерно сопровождается разнообразными нелинейными эффектами, по масштабу соизмеримыми с масштабом порождающих их структур и процессов [Pushcharovsky, 1994, 1998].

Из широкого спектра структурных элементов литосферы удобными для исследования физической природы возникновения нелинейных эффектов являются разномасштабные зоны разломов. Доступность и накопленный опыт изучения общих закономерностей их развития, а также широко практикуемое количественное описание делают их своеобразными эталонными объектами для подобного рода исследований. На сегодняшний день для различных морфолого-генетических типов разломных зон установлен нелинейный характер вариаций их ширины по простиранию, связей между количественными параметрами участвующих в их внутреннем строении систем разрывов, полей напряжений, деформаций и сейсмических событий [Sherman et al., 1983, 1991, 1992, 2002; Seminsky, 2003; Mikhailova, 1971; Lobatskaya, 2003; Sadovsky, 1979; Sadovsky, Pisarenko, 1991; Levi, Sherman, 1991; Grigoriev, Osokina, 1979; Bornyakov, Sherman, 2003; и др.]. Нелинейность перечисленных явлений имеет многофакторную природу. Из большой группы факторов важная роль в ее формировании принадлежит внутреннему, функциональному свойству эволюционной динамики зон разломов, связанному с проявлением процессов самоорганизации внутриразломных систем разрывов [Bornyakov, Sherman, 2000].

Фундаментальной закономерностью процесса структурных преобразований в зонах разломов является его стадийность [Sherman et al., 1991, 1992; Seminsky, 2003; Bornyakov, Sherman, 2003]. Используемый нами ранее подход к объяснению ее природы с позиции модели лавинонеустойчивого трещинообразования (ЛНТ) [Kostrov, 1975; Myachin, 1978] сыграл в свое время важную конструктивную роль, но потребовал корректировки сложившихся представлений. В настоящее время мы рассматриваем эволюционную динамику зоны разлома как синергетический процесс, протекающий в виде последовательной смены стадий или структурных уровней, с характерным для каждого из них набором структурных элементов и механизмов деформации [Panin, 1998; Panin et al., 1995; Bornyakov, Sherman, 2000, 2003]. Определяющая роль перехода с одного структурного уровня на другой принадлежит особому состоянию систем разрывов в зоне разлома, обусловленному их самоорганизацией, спонтанно возникающей в условиях высокой динамической неравновесности разрывной системы перед структурными перестройками.

Известно, что функцией состояния открытой неравновесной динамической системы, по которой можно судить о наличии или отсутствии в ней процессов самоорганизации, является термодинамическая энтропия S [Prigozhin, Kondepudi, 2002]. Ее вариации при эволюции системы определяются характером изменения двух составляющих:

$$
\mathrm{dS}=\mathrm{dS}_{\mathrm{e}}+\mathrm{dS}_{\mathrm{i}}
$$

где $S_{e}-$ внешняя энтропия, привнесенная в систему извне; $S_{i}-$ внутренняя энтропия, произведенная самой системой. Согласно принципу минимума производства энтропии [Prigozhin, Kondepudi, 2002] в моменты развития процесса самоорганизации в такой системе второй член $\mathrm{dS}_{\mathrm{i}}$ уравнения (6) стремится к минимуму. Не имея возможности оценить для модельной системы разрывов термодинамическую энтропию, можно ограничиться оценкой информационной энтропии Шеннона $\left(S_{\text {inf }}\right)$ :

$$
\mathrm{S}_{\mathrm{inf}}=-\Sigma \mathrm{p}_{\mathrm{i}} \cdot \log _{2} \mathrm{p}_{\mathrm{i}}
$$

где $\mathrm{p}_{\mathrm{i}}$ - вероятность. На качественную аналогию $\mathrm{S}_{\mathrm{inf}}$ и $\mathrm{S}$ неоднократно обращалось внимание [Prigozhin, Kondepudi, 2002; Akopian, 1995, 1998; Brillouin, 1966; Ventcel, Ovcharov, 2000; Zubarev et al., 2002].

На рисунке 7 для примера приведены результаты расчета информационной энтропии разрывов и ее приращения за контрольный временной интервал $\left(\Delta \mathrm{S}_{\mathrm{inf}}=\right.$ $=S_{\text {inf } i+1}-S_{\text {inf i }}$ ) для фрагмента зоны формирующегося разлома. Видно, что площадное распределение $\Delta \mathrm{S}_{\text {inf }}$ имеет дифференцированный характер. Выделяются неравномерно распределенные локальные максимумы положительных и отрицательных значений $\Delta \mathrm{S}_{\text {inf. }}$

Универсальной особенностью эволюции открытых неравновесных динамических систем является периодическое чередование двух качественных состояний организации и самоорганизации [Zubarev et al., 2002]. C самоорганизацией связано формирование особого рода пространственно-временных «диссипативных» структур [Prigozhin, Kondepudi, 2002]. В условиях 


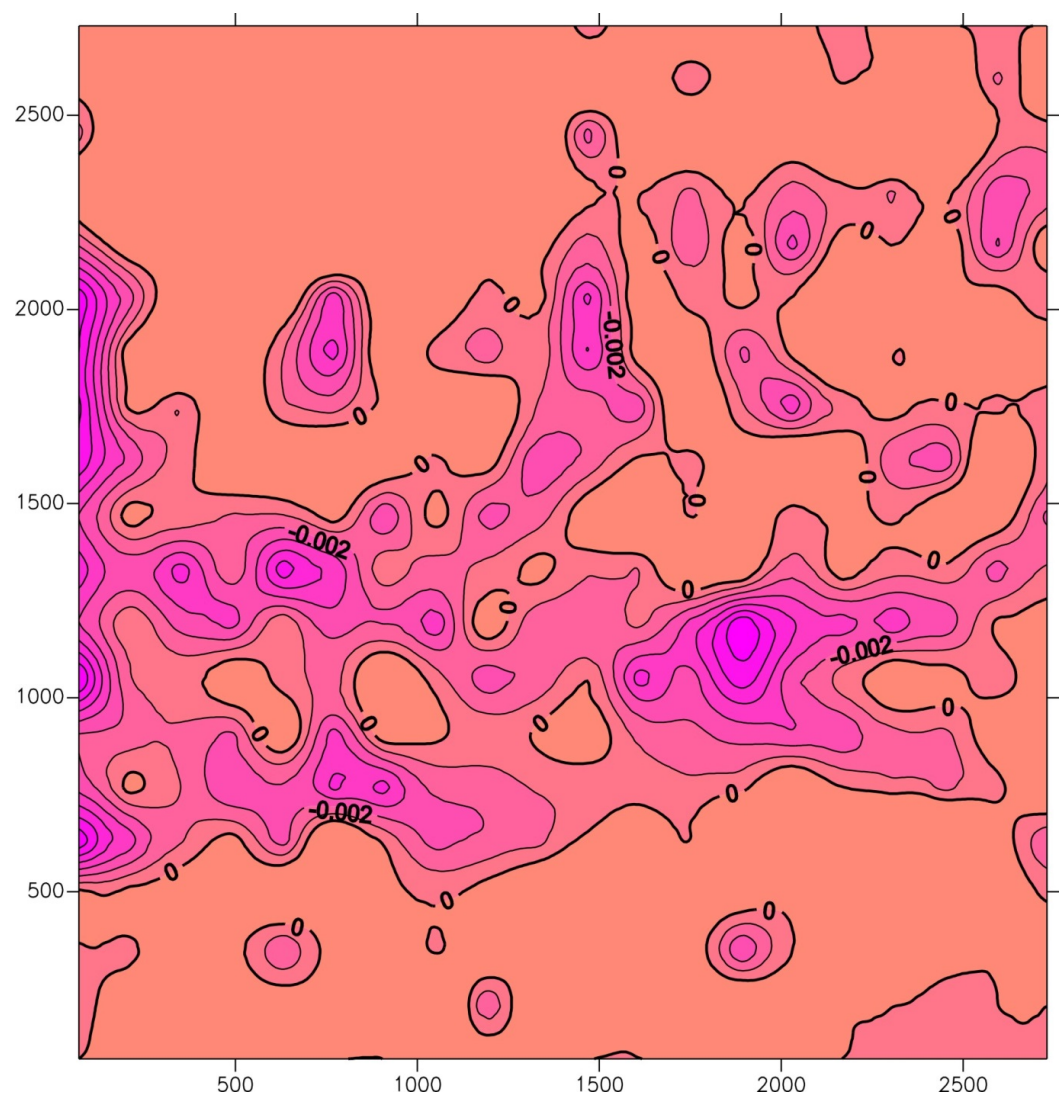

Рис. 7. Схема площадного распределения значений приращения информационной энтропии разрывов $\mathrm{S}_{\mathrm{inf}}$ в пределах фрагмента формирующейся зоны крупного разлома.

Fig. 7. Spacial pattern of information entropy increment values of faults, $S_{\text {inf }}$ within the limits of the fragment wherein a major fault zone is developing.

организации эволюция многочисленных разноранговых элементов такой системы происходит несогласованно и независимо, сопровождаясь ростом энтропии. В условиях же самоорганизации в рамках возникающей диссипативной структуры взаимодействие элементов системы носит согласованный, кооперативный характер, суммарным эффектом которого является уменьшение производства энтропии системы [Prigozhin, Kondepudi, 2002; Klimontovich, 1989; Letnikov, 1992]. В нашем случае, в свете вышеизложенного, локальные совокупности разрывных нарушений в зоне формирующегося разлома, характеризующиеся положительными и отрицательными значениями $\Delta \mathrm{S}_{\mathrm{inf}}$, в анализируемый временной интервал находились соответственно в состоянии организации и самоорганизации, переходя в последнем случае в особое динамическое состояние с образованием «разрывных диссипативных структур» (РДС). В каком локальном участке зоны разлома и когда проявится самоорганизация и возникнет РДС - определить заранее трудно. По направленности изменения энтропии можно как постфактум сделать вывод о месте и масштабах ее проявления за контрольный интервал времени (рис. 7). Пространственно-временная динамика центров самоорга- низации характеризуется нелинейностью и непредсказуемостью. При этом сам процесс самоорганизации представляет собой в большинстве случаев кратковременное явление и соответствует критическому, переходному состоянию той или иной совокупности разрывов перед их структурной перестройкой. В этом динамическом состоянии разрывы проявляют существенно нелинейные свойства с непропорциональным откликом на внешнее воздействие [Prigozhin, Kondepudi, 2002; Bornyakov et al., 2003; Kuznetsov, 1981].

\subsection{5. Сопутствующие процессы в деструктивньх зонах литосферы}

В качестве сопутствующих формированию зон разломов в моделях процессов рассматриваются акустическая эмиссия и рельефообразование.

Эксперименты по изучению акустической эмиссии выполнены В.А. Трусковым на специальном оборудовании в звукоизолированном боксе. Схема их проведения представлена на рисунке 8, а методика подробно описана в работе [Sherman et al., 1991].

Моделировался процесс формирования крупной деструктивной зоны сдвига. Модель из водной пасты 


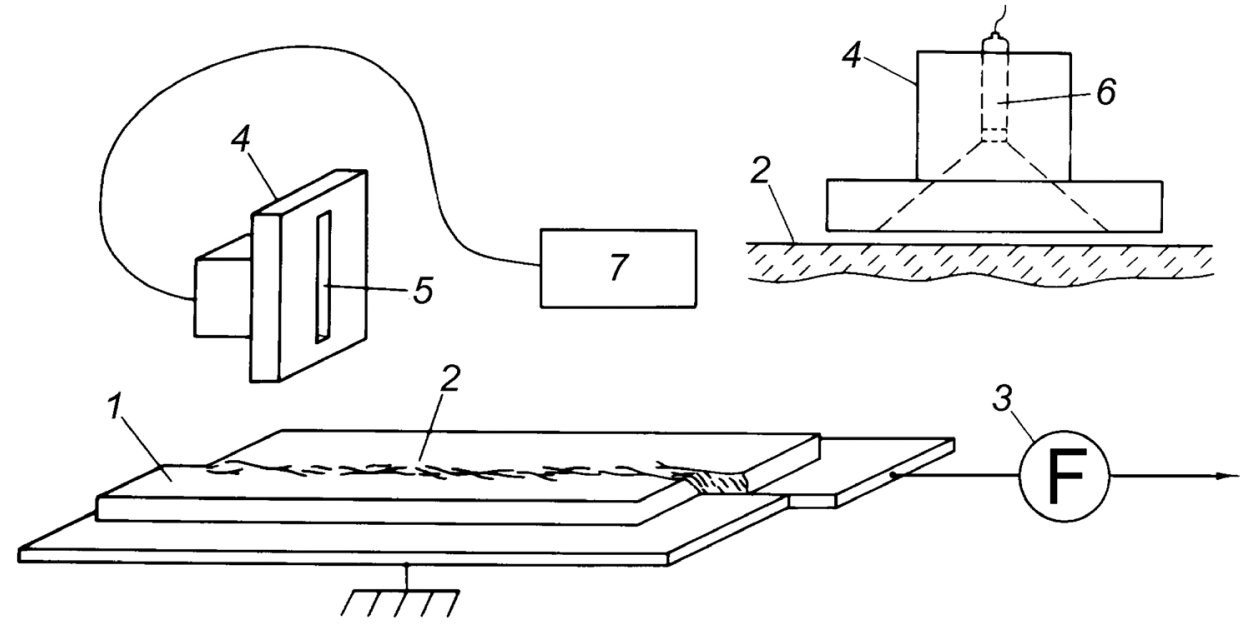

Рис. 8. Схема эксперимента. 1 - модель, 2 - сдвиговая зона, 3 - тензодинамометр, 4 - датчик АЭ, 5 - пирамидальный вырез к микрофону, 6 - микрофон, 7 - регистрирующая аппаратура.

Fig. 8. Experiment scheme. 1 - model; 2 - shear zone; 3 - strain gauge; 4 - acoustic emission sensor; 5 - pyramid-shaped cut to microphone; 6 - microphone; 7 - recorder.

бурой глины длиной 1.5 м, шириной 0.4 м и толщиной 0.04 м размещалась слоем равной толщины на двух штампах, один из которых перемещался параллельно другому с постоянной скоростью $10^{-4} \mathrm{~m} / \mathrm{c}$. Над моделью размещался акустический датчик, сигналы с которого записывались комплексом аппаратуры. При обработке полученных записей в последовательных десятисекундных интервалах подсчитывались: общее количество сигналов без ранжирования их по амплитудам (N); суммарное количество выделившейся акустической энергии (E); средняя энергия сигнала $\left(\mathrm{E}_{\mathrm{cp}}=\mathrm{E} / \mathrm{N}\right)$. За энергетический показатель сигнала принималась его амплитуда, выраженная в условных единицах. Далее десятисекундные интервалы группировались в минутные и для них рассчитывались: фрактальная размерность $\left(\mathrm{D}_{\mathrm{k}}\right)$ для $\mathrm{N}$ и информационная энтропия $\mathrm{S}_{\mathrm{inf}}$ для $\mathrm{N}$ и Е соответственно.

Фрактальная размерность $\mathrm{D}_{\mathrm{k}}$ рассчитывалась методом Кантора по аналогии с [Velde et al., 1990]. Расчет информационной энтропии производился посредством компьютерной программы, основу которой составляет приведенный в предыдущем разделе алгоритм 7.

Для полученного спектра сигналов АЭ интерес представляют два временных интервала 461-521 с и 811-891 с, в которых, по ряду признаков, развивались процессы самоорганизации и возникали РДС (рис. 9). Из приведенных графиков видно, что изменение $\mathrm{N}, \mathrm{E}$ и $\mathrm{E} / \mathrm{N}$ вне этих интервалов происходит преимущественно синхронно: рост или уменьшение первого параметра соответственно сопровождается аналогичными изменениями двух других (рис 9, A). В рамках же отмеченных временных интервалов существования РДС на фоне роста общего количества сигналов их средняя энергия уменьшается. При этом суммарная энергия сигналов уменьшается в пределах первой и незначительно возрастает в пределах второй РДС, хотя при этом градиент ее роста снижается по сравнению с предыдущим и последующим временными интервалами. Анализ распределения сигналов АЭ, ранжированных по амплитуде на группы, показал, что в пределах РДС существенно возрастает количество сигналов малых амплитуд на фоне сокращения количества сигналов с большими амплитудами, что в совокупности и приводит к снижению значений их средней энергии даже в тех случаях, когда суммарная энергия Е сигналов возрастает (рис. 9, А). При этом распределение сигналов АЭ по энергии становится более неравномерным, на что указывает снижение значений информационной энтропии $\left(\mathrm{S}_{\mathrm{inf}} \mathrm{E}\right)$ (рис. 9, Б). Информационная энтропия и фрактальная размерность количества сигналов $(\mathrm{N})$ в обеих РДС возрастает (рис. 9, Б), что в целом позволяет говорить о более однородном их распределении.

Анализ спектра акустической эмиссии, полученного при моделировании процесса формирования зоны сдвига, позволил определить ряд количественных параметров, по характерному поведению которых можно проводить пространственно-временную диагностику РДС. Установлено, что в их пределах количество сигналов АЭ $(\mathrm{N})$ возрастает с уменьшением их средней энергии, информационная энтропия и фрактальная размерность $\left(\mathrm{S}_{\text {inf } \mathrm{N}}, \mathrm{D}_{\mathrm{N}}\right)$, рассчитанные по $\mathrm{N}$, возрастают, информационная энтропия $\left(S_{\text {inf }}\right)$, рассчитанная по энергии Е, уменьшается. С точки зрения информационной энтропии и фрактальной размерности, поведение последних трех параметров говорит о том, что в пределах РДС импульсы АЭ стремятся к более равномерному и хаотичному временному распределению, тогда 


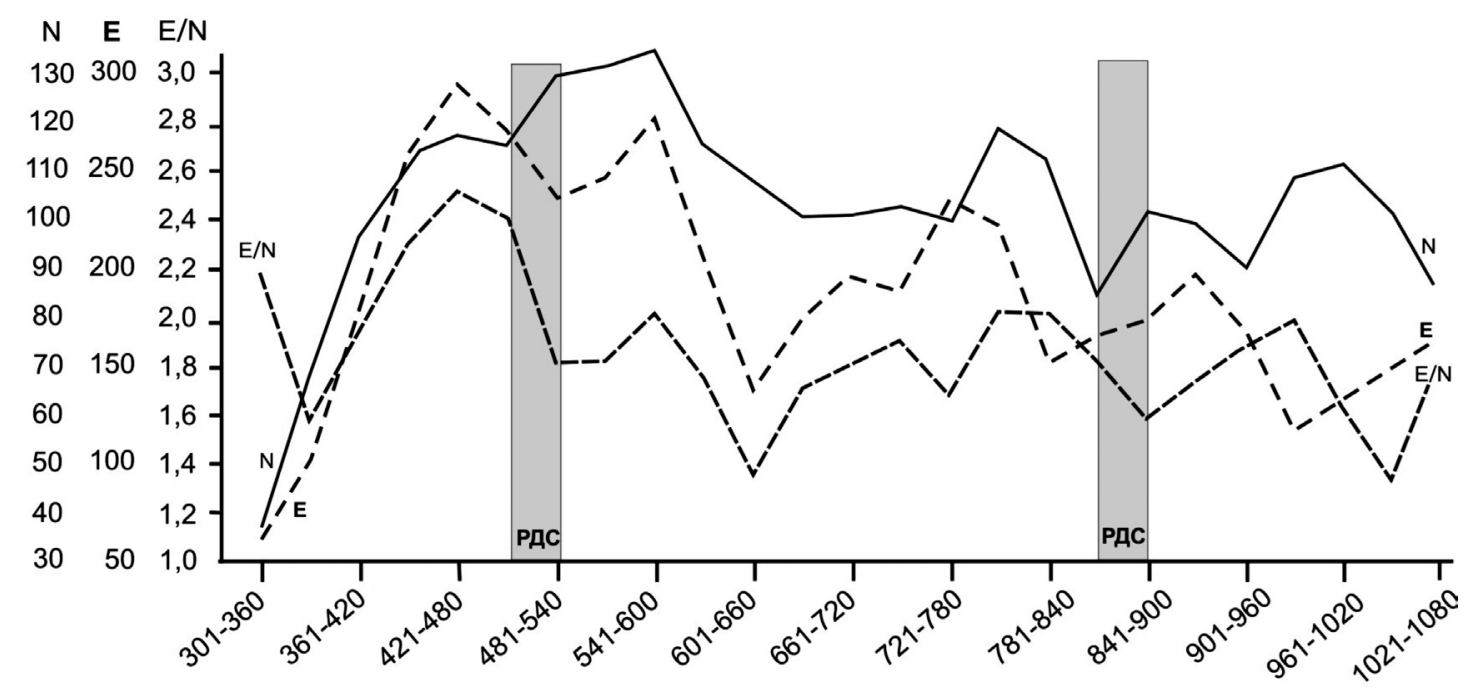

Б

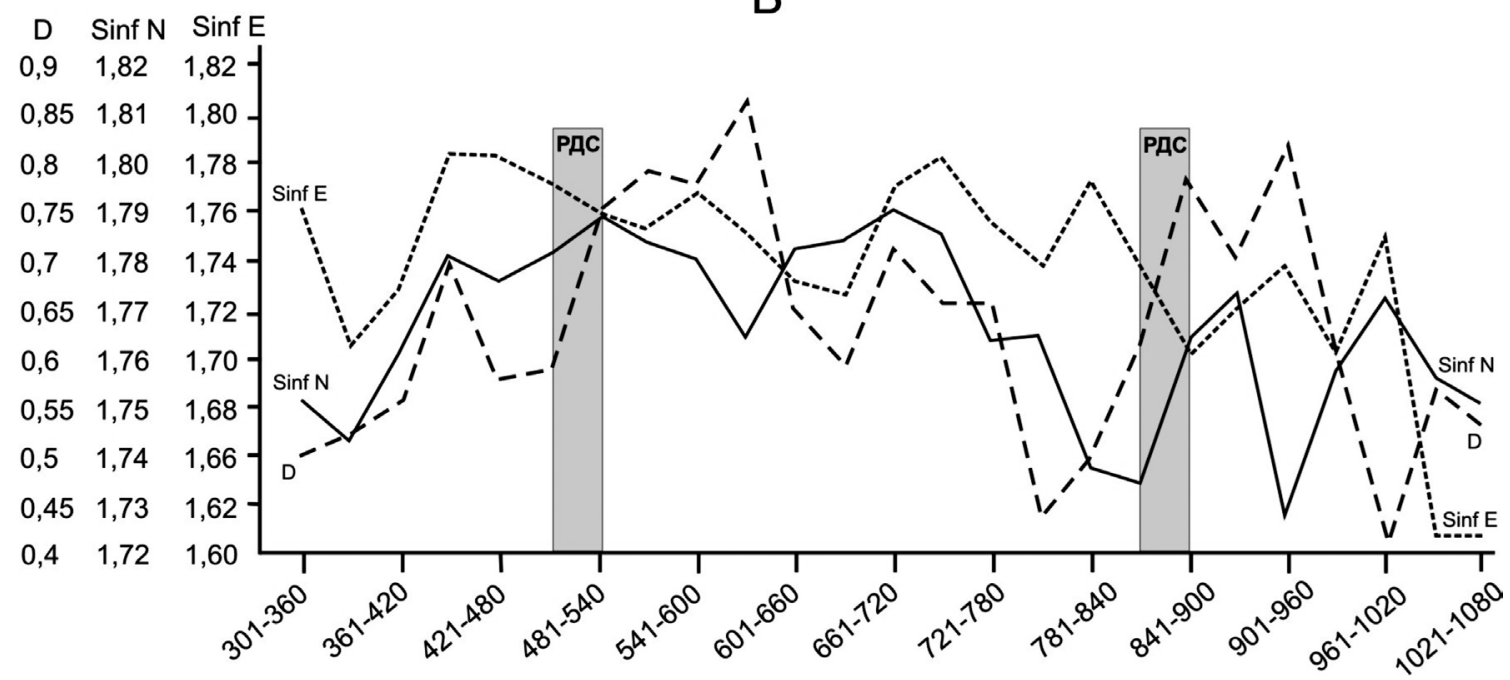

Рис. 9. Вариации параметров акустической эмиссии в процессе формирования сдвиговой зоны в упруговязкопластичной модели (пояснения символов в тексте).

Fig. 9. Variations of acoustic emission parameters during development of a shear zone in the elasto-visco-plastic model (see descriptions of symbols in the text).

как их энергия испытывает обратную тенденцию.

Экспериментально выявленные закономерности в поведении комплекса параметров АЭ могут быть использованы для анализа временных рядов землетрясений с целью превентивного прогноза перехода разрывных систем в зонах разломов в критическое предсейсмогенное состояние.

Другим экспериментально изученным сопутствующим разломообразованию процессом является рельефообразование над разломными зонами. В натурных условиях появление положительных и отрицательных форм рельефа в зонах крупных разломов генетически связано с дифференцированными вертикальными движениями составляющих их внутреннюю структуру разномасштабных блоков. Аналогичная ситуация про- является и в моделях в условиях эксперимента. Для изучения влияния на морфологическую выраженность разломных зон их морфолого-генетического типа, толщины и вязкости литосферы, скоростного режима ее деформирования и других факторов в последние годы проводится специальный комплекс экспериментов. Результаты одного из них в качестве иллюстрации приведены ниже. Измерения рельефа поверхности модели выполнялись по сети из 27 профилей по 23 пикета на каждом, проведенных вкрест простирания формирующейся зоны сдвига. Расстояние между профилями 3 см, пикетами - 1 см. На каждом пикете лазерной линейкой измерялось значение высоты рельефа с точностью 1 мм. По полученным данным строились схемы рельефа и средних градиентов изменений углов 


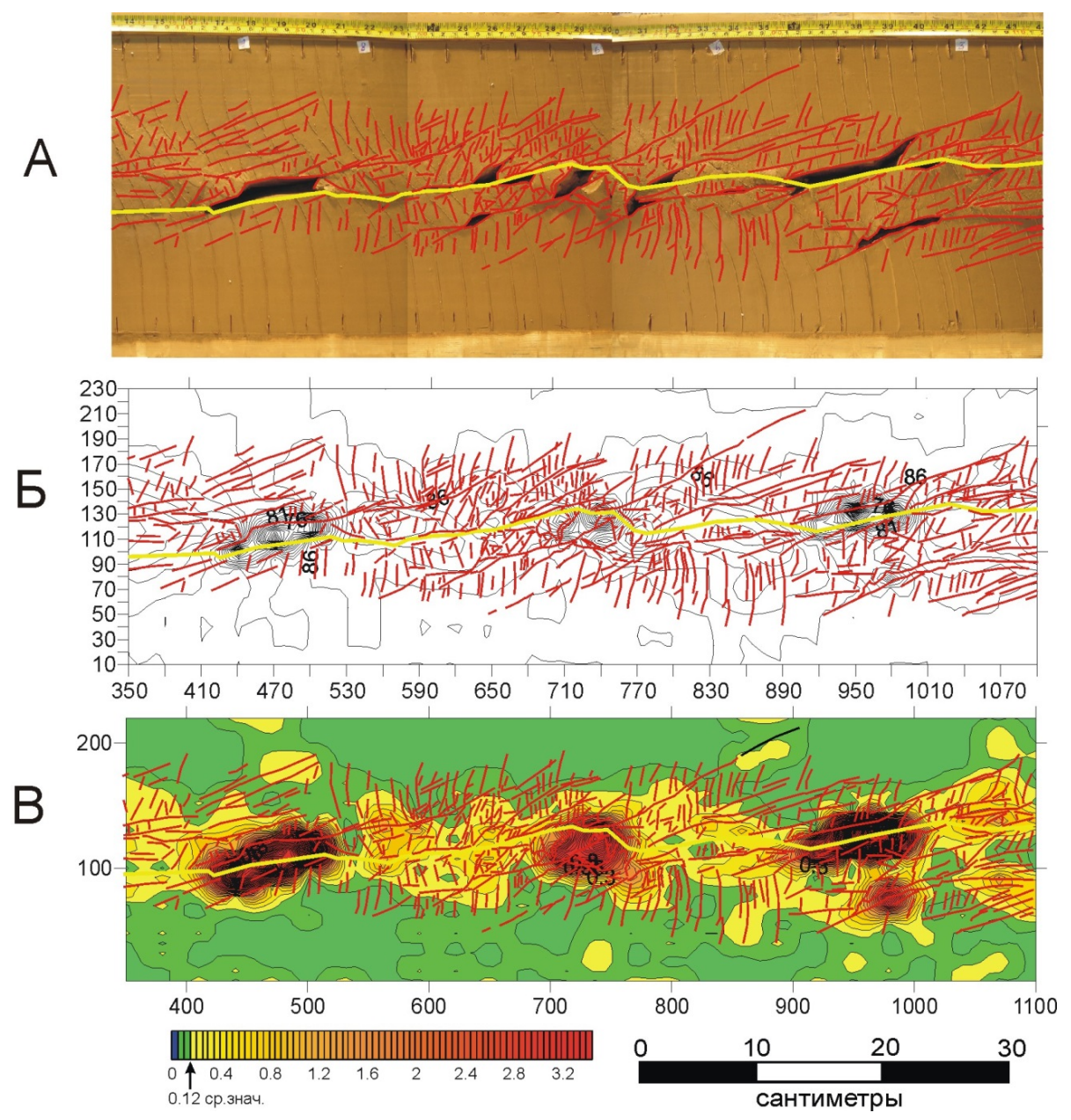

Рис. 10. Сдвиговая зона в модели $(A)$, цифровая модель рельефа (Б) и градиент вертикальных движений экспериментальной модели $(B)$.

Fig. 10. Simulated shear zone $(A)$, digital model of the surface pattern $(Б)$, and vertical movement gradient $(B)$.

наклона рельефа (рис. 10, A-B); последний рассчитывался по формуле:

$$
|\operatorname{grad}|=\frac{h_{A}-h_{B}}{l_{A B}},
$$

где $h_{A}-h_{B}-$ разность отметок высот двух соседних пикетов профиля, м; $l_{A B}-$ расстояние между ними, м.

Эксперимент показал, что в целом сдвиговая зона в модели отчетливо выделяется в виде линейного поднятия с расчлененным рельефом, представленным чередующимися поднятиями и впадинами (рис. 10, Б, 11, A).

Рельеф над деструктивной зоной сдвига в модели имеет хорошее сходство с природными аналогами (рис. 11, Б).

\subsection{6. Физическое моделирование в решении прикладных задач}

С 2001 г. сотрудниками лаборатории тектонофизики проводятся полевые структурно-геологические иссле- дования разломов в пределах кимберлитовых районов Якутской алмазоносной провинции с целью выяснения их роли в структурном контроле кимберлитовых тел. Важной составляющей этих исследований является физическое моделирование. В качестве иллюстрации приведем результаты ряда экспериментов по моделированию разломных узлов и пулл-апарт структур как кимберлитовмещающих структур, выполненных с целью проверки основных выводов, сделанных по результатам изучения разломной тектоники Мало-Ботуобинского и Алакит-Мархинского алмазоносных районов.

Для моделирования использовалась конструкция из четырех штампов, одновременно перемещающихся относительно друг друга и имитирующих одновременную активизацию двух ортогональных разломов фундамента (рис. 12). Приведенная фотография модели, деформированной в два этапа с реверсом движений штампов, иллюстрирует сложнопостроенный разломный узел. Простые горизонтальные смещения по линейным ветвям сдвиговых зон трансформируются в сложную систему разнонаправленных движений в 

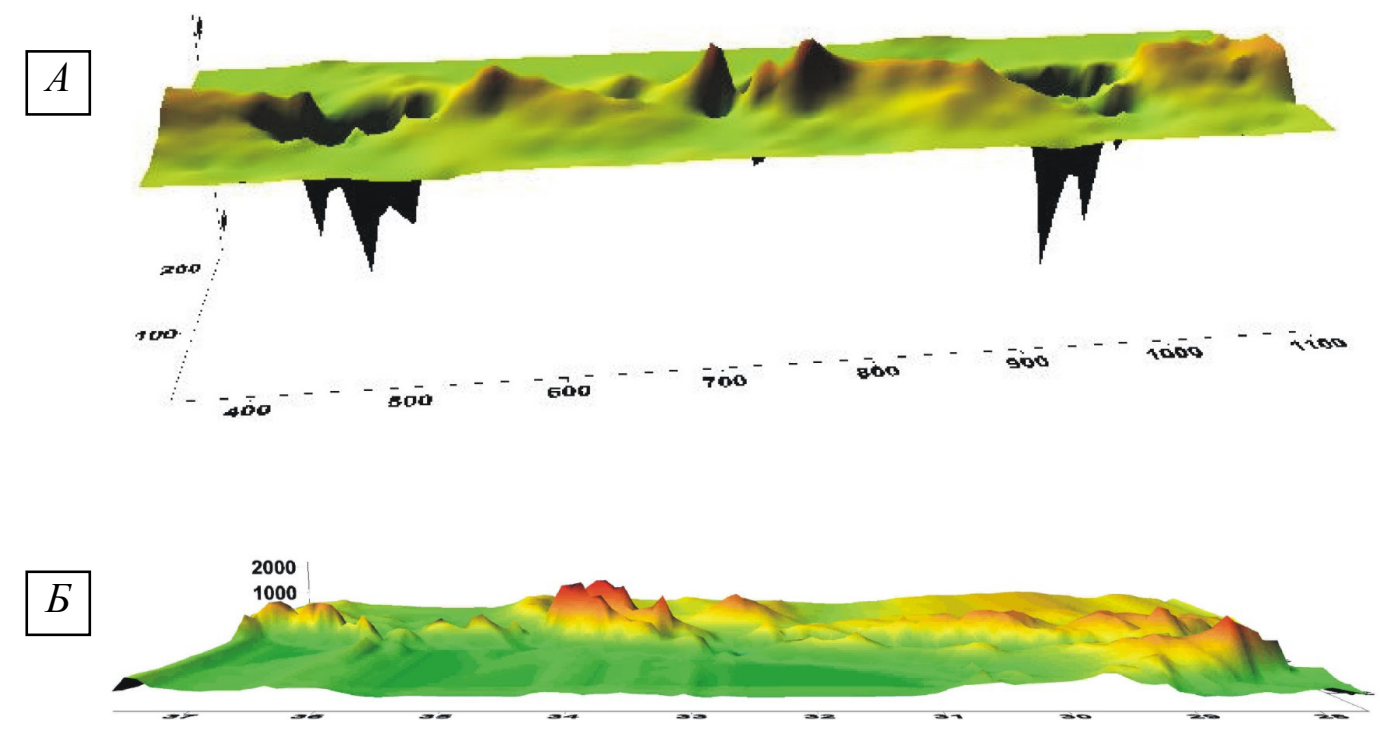

Рис. 11. Объемные цифровые модели рельефа для сдвиговой зоны в модели (А) и Левантийской деструктивной зоны сдвига (Б).

Fig. 11. 3D digital models: $(A)$ surface pattern of the simulated shear zone; $(Б)$ terrain of the Levant shear zone $(Б)$.

A

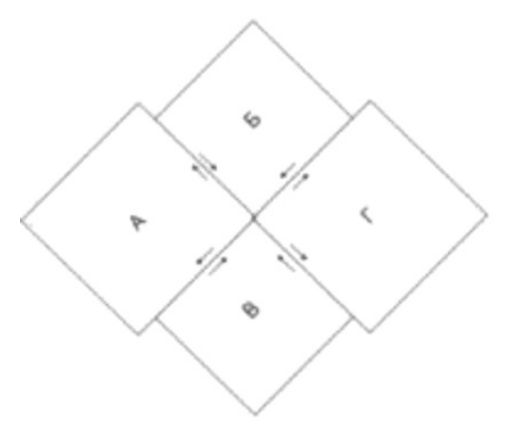

B

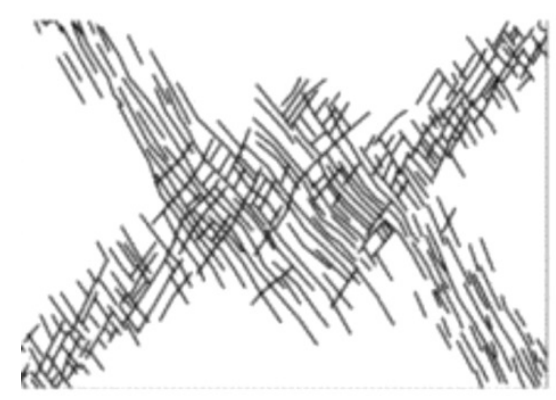

Б

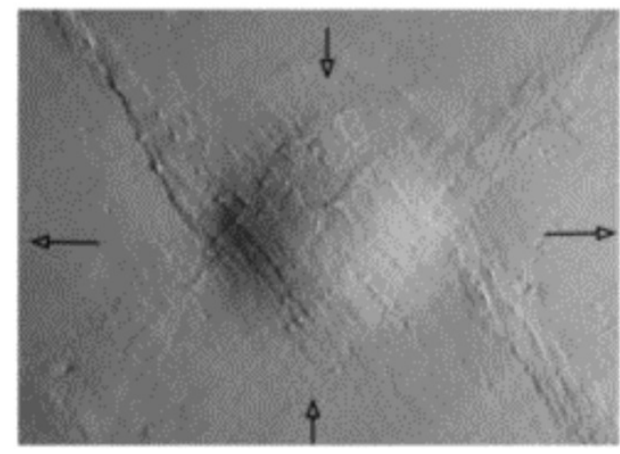

$\Gamma$

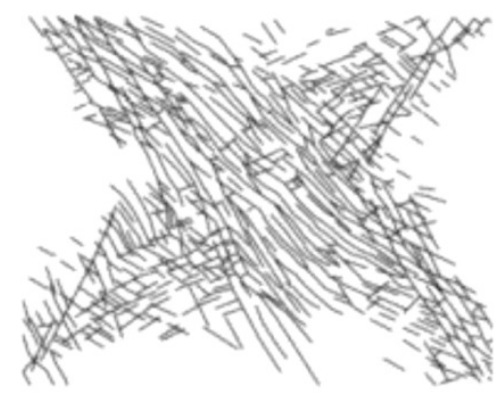

Рис. 12. Результаты моделирования формирования разрывов в «осадочном чехле» над узлом пересечения разломов в «фундаменте».

$A$ - схема расположения штампов экспериментальной установки; 5 - фрагмент разломного узла в модели и его структурные схемы в конце первого $(B)$ и второго $(\Gamma)$ этапов.

Fig. 12. Modelling results showing faulting in the 'sedimentary cover' above the fault intersection in the 'base'.

$A$ - scheme showing positions of RAZLOM installation's stamps; 5 - fragment of the fault intersection in the model, and its structural schemes at the end of Stage $1(B)$ and Stage $2(\Gamma)$. 


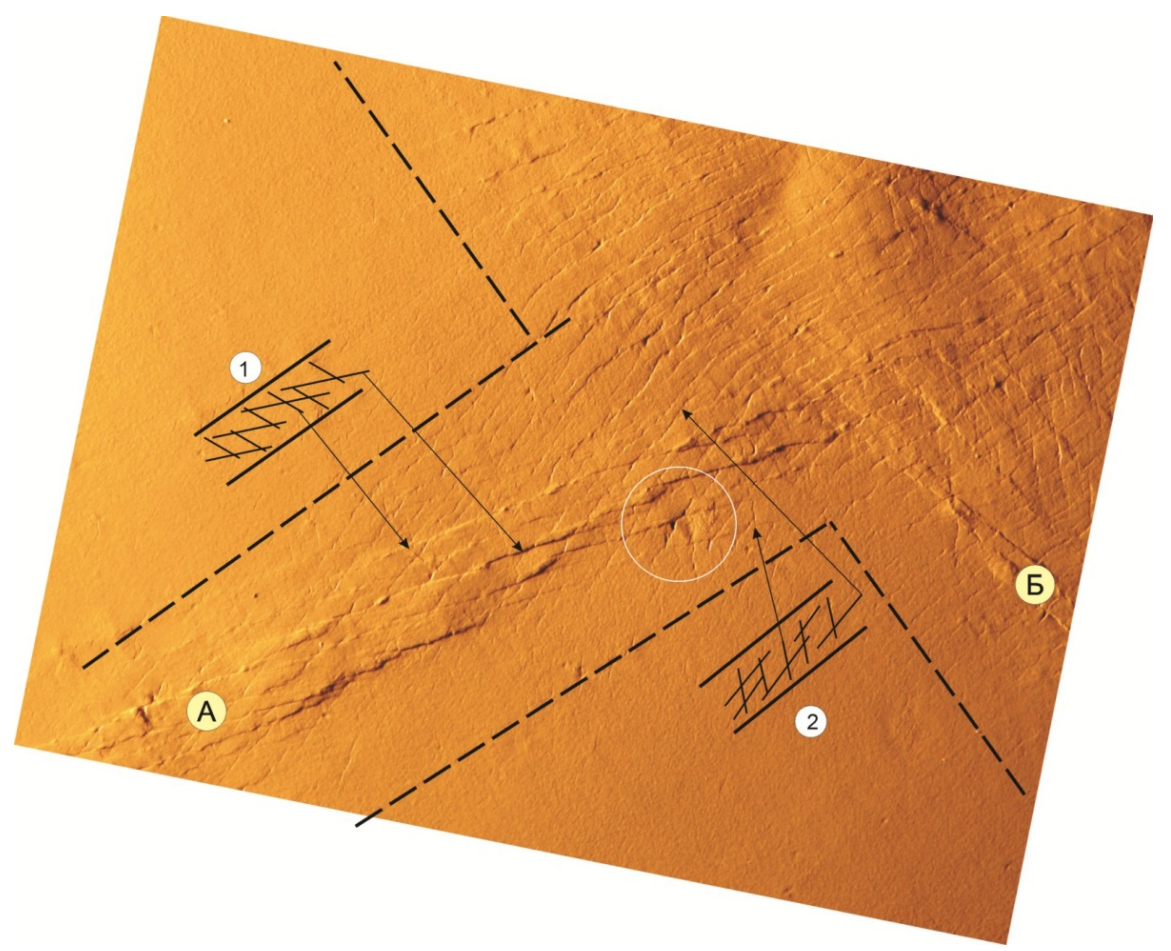

Рис. 13. Фрагмент модели узла пересечения сдвиговых зон сформировавшихся в результате двух этапов разнонаправленных сдвиговых движений.

А и Б - сдвиговые зоны. 1 и 2 - пример наложения разрывных парагенезов для зоны А. Белым кругом отмечен участок проявления локальной структуры раскрытия.

Fig. 13. A fragment of the intersection of shear zones resulting from shear movements in opposite directions which occurred in two stages.

A and $\mathrm{B}$ - shear zones. 1 and 2 - superposition of fracturing paragenesises for zone A. The area where a local opening structure occurred is marked by the white circle.

местах их пересечений (рис. 12). Приведенные структурные схемы отражают состояние разрывной сети в модели при разных направлениях смещений штампов в первый и второй этап деформирования. На первом этапе движения штампов осуществлялось в соответствии с направлением стрелок на рисунке 12 , Б. Когда в модели сформировалась хорошо выраженная сеть разрывов (рис. 12, B), движение штампов менялось на обратное и продолжалось до формирования новой, наложенной на старую, сети разрывов (рис. $12, \Gamma$ ). Не останавливаясь на детальном рассмотрении результатов экспериментов, подчеркнем, что в итоге в боковых ветвях узлового сочленения пересекающихся сдвиговых зон формируются два разрывных парагенезиса $(R$ и $R$ '-сколы), соответствующие различной кинематике движения штампов (рис. 13).

Полученная в результате моделирования разрывная сеть в целом подобна разрывной сети Накынского кимберлитового поля, а сформировавшаяся в модели структура локального раскрытия по своему строению подобна участку локализации трубки Нюрбинская (рис. 14). Аналогичные по выводам экспериментальные результаты получены применительно к струк- турам Алакит-Мархинского района [Gladkov et al., 2008].

В целом, выполненное моделирование подтвердило выводы полевых тектонофизических исследований о структурном контроле кимберлитовых тел разрывными нарушениями и показало механизм и многоэтапность их формирования в условиях сдвиговых деформаций.

\section{3. ОСНОВНЫЕ РЕЗУЛЬТАТЫ ФИЗИЧЕСКОГО МОДЕЛИРОВАНИЯ ПРОЦЕССОВ РАЗЛОМООБРАЗОВАНИЯ НА УПРУГИХ ОПТИЧЕСКИ-АКТИВНЫХ МОДЕЛЯХ ЛИТОСФЕРЫ}

Поиск общих закономерностей внутреннего строения разломных зон, их напряженно-деформированного состояния, распределения напряжений в окрестностях разломов с оценкой степени их активности является актуальной задачей тектонофизических исследований, решаемых, в том числе, с помощью лабораторного моделирования. Основным является поляризационно-оптический метод, позволяющий оценить общую картину 


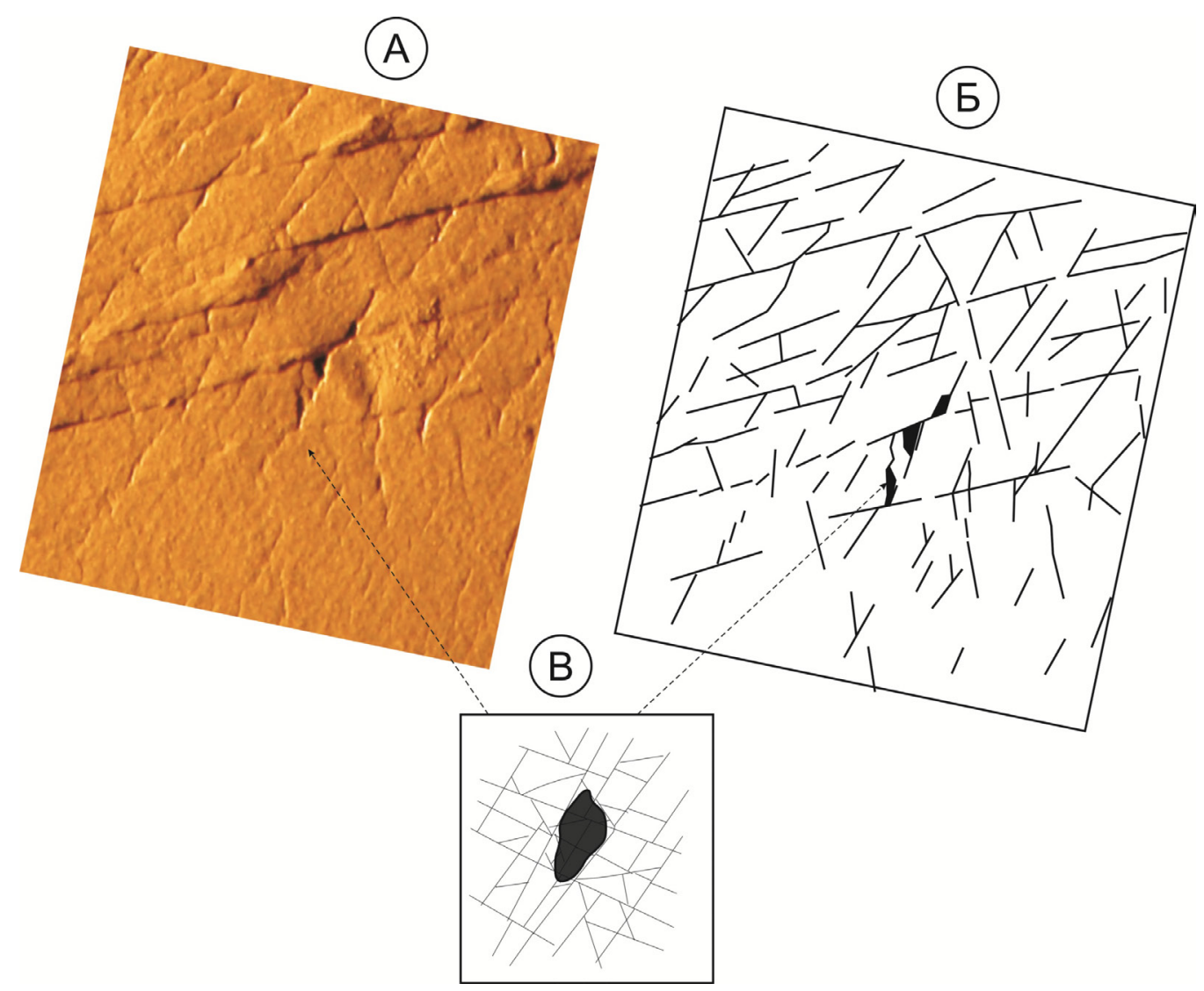

Рис. 14. Локальная структура раскрытия в приузловой части сдвиговой зоны.

$A$ и $Б$ - разрывная сеть, полученная на модели, и локальная структура раскрытия; $B$ - разломная сеть участка локализации трубки Нюрбинской по результатам тектонофизического анализа.

Fig. 14. Local opening structure in the near-fault-junction part of the shear zone.

$A$ - fault pattern in the model; 5 - local opening structure; $B$ - fault pattern of the Nyurba pipe site according to results tectonophysical analyses.

распределения напряжений в моделях с системами разрывов, а также получить их количественные характеристики. Этот метод основан на открытом Д. Брюстером явлении искусственного двулучепреломления в прозрачных оптически-изотропных материалах под действием деформации. В деформируемой модели, помещенной между пластинами со скрещенными плоскостями поляризации (поляризатором и анализатором), наблюдается картина цветных и темных областей или полос, соответствующая напряженному состоянию в модели. При поляризационно-оптических исследованиях нами анализировались полосы двух типов: изохромы и изоклины. Изохромы - полосы одинакового цвета, являющиеся геометрическим местом точек с одинаковой оптической разностью хода, пропорциональной разности квазиглавных (для направления просвечивания) напряжений. При осуществлении в модели плосконапряженного состояния квазиглавные напряжения совпадают с главными нормальными напряжениями. Изоклины - темные полосы, во всех точках которых направление осей квазиглавных напряжений одинаково, а параметры изоклин определяются поло- жением плоскостей поляризации относительно исследуемой модели. Между оптической разностью хода $(R)$ и величиной максимальных касательных напряжений $\left(\tau_{\max }\right)$ существует линейная зависимость:

$$
R=B_{\tau} \cdot \tau_{\max } / \mathrm{d},
$$

где $\tau_{\max }-$ величина максимальных касательных напряжений, d - толщина модели. Коэффициент пропорциональности $B_{\tau}$ называется коэффициентом оптической активности. Его величина зависит от свойств модельного материала и может варьироваться в широких пределах. Таким образом, метод поляризационно-оптического моделирования позволяет изучить особенности распределения и концентрации максимальных касательных напряжений и ориентацию главных нормальных напряжений по всей модели в целом, а также получить количественные характеристики напряжений для любой точки изучаемого объекта.

Моделирование полей тектонических напряжений на оптически анизотропных материалах широко используется при решении различных задач тектоники, 
разведочной и рудной геологии [Gzovsky, 1970; Gzovsky et al., 1974; Bondarenko, 1989; Osokina, 1989; Yin et al., 2002; Noselli et al., 2010].

В лаборатории тектонофизики ИЗК СО РАН поляризационно-оптический метод используется с 1984 г. для выяснения условий активизации зон сочленения разломов (ЗСР) и разломных систем. Эти экспериментальные исследования можно условно разделить на три этапа. На первом этапе анализировались формализованные зоны сочленения разломов, представляющие из себя место сопряжения разрывов и окружающее его пространство, на котором проявляется изменение напряженно-деформированного состояния, обусловленное динамическим взаимодействием сопряженных разрывов [Miroshnichenko, 1989; Miroshnichenko, Adamovich, 1990]. На втором этапе проводилось моделирование напряженно-деформированного состояния природных ЗСР и их систем [San'kov et al., 2004; Miroshnitchenko et al., 2007]. Модели первых двух этапов изготавливались из однородного материала, на третьем этапе исследовались комбинированные модели, отдельные части которых имели различные свойства [Sherman, 1984].

\section{1. МЕТОДИКА МОДЕЛИРОВАНИЯ}

\subsection{1. Условия подобия}

Условия подобия при моделировании полей тектонических напряжений на оптически анизотропных материалах рассмотрены в работах М.В. Гзовского, Д.Н. Осокиной, С.И. Шермана, А.А. Бабичева и др. [Gzovsky, 1975; Babichev, 1987; Osokina, Bondarenko, 1989; Sherman et al., 2005].

При решении поставленных задач условия моделирования (концентрация желатина, размеры модели, прилагаемая нагрузка) подобраны таким образом, чтобы в модели реализовывалось плоское напряженное состояние [Aleksandrov, Akhmetzyanov, 1973]. Модель может быть изготовлена из любого однородного, изотропного и упругого материала, поскольку распределение напряжений не зависит от его упругих констант. Условия моделирования в этом случае будут определяться критерием-симплексом:

$$
\tau_{\max } / \sigma-i d e m,
$$

где $\tau_{\text {max }}-$ максимальные касательные напряжения, б сосредоточенные нагрузки. По литературным данным в природе это отношение составляет от долей до нескольких единиц [Gzovsky, 1975; Turcotte, Schubert, 1985; Byerlee, 1978; Rebetsky, 2007]. В моделях из желатина, используемых для наших экспериментов, данное отношение в зависимости от концентрации желатина и размеров модели составляет первые доли единиц. Это позволяет считать, что условия моделирования при проведении экспериментов выполняются.
Коэффициенты подобия, вычисленные с помощью критерия-симплекса, позволяют рассчитать параметры моделирования. Статически нагруженная модель сопоставляется с массивом горных пород, напряженнодеформированное состояние которых определяется действием внешней нагрузки. Величина нагружения модели, вычисленная через коэффициенты подобия, должна составлять 1-10 Па, что соответствует величинам напряжений, предполагаемых для сейсмоактивных регионов. Полученные значения совпадают с параметрами моделирования, принятыми в работе [Osokina, Tsvetkova, 1979].

\subsection{2. Модельный материал}

В качестве модельного материала использовались студни желатина (желатин фотографический активный, марки Б, низковязкий медленный), обладающего высоким коэффициентом оптической активности и удовлетворяющего требованиям теории подобия [Gzovsky, 1975; Bondarenko, 1989; Osokina, 1963].

На рисунке $15, A, B$, представлены схема экспериментов и эталонные варианты ЗСР. Модель с разрывами, имитирующими тектонические нарушения, подвергалась нагружению. При исследовании модели в проходящем поляризованном свете наблюдается сложная картина цветных и темных полос (изохром и изоклин), отражающая напряженное состояние в окрестностях разрывов. Фиксирование этих картин проводилось посредством зарисовок и фотографирования. В результате обработки изображений строились схемы траекторий главных нормальных напряжений и карты изолиний максимальных касательных напряжений (рис. 15, C).

Так как оптические свойства гелей желатина существенно зависят от условий обработки [Osokina, 1963], все модели изготовлялись по единой схеме. Гранулы желатина выдерживались в воде с температурой $20^{\circ} \mathrm{C}$ для набухания в течение двух часов, затем растворялись при непрерывном перемешивании на водяной бане при $70{ }^{\circ} \mathrm{C}$. Полученный раствор заливался в форму через час после полного растворения и выдерживался в течение 24 часов. Исследование модели производилось через час после освобождения ее из формы. Исследовались модели с содержанием желатина от 5 до $20 \%$.

Соблюдение основных требований, предъявляемых к моделям для поляризационно-оптического моделирования, проверялось тестовыми экспериментами [Durelli, Riley, 1970; Aleksandrov, Akhmetzyanov, 1973].

\subsection{3. Экспериментальная установка}

Эксперименты выполнялись на установке «Деформатор», разработанной и изготовленной в Иркутском филиале Новосибирского опытного завода. «Деформа- 


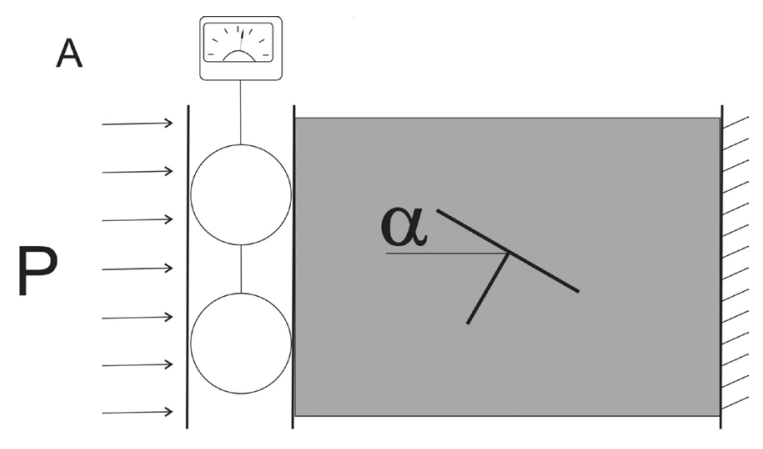

$\mathrm{B}$

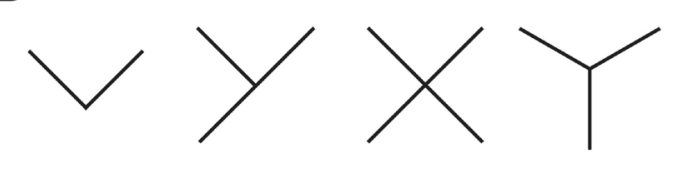

C

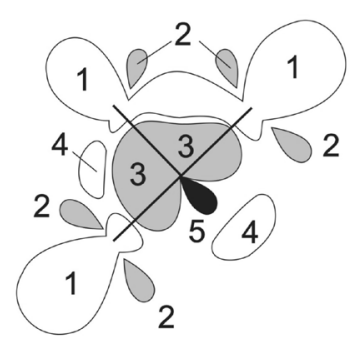

Рис. 15. Схема эксперимента (A): P - нагрузка на модель, $\alpha$ - угол нагружения; элементарные геометрические типы ЗСР $(B)$ и принципиальная схема строения локальных полей максимальных касательных напряжений (C). Описание условных обозначений дано в тексте.

Fig. 15. Modelling scheme (A): $\mathrm{P}$ - load applied to the model; $\alpha$ - loading angle; elementary geometric types of fault conjugation zones $(B)$, and principal pattern of local fields of maximum tangential stresses $(C)$. See descriptions of symbols in the text.

тор» представляет собой стол, стоящий на двух стойках с опорами, служащими для регулировки положения плоскости стола (рис. 16) На столе установлена емкость с прозрачным дном, в которую помещается модель. С двух сторон емкости расположены каретки, соединенные через упругие кольца с механическим приводом с одной стороны, со стенкой емкости - с другой. Каретки снабжены съемными частями, которые устанавливаются в пазы и крепятся винтами. Применение определенных съемных частей позволяет деформировать модель по нужной схеме. Перемещение кареток осуществляется с помощью системы шарикоподшипников, исключающей неравномерность нагружения модели по ее толщине. Деформация модели осуществляется при движении каретки, соединенной с механическим приводом. Деформатор позволяет осуществлять нагружение модели с усилием от I до 500 Н как в динамическом, так и в статическом режиме.

\subsection{4. Техника проведения экспериментов}

Непосредственно перед каждым экспериментом производилась градуировка модели, в результате которой определялась зависимость двойного лучепрелом- ления от величины максимальных касательных напряжений, вычисляемых по формуле:

$$
\tau_{\text {max }}^{0}=\mathrm{P} / 2 \mathrm{~S},
$$

где $\tau_{\max }^{0}$ величина касательных напряжений в ненарушенной модели; Р - прилагаемая к модели нагрузка, S - площадь грани модели, к которой приложена нагрузка.

Картина изохром, отражающая строение локальных полей максимальных касательных напряжений, фиксировалась фотоаппаратом. С помощью градуировочного графика на полученном изображении проводились изолинии коэффициентов концентрации максимальных касательных напряжений:

$$
K_{\tau}=\tau_{\max /}^{\mathrm{i}} \tau_{\max }^{0}
$$

где $\tau_{\text {max }}^{\mathrm{i}}$ - величина максимальных касательных напряжений в исследуемой точке модели с разрезами.

Границы локальных максимумов $\left(K_{\tau}>1\right)$ и минимумов $\left(K_{\tau}<1\right)$ проводились по изолинии $K_{\tau}$, значение которой отличалось от единицы на $10 \%$ и более; изолинии проводились по центру цветовых полос. 


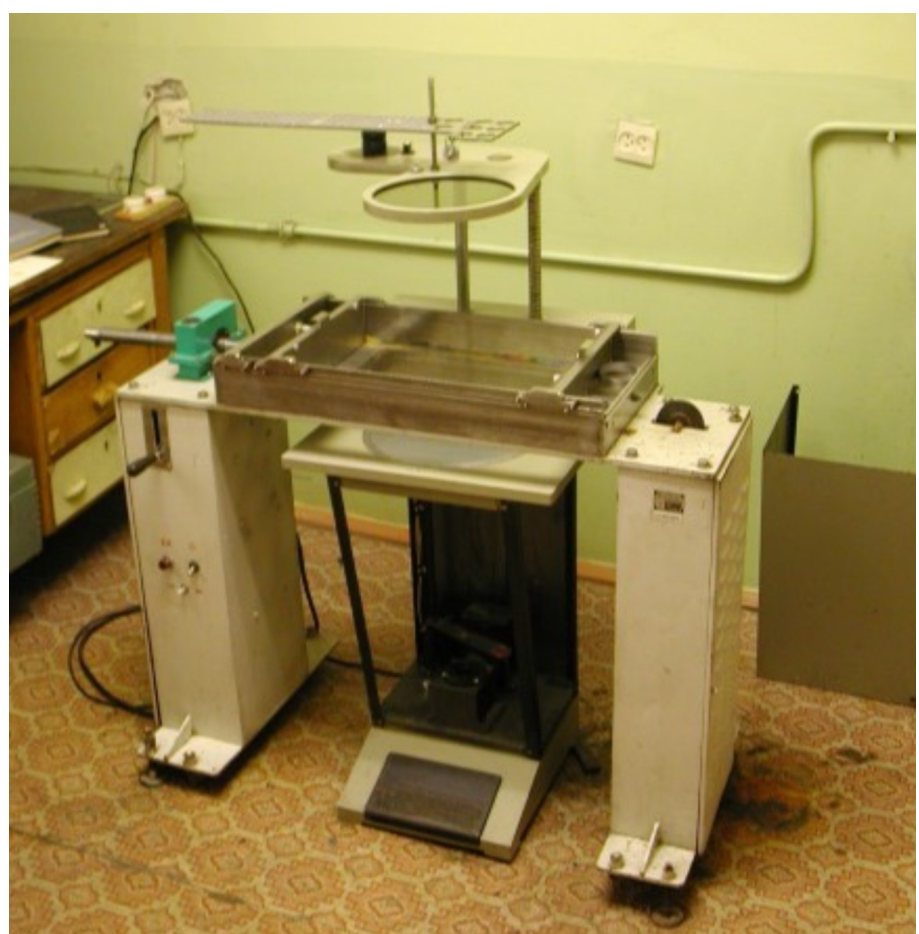

Рис. 16. Установка для моделирования на оптически активных эквивалентных материалах.

Fig. 16. Installation for modelling on optically active equivalent materials.

Для определения траекторий главных нормальных напряжений изоклины фиксировались по всему полю модели. При изменении ориентации плоскостей поляризации с шагом $10^{\circ}$ получены карты изоклин, по которым способом штрихов зарисовывались изостаты траектории главных нормальных напряжений. Прослеживание изостат от свободных контуров модели позволяет их идентифицировать однозначно.

Таким образом, в результате моделирования были получены схемы распределения и концентрации максимальных касательных напряжений и траектории главных нормальных напряжений, отражающие особенности деформации в окрестностях ЗСР элементарных геометрических типов в силовых полях одноосного сжатия или растяжения. Кроме того, в процессе экспериментов изучались относительная величина, тип подвижек по разрывам и особенности перемещения вычленяемых ими блоков.

\section{2. МОДЕЛИРОВАНИЕ НАПРЯЖЕННО-ДЕФОРМИРОВАННОГО СОСТОЯНИЯ ЗСР}

Основной задачей при физическом моделировании было изучение особенностей перестройки исходного поля напряжений в окрестностях сочленяющихся разрывов в зависимости от их ориентации в различных силовых полях. Для анализа были привлечены элемен- тарные геометрические типы сочленений, широко проявленные в строении разломных систем различных сейсмоактивных территорий (рис. 15, B).

Согласно схеме, предложенной Д.Н. Осокиной, по величине относительных напряжений $K_{\tau}$ и их положению в окрестностях разрывов были выделены следующие основные типы локальных полей максимальных касательных напряжений в ЗСР (см. рис $15, C$ ):

1. Концевые максимумы - области интенсивной концентрации вблизи концов трещин $\left(K_{\tau}>1.2\right)$.

2. Концевые минимумы - области умеренного снижения напряжений, сопровождающие концевые максимумы $\left(K_{\tau}=0.9-0.8\right)$.

3. Боковые минимумы - области значительного снижения напряжений $\left(K_{\tau}<0.8\right)$, расположены по бокам разрывов, примыкая к ним.

4. Боковые максимумы - области умеренной концентрации по бокам разрывов или между их концами на удалении от плоскости разрывов $\left(K_{\tau}=1.1-1.2\right)$.

5. Узловой максимум - область интенсивной концентрации напряжений в приузловых частях блоков. Образование данных максимумов обусловлено как взаимодействием углов блоков в разломном узле, так и особенностями деформации углов блоков. Узловой максимум обычно имеет меньшую по сравнению с другими типами площадь, но по интенсивности концентрации максимальных касательных напряжений сопоставим с концевыми максимумами $\left(K_{\tau}>1.2\right)$.

Выделение типов локальных полей максимальных касательных напряжений проводится на формальной основе, однако их анализ позволяет получить определенную информацию. Например, концевые максимумы в зависимости от формы и положения относительно разрывов показывают особенности перемещений или подвижек по разрывам, а величина $K_{\tau}$ в их пределах отражает интенсивность этих подвижек. На рисунке 17 приведены формы концевых максимумов, соответствующие различным типам подвижек по разрывам. Цифры рядом с прямоугольниками показывают соответствие цвета в концевом максимуме со значением $K_{\tau}$.

Боковые максимумы и минимумы определяются особенностями деформации блоков, вычленяемых разрывами. При этом значение $K_{\tau}>1$ указывает на концентрацию максимальных касательных напряжений относительно исходных; при $K_{\tau}<1$ происходит снижение максимальных касательных напряжений относительно исходных.

Кроме изучения отдельных типов локальных полей анализировались такие параметры, как площадь общей перестройки областей исходного поля, соотношение областей концентрации и снижения напряжений и т.п.

Зоны сочленения разломов, в отличие от единичных разрывов, характеризуются более сложным строе- 

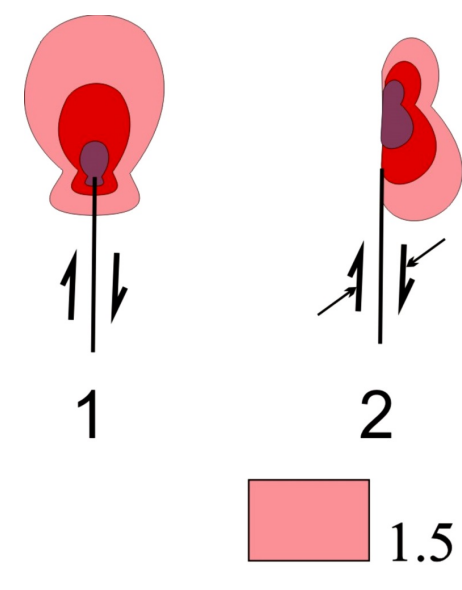

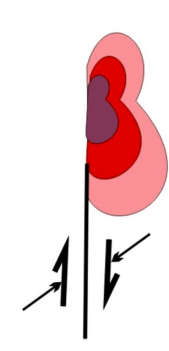

2

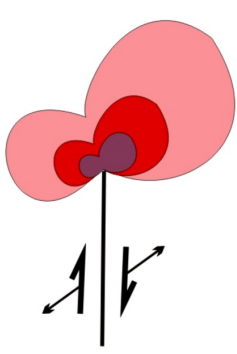

3

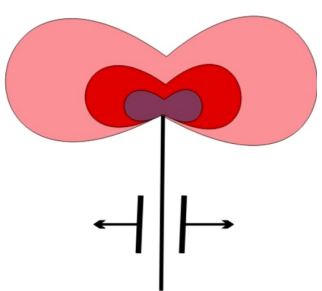

4
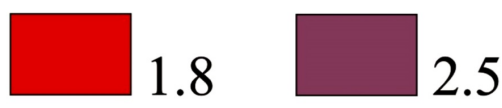

Рис. 17. Схемы строения концевых максимумов при подвижках по разрывам: 1 - сдвиговой, 2 - сдвиговой с поджатием бортов разрыва, 3 - сдвиго-раздвиговой, 4 - раздвиговой. Цифры рядом с цветными прямоугольниками - величины концентрации максимальных касательных напряжений $K_{\tau .}$.

Fig. 17. Schemes of end maximums during displacement along faults: 1 - shear, 2 - shear with contraction of fault sides, 3 - shear with extension, 4 - extension. Numbers at coloured boxes show values of maximum tangential stresses, $K_{\tau}$.

нием. По результатам первого этапа поляризационнооптического моделирования активизированных ЗСР были установлены следующие основные закономерности строения локальных полей напряжений:

1. В пределах ЗСР локальные максимумы или минимумы сливаются в единые зоны сложной конфигурации. При определенном положении ЗСР в силовом поле отсутствуют некоторые из выделенных типов локальных полей напряжений, наблюдается значительно большая дисперсия величины коэффициента концентрации $K_{\tau}$, меняется общая площадь перестройки исходных напряжений, соотношение площадей повышения и понижения максимальных касательных напряжений и т.п. В целом, область динамического влияния ЗСР имеет изометричную, овальную или неправильных очертаний форму и представляет собой совокупность концентрически расположенных относительно места пересечения или причленения разломов локальных максимумов и минимумов. Центральную часть занимает область концентрации напряжений - узловой максимум. Размеры этой области составляют первые проценты и колеблются в пределах 1-10 \% от общей площади ЗСР. Коэффициенты концентрации $K_{\tau}$ в пределах этой области принимают значения 1.5-1.8 и более. Узловой максимум оконтуривается областью значительного снижения напряжений, имеющей кольцевую или полукольцевую форму. Размеры площади составляют около 50 \%, величина $K_{\tau}$ составляет 0.9-0.6 и менее. На периферии ЗСР наблюдаются области концентрации напряжений, имеющие форму прерывистого кольца или выгнутого в сторону от центра ЗСР эллипса. Здесь коэффициент концентрации достигает 1.2, а размеры этих областей колеблются в пределах 30-50 \% общей площади. Раз- меры и форма области динамического влияния ЗСР, величина коэффициента концентрации максимальных касательных напряжений зависят от их геометрии, типа исходного поля напряжений и ориентации ЗСР в силовом поле.

2. Основные структурные элементы зон сочленения разломов (сочленяющиеся разломы, разломные узлы и блоки, разделяемые разломами) характеризуются определенными особенностями концентраций и распределения максимальных касательных, ориентации главных нормальных напряжений. Разломные узлы представляют собой области интенсивной концентрации напряжений $K_{\tau}$ и характеризуются концентрически-радиальной схемой расположения траекторий главных нормальных напряжений. В окрестностях разломов наблюдается снижение максимальных касательных напряжений. Вдоль разрывов ориентация главных нормальных напряжений постоянна, при этом ориентация осей сжатия субпараллельна, а осей растяжения субперпендикулярна их плоскостям. Ориентировка главных нормальных напряжений сочленяющихся разрывов может отличаться на $90^{\circ}$. В блоках наблюдается сочетание зонально расположенных локальных максимумов и минимумов, значительное искажение траекторий главных нормальных напряжений. Максимальные вариации их ориентировок наблюдается вблизи изотропных точек. Чаще всего соседние блоки отличаются по характеру концентрации максимальных касательных напряжений и схемам траекторий главных нормальных напряжений.

3. Вариации ориентировок зон сочленений в силовом поле вызывают изменение величины и типа подвижек по разрывам. В ЗСР наблюдается определенное сочетание сдвиговых, раздвиговых и сдвиго-раз- 
A

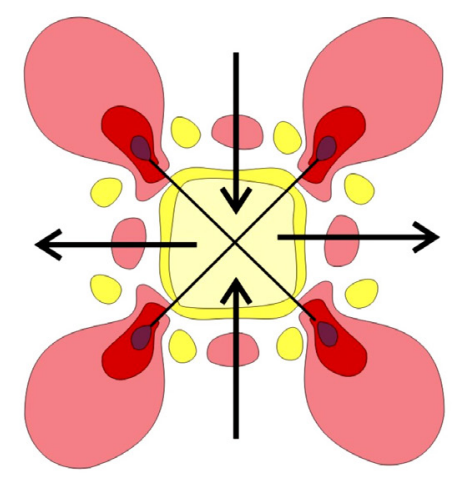

Б

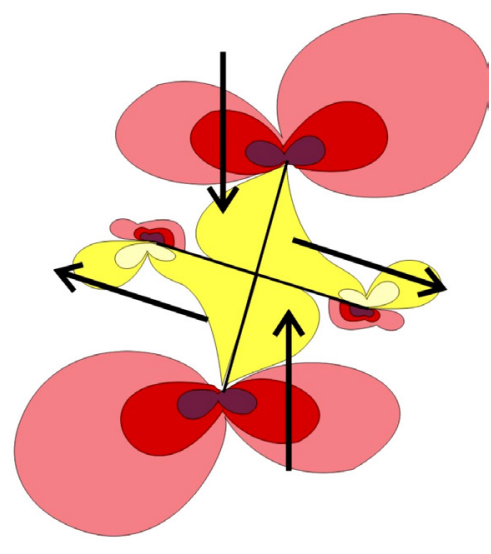

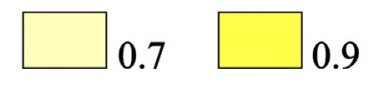

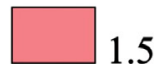
1.5

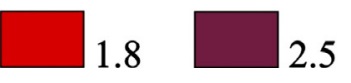

Рис. 18. Два основных типа активизированных ЗСР. Цифры рядом с цветными прямоугольниками - величины концентрации максимальных касательных напряжений $K_{\tau .}$. Стрелками показано направление движения блоков.

Fig. 18. Two basic types of activated fault conjugation zones. Numbers at coloured boxes show values of maximum tangential stresses, $K_{\tau}$. Arrows show block movement directions.

двиговых подвижек. Тип и интенсивность подвижек по сочленяющимся разрывам определяют характер перемещения деформации блоков, отражающихся в строении локальных полей напряжений.

По особенностям активизации ЗСР в течение второй стадии выделяются два принципиальных типа активизированных структур.

Один из них характеризуется изометричной формой области динамического влияния, равномерным распределением областей концентрации и уменьшения напряжений $\tau_{\text {max }}^{0}$ в окрестностях разрывов, имеющих приблизительно равные по величине и одинаковые по типу подвижки, интенсивной концентрацией напряжений в блоках и относительно простой схемой их перемещения (рис. 18, A).

В зонах сочленения второго типа области динамического влияния имеют сложные по очертаниям формы, дифференцированное распределение локальных минимумов и максимумов в окрестностях разрывов, различающихся по интенсивности и типам подвижек, преимущественное развитие областей уменьшения исходных напряжений $\tau_{\text {max }}^{0}$ в блоках, сложные блоковые перемещения (рис. 18, Б).

Существование двух типов активизированных 3СР определяется совместным действием двух факторов геометрии 3СР и ее ориентации в силовом поле. Тип исходного поля напряжений оказывает влияние на такие характеристики активизированных 3СР, как размеры областей динамического влияния, интенсивность концентрации напряжений $K_{\tau}$, специфика движения бортов разрывов и т.п.
Таким образом, общие закономерности морфологии и пространственного положения локальных максимумов и минимумов, строение схем траекторий главных нормальных напряжений, соотношение типов и интенсивности подвижек по разломам, блоковых движений и степени активности ЭСР определяются их геометрией и ориентацией в силовом поле.

Значения количественных характеристик напряженно-деформированного состояния, величин перемещения и деформации блоков закономерно связаны с типом и интенсивностью исходного поля тектонических напряжений.

\section{3. МОДЕЛИРОВАНИЕ НАПРЯЖЕННО-ДЕФОРМИРОВАННОГО СОСТОЯНИЯ ПРИРОДНЫХ ЗСР И РАЗЛОМНЫХ СИСТЕМ}

\subsection{1. Усть-Баргузинский разломный узел}

Изучено напряженное состояние Усть-Баргузинского разломного узла как региональной структуры, а также в окрестностях зон сочленения участвующих в ее внутреннем строении разрывов более низкого ранга (рис. 19, А). Эксперименты показали, что изменение напряжений в районе узлов сочленения разломов, как по величине, так и по простиранию главных осей, вызвано кооперативным поведением разрывов в зоне влияния более крупного разлома или разломного узла при активизации структуры (рис. 19, $B, \Gamma$ ). Выявлена следующая специфика перераспределения напряжений на концентраторах разных порядков. В региональном поле растяжения с ориентацией С3-ЮВ (первый порядок) развиваются наиболее крупные разломы, которые 

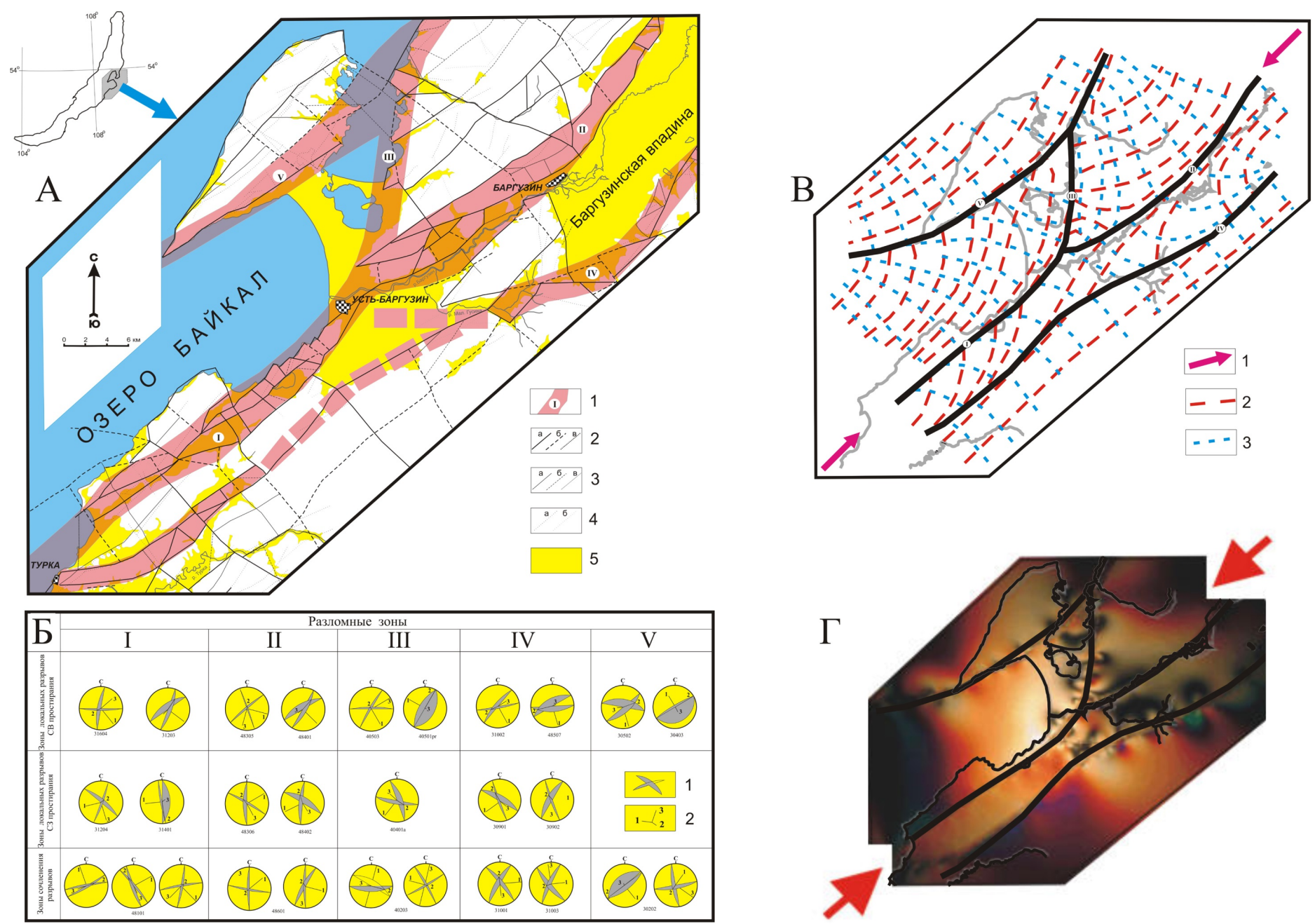

Рис. 19. Разломно-блоковая структура и напряженное состояние земной коры в окрестностях Усть-Баргузинского разломного узла по структурно-геологическим и экспериментальным данным.

A - схема разломно-блокового строения. 1 - зоны региональных разломов и их номера: I - Турка-Усть-Баргузинский, II - южная кулиса Баргузинского разлома, III - Чивыркуйский, IV - Суво-Усть-Баргузинский, V - разлом п-ва Святой Нос; 2 - активные границы локальных блоков 1-го уровня ( $a$ - хорошо выраженные в рельефе, б - слабо выраженные в рельефе, в - зафиксированные при геологоструктурных исследованиях); 3 - активные границы локальных блоков 2-го уровня ( $a$ - хорошо выраженные в рельефе, $\sigma$ - слабо выраженные в рельефе, $в$ - зафиксированные при геолого-структурных исследованиях); 4 - внутриблоковые разрывные нарушения ( $a$ - установленные, б - предполагаемые); 5 - кайнозойские отложения. Б - систематизация векторов главных нормальных напряжений по отношению к разломам разных рангов и ориентации. Диаграммы представлены в проекции верхней полусферы: 1 - сопряженные сколы; 2 оси главных нормальных напряжений: 1 - максимальная (растяжение), 2 - промежуточная, 3 - минимальная. $B$ - траектории главных напряжений модели Усть-Баргузинского разломного узла. 1 - направление действия нагрузки; 2 - траектории максимальных сжимающих напряжений; 3 - траектории минимальных сжимающих напряжений. $\Gamma$ - распределение в модели Усть-Баргузинского разломного узла максимальных касательных напряжений (фотография эксперимента).

Fig. 19. The fault-block structure and the state of stresses near the Ust Barguzin fault intersection according to structural geological and modelling data.

A - fault-block structure scheme. 1 - regional fault zones and their numbers: I - Turka-Ust Barguzin, II - southern wing of the Barguzin fault, III Chivyrkui, IV - Suvo- Ust Barguzin, V - Svyatoi Nos fault; 2 - active boundaries of local blocks (Level 1) ( $a$ - clearly manifested in topography, $\sigma$ - poorly manifested in topography, 8 - recorded by structural geological studies); 3 - active boundaries of local blocks (Level 2$)(a-$ clearly manifested in topography, $\sigma$ - poorly manifested in topography, $\boldsymbol{\varepsilon}$ - recorded by structural geological studies); 4 - intra-block fractures and faults ( $a$ - confirmed, $\sigma$ - assumed); 5 - Cenozoic sediments. 5 - systematization of main normal stress vectors in reference to faults of various ranks and orientations. Diagrams are given in the upper hemisphere projection: 1 - conjugated shears; 2 - axes of main normal stresses: 1 - maximum (extension), 2 - transitional, 3 - minimum. $B$ - trajectories of main stresses in the model of the Ust Barguzin fault intersection. 1 - loading direction; trajectories: 2 - maximum compression stress, 3 - minimum compression stress. $\Gamma$ - patterns of maximum tangential stresses in the model of the Ust Barguzin fault intersection (the photo was taken during modelling). 


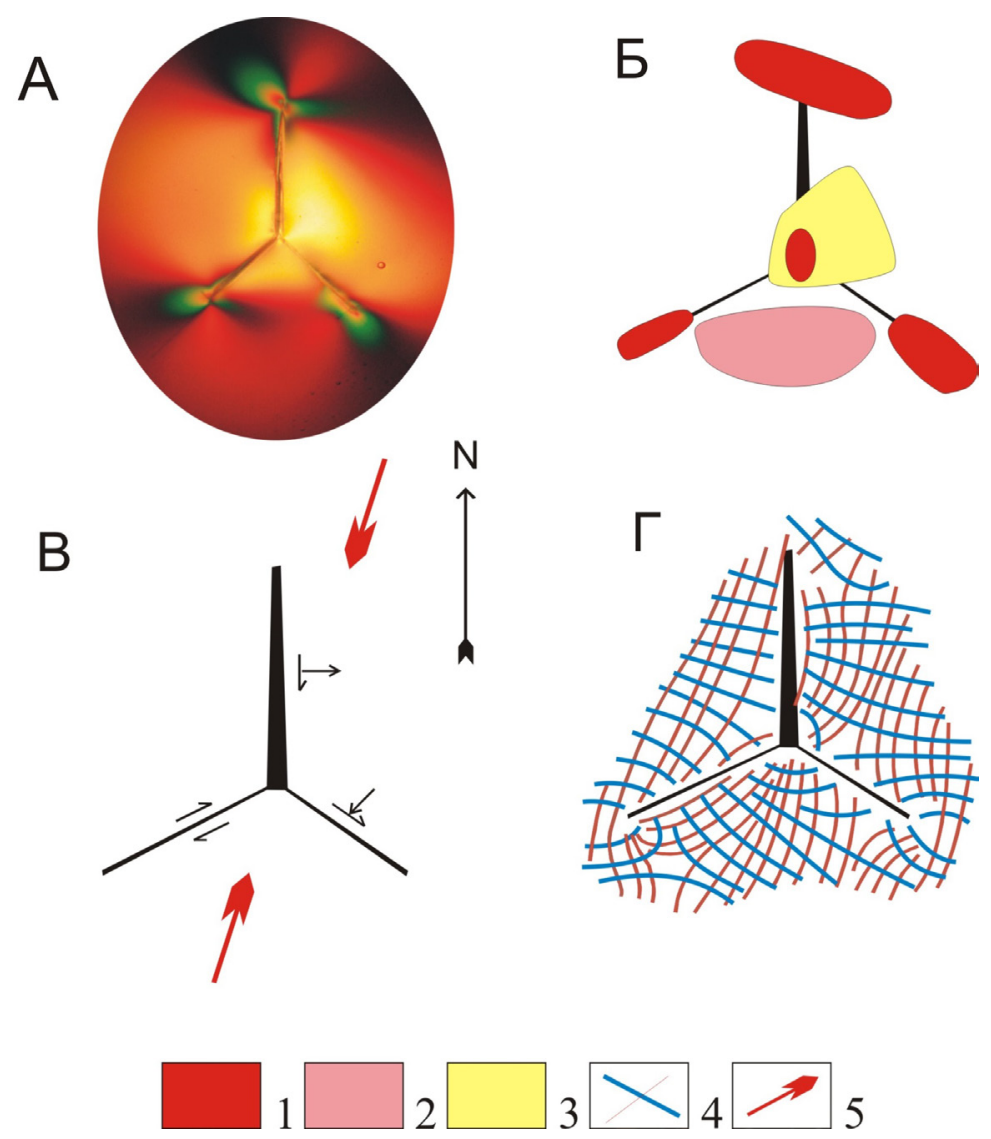

Рис. 20. Результаты поляризационно-оптического моделирования напряженного состояния Могодской ЗСР и их интерпретация.

$A$ - фотография модели из оптически-активного материала под нагрузкой; $Б$ - схема моделирования; красными стрелками обозначено направление сжатия модели, черными - направление смещения бортов разрывов; $B$ - положение областей с повышенным и пониженным значением касательных напряжений. Цифры рядом с цветными кубиками - величины концентрации максимальных касательных напряжений $K_{\tau .} . \Gamma$ - траектории главных нормальных напряжений в модели (линиями красного цвета обозначены траектории напряжений сжатия, синего - траектории напряжений растяжения).

Fig. 20. The state of stresses in the Mogod fault conjugation zone. Polarization-optical modeling results and interpretation.

$A$ - photo of the loaded model made of optically active material; $E$ - modelling scheme; red arrows show the direction in which the model is compressed; the direction of displacement of the fault wings is shown by black arrows; $B$ - areas of high and low values of shear stresses. Numbers next to colored boxes show concentration values of maximum shear stresses, $K \tau$. $\Gamma$-trajectories of main normal stresses in the model (red lines show compression stress trajectories; blue lines show extension stress trajectories).

из-за особенности строения своих зон (парагенезис разрывов второго порядка), ориентации в пространстве и характера взаимодействия (узлы сочленения различных типов) формируют поля напряжений более высоких порядков, отличающиеся ориентировкой осей главных нормальных напряжений [Cheremnykh, 2010].

\subsection{2. Могодская зона сочленения разломов}

По нашим представлениям, сейсмическая активность Могодской сейсмогенерирующей структуры определяется активизацией Y-образного сочленения под воздействием регионального сжатия ССВ направления. На рисунке 20, A, представлены результаты моделирования Могодской ЗСР и их интерпретация. Как видно из рисунка, максимальной амплитудой смещения бортов характеризуется меридиональный разрыв, характеризующийся наибольшей концентрацией напряжений на конце разрыва. По нему происходит раздвиговое перемещение с правосторонней составляющей. При этом раздвиг происходит за счет правосторонней подвижки по разрыву СЗ простирания, движение по которому осуществляется в условиях сжатия берегов. Амплитуда раскрытия разрыва в модели увеличивается с севера на юг с максимальными значениями в зоне сочленения разрывов. На местности, вдоль меридионального разлома развивается кайнозойская впадина. По разрыву СВ простирания происходит незначительный по амплитуде левосторонний сдвиг (рис. 20, Б). 
A

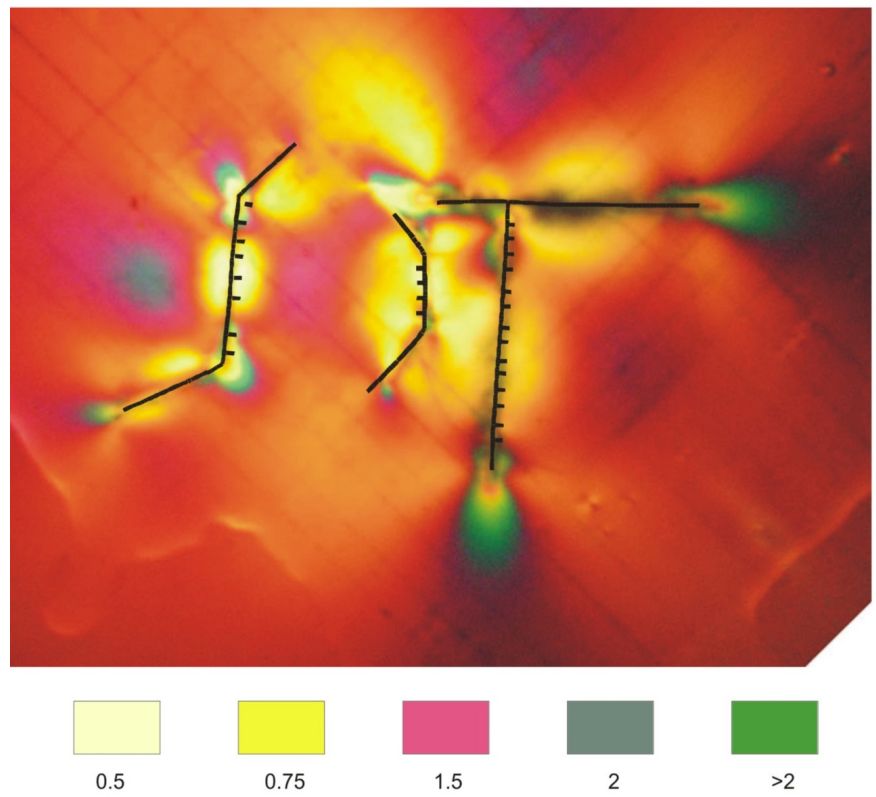

5

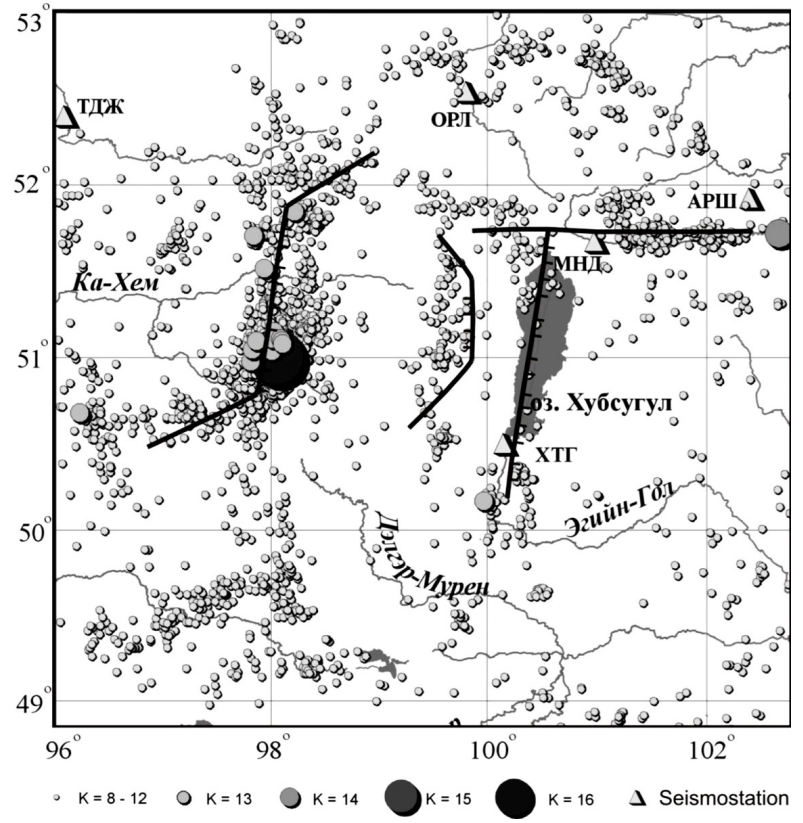

Рис. 21. Результаты поляризационно-оптического моделирования напряженного состояния сейсмоструктуры северо-монгольских впадин $(A)$.

1 - Бусийнгольская, 2 - Дархатская и 3 - Хубсугульская ЗСР. Цветом показаны области концентрации касательных напряжений, цифрами под закрашенными прямоугольниками - коэффициенты концентрации $K_{\tau}$. Описание в тексте. Б - карта эпицентров региона за $1991-$ 2003 гг.

Fig. 21. The state of stresses in the seismic structure of basins in Northern Mongolia. Polarization-optical modelling results (A).

1 - Busijngol, 2 - Darkhat, and 3 - Khubsugul fault conjugation zones. Colours show shear stress concentration areas; numbers under coloured boxes show concentration factors, $K \tau$. See descriptions in the text. 5 - map of regional epicentres from 1991 to 2003.

Характер деформаций вычленяемых разломами блоков определяется типом и интенсивностью подвижек по разрывам. Значительная концентрация максимальных касательных напряжений наблюдается в южном блоке, к которому на местности приурочена сейсмодислокация. Северо-восточный блок, который отличается максимальной величиной перемещения, характеризуется снижением напряжений. Максимальное увеличение касательных напряжений наблюдается в узле сочленения разрывов (рис. 20, B).

На рисунке 20, $\Gamma$, показаны траектории главных нормальных напряжений. Характерной особенностью Могодской структуры, как и других зон сочленения разломов, является значительная изменчивость направления осей напряжений, что подтверждается геологоструктурными исследованиями, проведенными в пределах Могодской зоны сочленения разломов.

\subsection{3. Система сейсмогенерирующих структур Хубсугул-Дархат-Бусийнгол}

Схема разломов и результаты моделирования системы рифтогенных впадин Северной Монголии - Хубсугульской, Дархатской и Бусийнгольской - представлены на рисунке 21. Активизация разломных зон, формирующих структуру этих впадин, в модели определяется действием сжатия СВ простирания, ориентация которого определена по данным GPS-измерений [Lukhnev et al., 2008].

В целом модель характеризуется повышением максимальных касательных напряжений в широтном направлении с востока на запад. При этом проявляется сокращение размеров областей высоких значений напряжений. Вблизи Хубсугульского разрыва наблюдаются обширные области снижения напряжений, Бусийнгольская структура характеризуется максимумами напряжений практически вдоль всего простирания.

Деформации в районе Хубсугульской структуры подобны описанным выше. Отличительной особенностью данной модели является объединение высоких концентраций максимальных касательных напряжений западного окончания широтного разрыва Хубсугульской структуры и северного окончания СЗ разрыва Дархатской структуры. Большая по площади область высокой концентрации напряжений формируется в узле сочленения меридионального и широтного разрывов.

Между Бусийнгольским и Хубсугульским разрывами, в районе Дархатской впадины, наблюдается обширная по площади область высоких значений максимальных касательных напряжений, формирующая вы- 

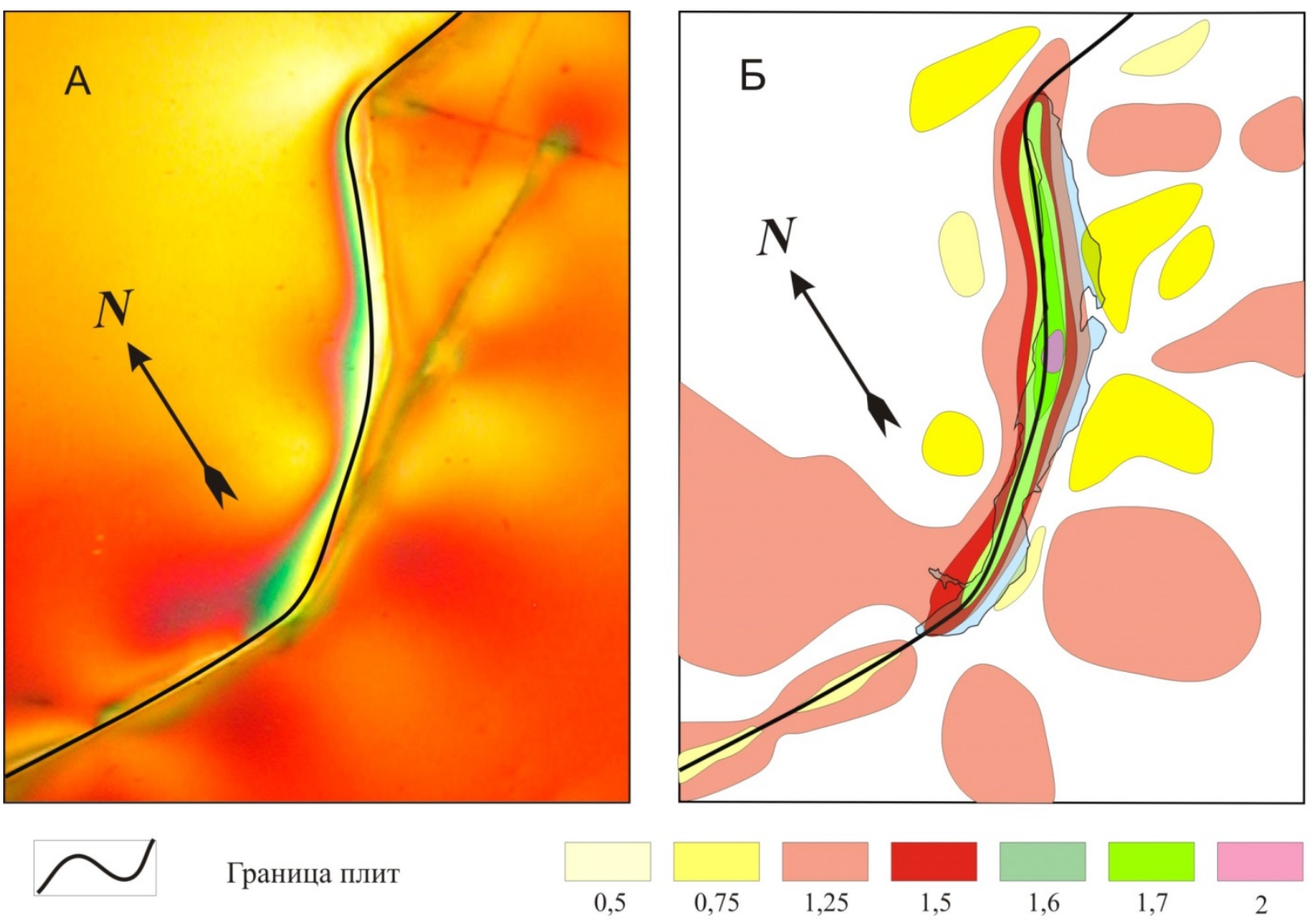

Рис. 22. Результаты поляризационно-оптического моделирования напряженного состояния структурного шва между Сибирской платформой и Забайкальской плитой и их интерпретация.

$A$ - фотография модели из оптически-активного материала под нагрузкой; $Б$ - положение областей с повышенным и пониженным значением касательных напряжений. Цветом показаны области концентрации касательных напряжений, цифрами под закрашенными прямоугольниками - коэффициенты концентрации $K_{\tau}$.

Fig. 22. The state of stresses in the structural suture between the Siberian platform and the Transbaikalia plate and their interpretation. Polarization-optical modeling and interpretation.

$A$ - photo of the loaded model made of optically active material; $\square$ - areas of high and low values of shear stresses. Colours show shear stress concentration areas; numbers under coloured boxes show concentration factors, $K \tau$.

сокоградиентную зону напряжений меридионального направления (рис. 21), на местности совпадающую с западной границей Дархатской впадины. Эта зона определяет пространственное положение полосы эпицентров землетрясений меридионального простирания в окрестностях Дархатской впадины.

Результаты экспериментов позволяют предположить, что активизация систем разломных структур Хубсугул-Дархат-Бусийнгол происходит в региональном поле напряжений, возникающих при взаимодействии Тункинской и Северо-Хангайской разломных зон, характеризующихся левосторонними подвижками. Установлено, что взаимовлияние разрывов и их систем происходит как в результате их непосредственного взаимодействия, так и на расстояниях, сопоставимых с их размерами.

Наблюдается пространственное совпадение обла- стей интенсивной концентрации максимальных касательных напряжений в модели и эпицентров землетрясений (рис. 21, $A$, Б).

\section{4. МОДЕЛИРОВАНИЕ НАПРЯЖЕННО-ДЕФОРМИРОВАННОГО СОСТОЯНИЯ БАЙКАЛЬСКОЙ РИФТОВОЙ СИСТЕМЫ}

При моделировании напряженно-деформированного состояния Байкальской рифтовой системы (БРС) были выполнены три серии экспериментов. В первой серии изучалось влияние структурного шва между Сибирской платформой и Забайкальским мегаблоком, существенно отличающимися по реологическим свойствам.

На рисунке 22 показаны результаты (рис. 22, A) и интерпретация (рис. 22, Б) одного из экспериментов первой серии. В модели представлено два блока: севе- 

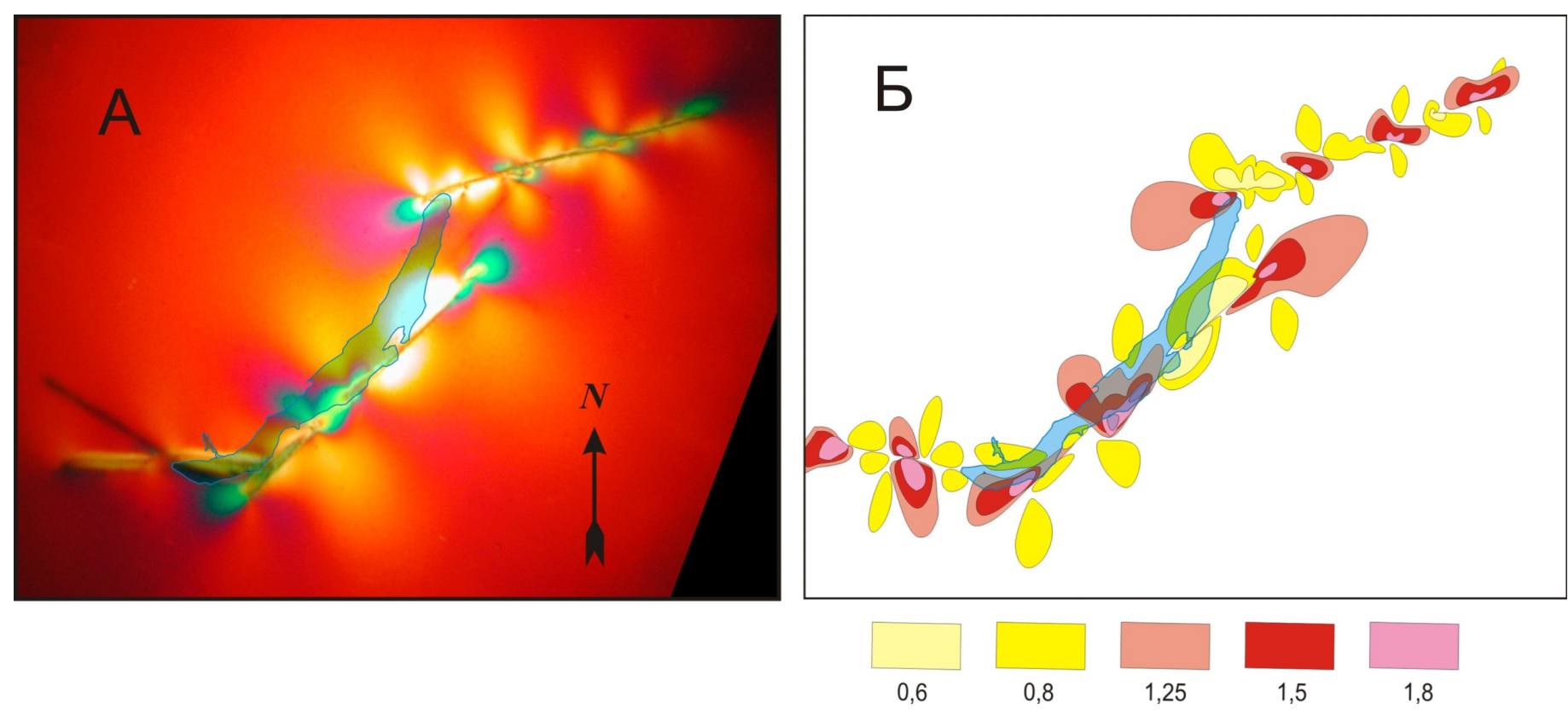

Рис. 23. Результаты поляризационно-оптического моделирования напряженного состояния БРС и их интерпретация.

$A$ - фотография модели из оптически-активного материала под нагрузкой; 5 - положение областей с повышенным и пониженным значением касательных напряжений. Цветом показаны области концентрации касательных напряжений, цифрами под закрашенными прямоугольниками - коэффициенты концентрации $K_{\tau}$.

Fig. 23. The state of stresses in the Baikal rift system (BRS). Polarization-optical modelling results and interpretation.

$A$ - photo of the loaded model made of optically active material; 5 - areas of high and low values of shear stresses. Colours show shear stress concentration areas; numbers under coloured boxes show concentration factors, $K_{\tau}$.

ро-восточный, имеющий более высокую плотность, и юго-восточный, с плотностью меньше предыдущего на $20 \%$. Граница между блоками представлена градиентной по плотности зоной. К модели была приложена внешняя нагрузка, соответствующая типичному для БРС северо-запад - юго-восточному растяжению с векторами смещения, характерными для современного этапа развития БРС.

Отмечаются следующие главные особенности в распределении полей максимальных касательных напряжений:

1. Наблюдается узкая градиентная область высоких значений коэффициента концентрации напряжений $\left(K_{\tau}\right)$ вдоль градиентной зоны плотности материала модели. Ее мощность существенно возрастает в местах изменения ориентации границ блоков.

2. Области умеренной концентрации напряжений прослеживаются на значительное расстояние к юговостоку от границ блоков, тогда как на северозападе прослеживаются в виде узкой полосы вдоль этой границы.

Во второй серии экспериментов структура модели усложнялась разрезами, имитирующими основные зоны деструкции БРС. На рисунке 23 приведены результаты одного из экспериментов и его интерпретация (условные обозначения на рис. 22). Добавление в модель разрывов расширяет область пониженных значе- ний $\tau_{\max }$, а область их повышенных значений смещается к северо-востоку. Фиксируется пространственное сочетание областей снижения и повышения максимальных касательных напряжений по простиранию БРС (рис. 23, Б).

По распределению касательных напряжений можно выделить близкие по структуре поля три области:

1) юго-западный и северо-восточный фланги БРС;

2) Южно-Байкальскую впадину, объединяющуюся с Баргузинской, которые образуют центральную часть БРC;

3) северную котловину оз. Байкал.

Юго-западная и северо-восточная фланговые зоны делятся на фрагменты с различными относительными величинами касательных напряжений. Для флангов преимущественно характерны сдвиговые подвижки, иногда сочетающиеся с небольшим растяжением или сжатием.

В третьей серии экспериментов выяснялось влияние на поле напряжений БРС возможных энергетических источников, обусловливающих процесс рифтогенеза на современном этапе, и выявлялась специфика перераспределения напряжений в ее разломно-блоковой структуре на разных иерархических уровнях. Применены различные условия на границах моделей (рис. 24), которые воспроизводят деформацию растяжения, характерную для центральной части БРС. Экс- 

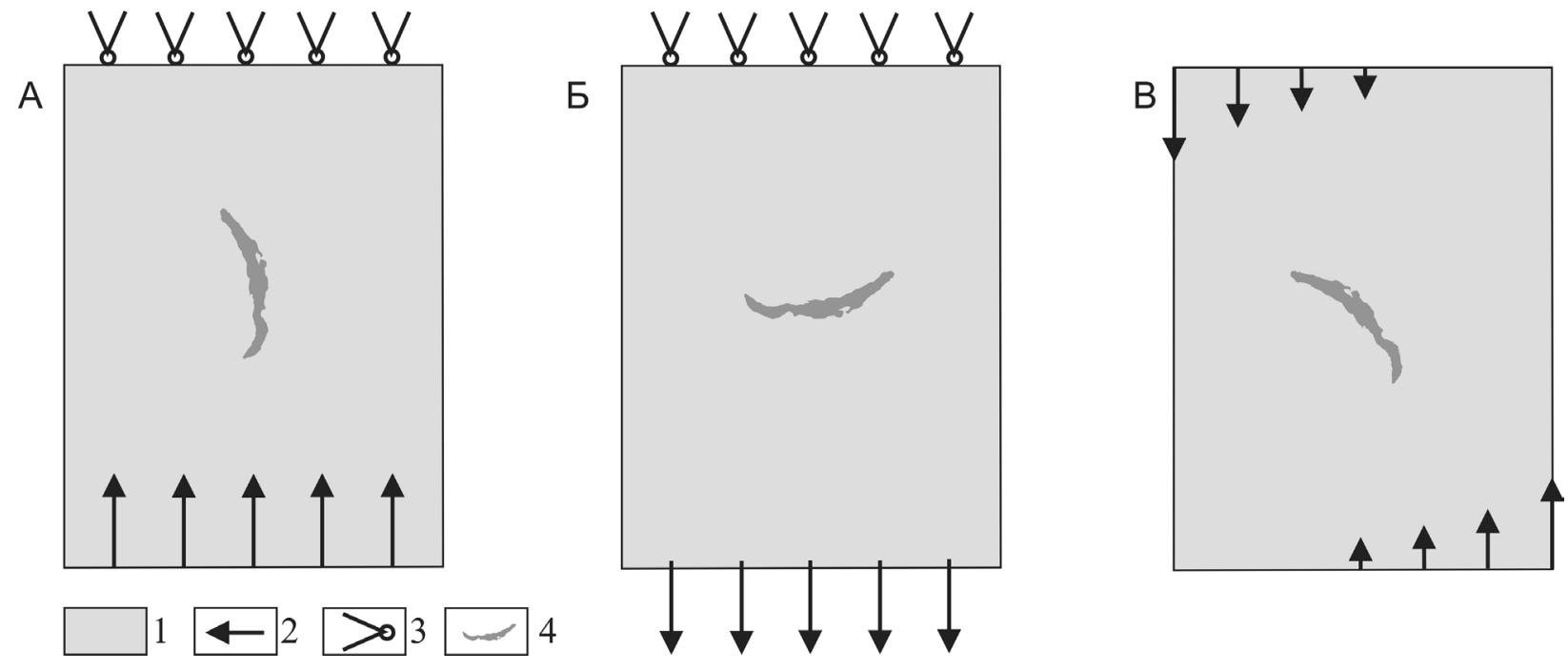

Рис. 24. Схемы деформирования моделей.

$A$ - имитация действия Индостанской коллизии; 5 - имитация действия подлитосферного потока аномальной мантии; $B$ - имитация поворота Амурской плиты под действием одного или нескольких энергетических источников. 1 - модель; 2 - направление действия нагрузки; 3 - упор с возможностью бокового смещения; 4 - контур оз. Байкал.

Fig. 24. Deformation models.

$A$ - impact of the Indian Subcontinent collision; 5 - impact of the sub-lithospheric flow of the anomalous mantle; $B$ - rotation of the Amur plate that is triggered by one or several energy sources. 1 - model; 2 - loading direction; 3 - locking with possible lateral displacement; 4 - Lake Baikal.

периментальное исследование, выполненное при разных вариантах действия внешних сил, выявило черты сходства и отличия в распределении напряжений по отношению к заданной в моделях консервативной сетке разрывов. Полученные результаты показали, что из воспроизведенных в моделях энергетических источников, местного (подлитосферный конвекционный поток) и двух удаленных (Индостанская коллизия и поддвиг Тихоокеанской плиты), при имитации деформационного воздействия Индостанской коллизии и подлитосферной конвекции генерируются поля напряжений, имеющие сходство с напряженным состоянием литосферы региона на современном этапе развития. С результатами моделирования находят удовлетворительное соответствие основные параметры очагов сильных землетрясений, зафиксированных за период инструментальных наблюдений (рис. 25). Третий энергетический источник, по-видимому, влияет на кратковременные флуктуации напряженно-деформированного состояния в БРС [Cheremnykh, 2005].

Для изучения стационарной составляющей поля напряжений в БРС проведена серия опытов, по результатам которых была оконтурена область динамического влияния деструктивной зоны и установлены особенности долговременной составляющей ее напряженного состояния на различных участках. С учетом того, что БРС развивается на границе плит с различной мощностью и реологическими свойствами литосферы, в модель изначально была заложена неоднородность в виде более плотного блока Сибирской платформы и несколько менее плотного Забайкальского блока. Область влияния деструктивной зоны охватывает территорию, значительно более широкую, чем непосредственное развитие структур БРС (см. рис. 23). Результат моделирования напряженного состояния БРС как структуры, развивающейся на границе плит, приведен на рисунке 22. Хорошо видны два разнящихся по величине напряжений поля: более низкое (Сибирская плита) и более высокое (Забайкальская плита). Они предопределяют дальнейшее разное тектоническое развитие этих сопредельных с областью рифтогенеза территорий. В рифтогенез полностью вовлечена юговосточная пограничная от шва территория, то есть северо-западная часть Забайкальской плиты. Так же отчетливо видно, что основные касательные напряжения возникают на границе плит в районе современного оз. Байкал со стороны северо-западной более жесткой платформенной структуры. Кроме того, область высоких касательных напряжений характеризуется зональным строением. Добавление в модель разрывов расширяет область пониженных значений $\tau_{\max }$, а область повышенных значений смещается к северо-востоку. Фиксируется пространственное сочетание областей снижения и повышения максимальных касательных напряжений по простиранию БР3 (см. рис. 23). Напряженное состояние внутри области динамического влияния зоны современной деструкции характеризуется пространственным сочетанием областей снижения и 

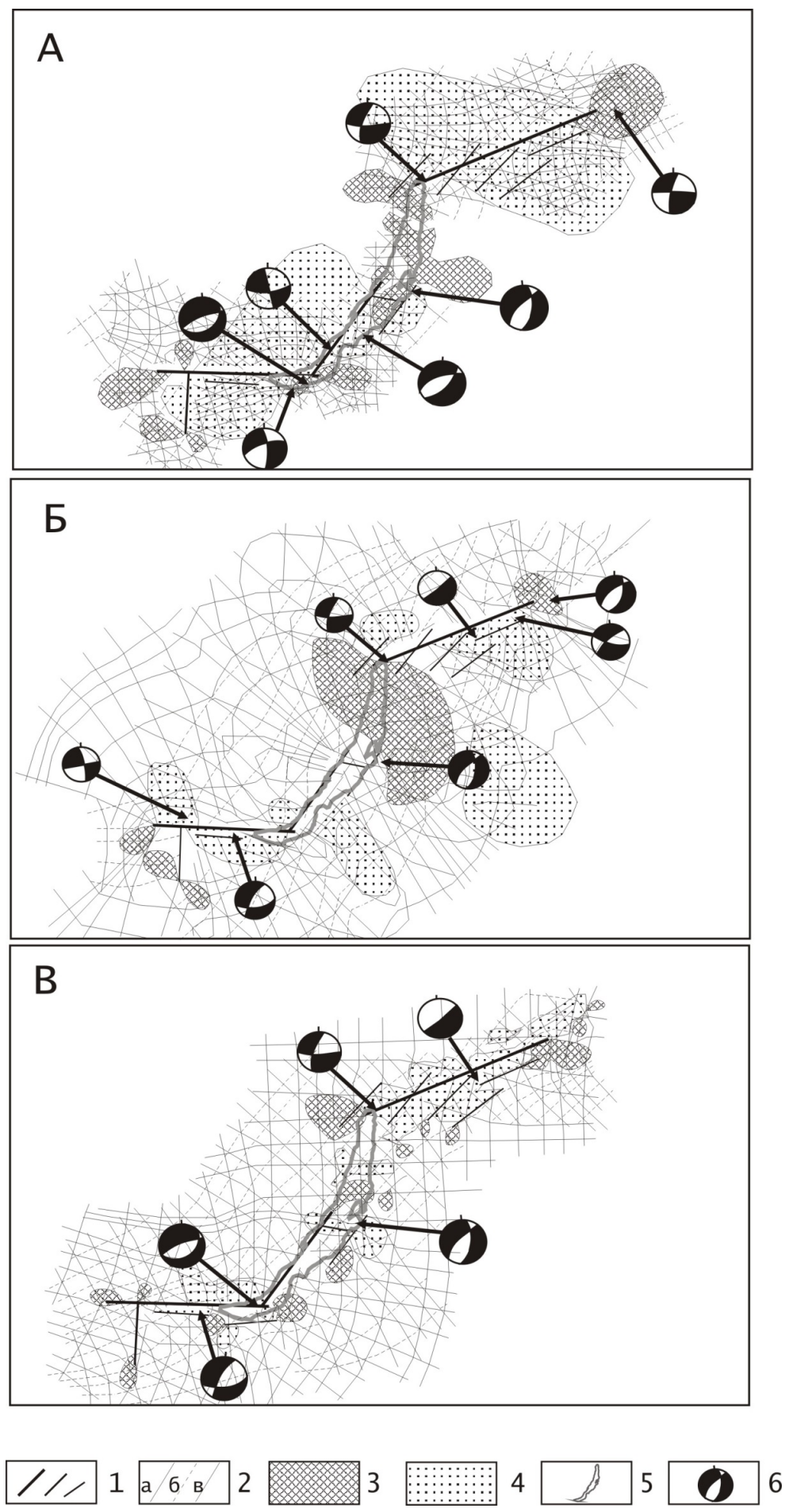

Рис. 25. Сопоставление поля максимальных касательных напряжений в моделях с механизмами очагов землетрясений в Байкальской рифтовой зоне.

$A, 5, B$ - результаты деформирования моделей в соответствующих условиях (см. рис. 24). 1 - разноранговые разломы; 2 - траектории напряжений: а - растяжения, б - сжатия, в - скола (касательные); 3 - области повышенных значений т тах 4 - области пониженных значений $\tau_{\max } ; 5$ - контур оз. Байкал; 6 - механизмы очагов сильных землетрясений (проекции нижней полусферы) [Solonenko et al., 1997; Melnikova, Radziminovich, 1998]. Закрашенные области на диаграммах соответствуют областям волн сжатия, светлые - областям волн разрежения.

Fig. 25. Comparison between the field of maximum tangential stresses in the models and earthquake focal mechanisms in the Baikal rift system.

A, Б, B - simulated deformation under specified conditions (see Fig. 24). 1 - faults of various ranks; 2 - stress trajectories: a - extension, 6 - compression, в - shear; 3 - areas of high $\tau_{\max } ; 4$ - areas of low $\tau_{\max } ; 5$ - countour of Lake Baikal; 6 - mechanisms of strong earthquake foci (lower hemispre projections) [Solonenko et al., 1997; Melnikova, Radziminovich, 1998]. In diagrams, areas of compression waves are shaded, and areas of extension waves are light. 

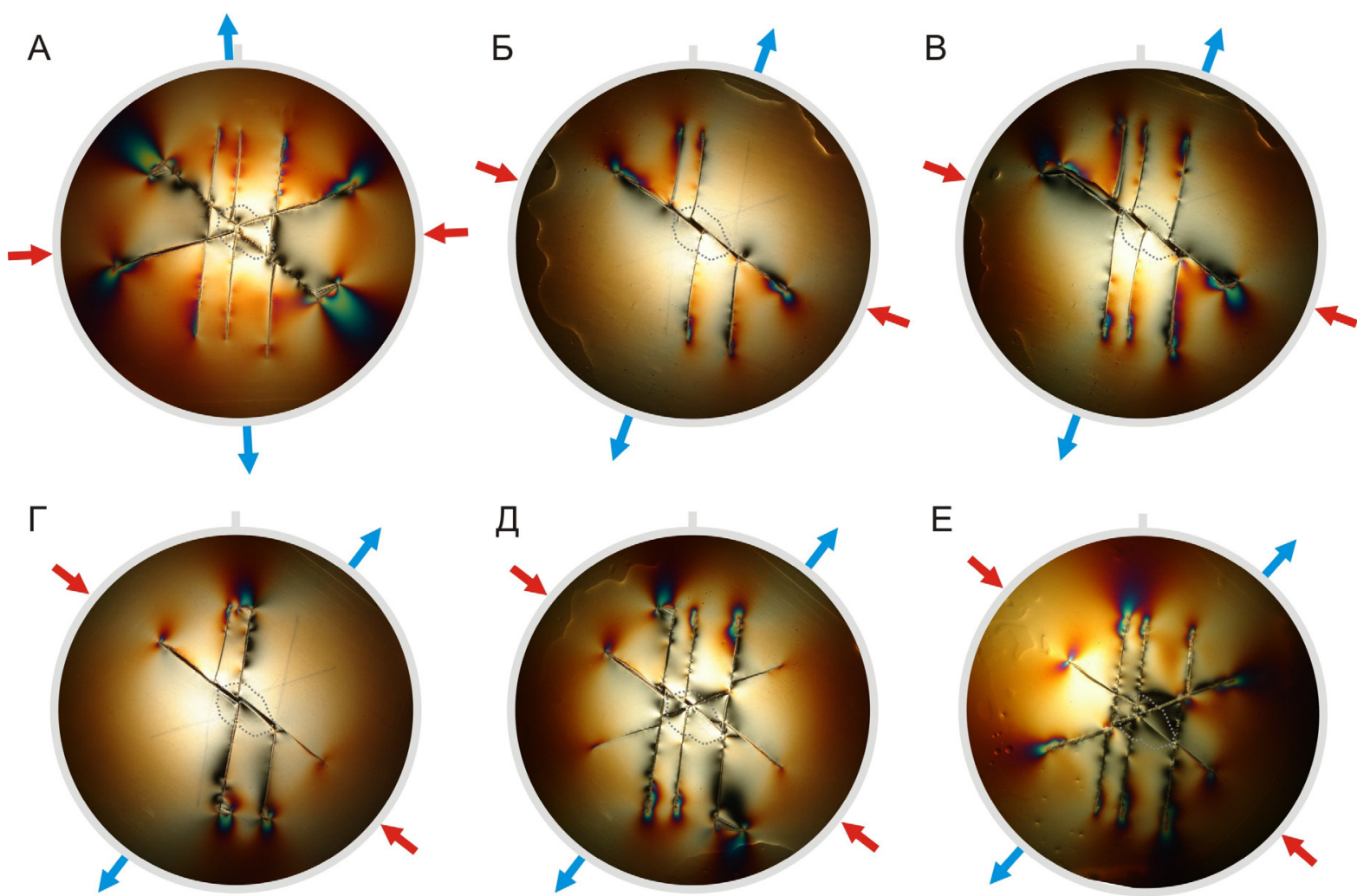

Рис. 26. Результаты поляризационно-оптического моделирования напряженно-деформированного состояния элементов разломного узла, вмещающего трубку Мир, при разных граничных условиях экспериментов (фото экспериментов).

Граничные условия: $A$ - сжатие $265^{\circ}$ - растяжение $355^{\circ}$; Б, В - сжатие $290^{\circ}$ - растяжение $20^{\circ}$; $\Gamma$, Д - сжатие $~ 310^{\circ}-$ растяжение $\sim 40^{\circ}$; $E$ - сжатие $312^{\circ}$ - растяжение $42^{\circ}$. Пунктирной линией серого цвета обозначено положение выхода на поверхность трубки Мир. Стрелками показана ориентировка внешних воздействий на границах модели.

Fig. 26. The stress-and strain state of elements comprising the fault conjugation site including the Mir mine. Polarization-optical modelling results under different boundary conditions of modelling (photos of modelled cases).

Boundary conditions: $A$ - compression $265^{\circ}$ - extension $355^{\circ}$; Б, B - compression $290^{\circ}$ - extension $20^{\circ} ; \Gamma$, Д - compression $\sim 310^{\circ}-$ extension $\sim 40^{\circ}$; $E$ - compression $312^{\circ}$ - extension $42^{\circ}$. The dotted line shows the Mir mine of the surface. Arrows show orientations of external impacts at the model's boundaries.

повышения максимальных касательных напряжений по ее простиранию, что объясняет избирательную по площади рифтогенеза относительную активизацию разноранговых разломов [Sherman et al., 2005].

\section{5. МОДЕЛИРОВАНИЕ НАПРЯЖЕННО-ДЕФОРМИРОВАННОГО СОСТОЯНИЯ В РАЗЛОМНЫХ УЗЛАХ, ВМЕЩАЮЩИХ КОРЕННЫЕ МЕСТОРОЖДЕНИЯ ЯКУТСКОЙ АЛМАЗОНОСНОЙ ПРОВИНЩИИ}

В последнее время начаты исследования прикладного характера по моделированию напряженно-деформированного состояния в окрестностях разломных узлов, вмещающих кимберлитовые тела Якутской алмазоносной провинции. Данные исследования входят в комплекс работ, направленных на детальное изучение коренных месторождений алмазов России, с созданием для каждого из них трехмерных моделей структурно- вещественного строения и динамики развития рудовмещающих разломных узлов. Цель моделирования заключалась в выявлении специфики напряженно-деформированного состояния при активизации разных фрагментов разломного узла во внешнем поле тектонических напряжений. Выполнены постановочные эксперименты для окрестностей алмазоносных кимберлитовых трубок Мир и Нюрбинская. Так, в 15 опытах, отличающихся спецификой сети дизъюнктивных дислокаций разломного узла и граничными условиями воздействия на модель, были воспроизведены различные сочетания разрывов в окрестностях разломного узла, вмещающего кимберлитовую трубку Мир (рис. 26). Моделирование показало, что благоприятные для локализации трубки структуры формируются в результате активизации северо-западных и субмеридиональных разрывов в сдвиговом поле напряжений с ориентировкой оси сжатия 290-310 [Cheremnykh et al., 2014]. 


\section{4. ЗАКЛЮЧЕНИЕ}

Многолетние экспериментальные исследования позволили установить ряд закономерностей развития разломных зон в моделях, которые, с одной стороны, расширяют наши представления о протекании процессов разломообразования в литосфере, а с другой стороны - способствуют адресному переносу этих закономерностей на природные аналоги. Отдельные элементы найденных закономерностей были намечены ранее в работах М.В. Гзовского и В.В. Белоусова и некоторых зарубежных исследователей-экспериментаторов и благодаря комплексным экспериментальным исследованиям, проводимым в лаборатории тектонофизики ИЗК СО РАН, получили дальнейшее развитие.

Например, именно наблюдения за структурной эволюцией зоны разлома в модели инициировали введение понятия ОАДВР для ее характеристики как объемной трехмерной структуры. Благодаря многочисленным экспериментам с меняющимися граничными условиями был собран представительный цифровой фактический материал и рассчитаны уравнения множественной корреляции для оценки ширины ОАДВР [Sherman et al., 1983]. На основе этих уравнений в дальнейшем были выполнены количественные оценки ширины зон разломов разных морфолого-генетических типов с учетом категорий пород и скоростного режима их деформирования. Эти оценки, представленные для удобства в табличной форме, были рекомендованы для практического использования [Sherman et al., 1985]. Эксперименты способствовали дальнейшему развитию сложившихся представлений о масштабной ранжированности разломов и привели к необходимости введения понятия «деструктивные зоны литосферы» для описания наиболее крупных межплитных и внутриплитных структур разрушения [Sherman, 1996].

Рассмотренные ранее в общих чертах на качественном уровне в работах М.В. Гзовского, Дж. Чаленко, С. Стоянова и других представления о стадийности формирования зон разломов получили существенное развитие, в том числе и на количественном уровне. Показано, что периодичность эволюционного процесса внутриразломной разрывной структуры является фундаментальной закономерностью и проявляется не только в его стадийности, но и в делении самих стадий на этапы [Seminsky, 2003; Bornyakov, Semenova, 2011; u $\partial p$.$] . Эта временная неравномерность дополняется не-$ равномерностью пространственной, выражающейся в вариациях геометрических параметров внутриразломных систем разрывов по простиранию и вкрест простирания зон разломов. Выражением пространственной неравномерности развития их внутренней структуры является большая раздробленность активного крыла разлома по отношению к пассивному, а также чередующихся по их простиранию двух типов областей с разной интенсивностью развития. Это находит отражение в густоте разрывов в их пределах и накопленных на них суммарных амплитудах смещений. Пространственная неравномерность разрушения в зонах разломов характеризуется также наличием определенного шага между областями с максимумами плотности разрывов, который зависит от стадии развития и скорости деформации [Seminsky, 2003]. Тесная взаимосвязь пространственных и временных проявлений неравномерности разрушения свидетельствует, что выявленные закономерности являются наиболее общими особенностями развития крупных разломных зон литосферы.

Благодаря экспериментам получила дальнейшее развитие идея количественной параметризации разломов, инициированная рядом исследователей в 70-х годах прошлого столетия [Sherman, 1977, 1996; Rats, Chernyshev, 1970; Ruzhich, 1977; Nesmeyanov, 2004; u дp.]. По результатам экспериментов установлено, что для единичных разломов выполняются лимитированные соотношения длины, ширины, глубины проникновения и амплитуды смещения, а для ансамблей разноранговых разрывных нарушений в ОАДВ крупной разломной зоны, при кажущейся их неупорядоченности, существуют свои закономерности пространственных взаимоотношений, выраженные через параметры густоты, плотности, средней длины и других. Впервые было подтверждено, что взаимоотношения между параметрами разломов закономерны и имеют многофакторную природу и видоизменяются в зависимости от морфолого-генетического типа разлома и стадии его развития, реологических свойств вмещающей его среды и скорости ее деформирования [Sherman et al., 1983; Bornyakov, 1990; Seminsky, 2003].

Уникальные эксперименты, не имеющие аналога в мировой экспериментальной практике, выполненные В.Ю. Буддо по инструментальному тензометрическому мониторингу объемных деформаций в ОАДВР, позволили впервые получить убедительные доказательства их пространственно-временной мобильности и волнового характера миграции в объеме формирующейся разломной зоны [Sherman et al., 1991; Buddo, Truskov, 1982]. Дальнейшие детальные исследования показали, что формирующаяся разломно-блоковая внутренняя структура зон разломов имеет сложную, но закономерную, дискретную деформационную динамику развития. Она реализуется через дифференцированную по типу деформацию блоков и избирательную пространственно-временную сегментную активизацию межблоковых контактов [Bornyakov, Semenova, 2011]. Установлено, что такая пространственно-временная дискретность деформационного процесса во внутренней структуре зоны разлома обусловлена внутренними свойствами упруговязкопластичной среды, обеспечивающими генерацию в ней деформационных волн даже при постоянной внешней нагрузке.

Наблюдения за структурной эволюцией внутриразломных систем разрывов в моделях и результаты их 
фрактального и энтропийного анализа дали основание для синергетической интерпретации этого процесса, согласно которой зоны разломов литосферы являются открытыми неравновесными динамическими системами, а их эволюция представляет собой синергетический процесс последовательной смены структурных уровней деформации с характерным для каждого из них набором разномасштабных разрывных нарушений, обладающих свойствами самоподобия. Определяющая роль при смене структурных уровней принадлежит процессам самоорганизации систем разрывных нарушений. Системы разрывных нарушений, охваченных самоорганизацией, представляют собой особый класс динамических структур, именуемых «разрывными диссипативными структурами» (РДС) [Bornyakov, Sherman, 2003; и дp.]. В условиях прогрессирующей деформации кооперативное поведение разрывных нарушений в РДС через механизм последовательной сегментации обеспечивает накопление в их пределах аномально высоких напряжений, способствующих процессам рудо- и сейсмогенеза. Такая интерпретация существенно обогатила представления о зоне разлома и привела, с одной стороны, к введению нового понятия, характеризующего его особое динамическое состояние как сложной, иерархически построенной структурно-динамической системы, с другой - позволила предложить новый подход к прогнозным построениям. Примерами его реализации являются разрабатываемые способ прогноза алмазоносных кимберлитовых тел [Gladkov et al., 2008; Matrosov et al., 2004] и способ прогноза землетрясений [Bornyakov et al., 2013; Bornyakov, 2010; Vstovsky, Bornyakov, 2010].

Возможность получения непрерывных в простран- стве параметров напряженно-деформированного состояния сложных тектонических структур, хорошая согласованность результатов поляризационно-оптического моделирования с данными, полученными в результате сейсмологических, геолого-структурных и геодезических исследований, позволяют использовать этот вид моделирования для геодинамических построений и прогнозирования зон повышенной сейсмической активности. С его помощью получены серии схем, отражающих распределение и концентрацию максимальных касательных напряжений, связанных с геологическими и тектоническими неоднородностями литосферы, ориентацией горизонтальных осей сжатия и растяжения. Произведена оценка интенсивности и типов подвижек по разломам. Установлено, что основные параметры сейсмической активности Могодской, Хубсугульской, Дархатской и Бусийнгольской кайнозойских впадин Монголии определяются взаимодействием систем разломов различной ориентации под воздействием регионального поля напряжений. Изучена пространственная зональность максимальных касательных напряжений в Байкальской рифтовой системе, связанная со структурным швом между Сибирской платформой и Забайкальским мегаблоком и разломными деструктивными зонами БРС.

В целом, приведенный выше обзор представляет собой краткую историю развития физического моделирования в лаборатории тектонофизики ИЗК СО РАН, которая на сегодняшний день является единственной профильной лабораторией в России и одной из немногих в мире, где системно и комплексно используется физическое моделирование процессов разломообразования в литосфере.

\section{5. ЛИTEPATУPA / REFERENCES}

Akopian S.T., 1995. Entropy of seismic system and new seismic law. Doklady AN 340 (4), $531-535$ (in Russian) [Акопян С.Ц. Энтропия сейсмической системы и новый сейсмический закон // Доклады АН. 1995. Т. 340. № 4. C. 531-535].

Akopian S.T., 1998. Quantitative description of seismic processes based on seismic entropy. Izvestiya, Physics of the Solid Earth 34 (1), 8-22.

Aleksandrov A.Ya., Akhmetzyanov M.Kh., 1973. Polarization Optical Methods in Deformed Body Mechanics. Nauka, Moscow, 576 p. (in Russian) [Александров А.Я., Ахметзянов М.X. Поляризационно-оптические методы механики деформируемого тела. М.: Наука, 1973. 576 с.].

Atmaoui N., Kukowski N., Stöckhert B., König D., 2006. Initiation and development of pull-apart basins with Riedel shear mechanism: insights from scaled clay experiments. International Journal of Earth Sciences 95 (2), 225-238. http://dx. doi.org/10.1007/s00531-005-0030-1.

Babichev A.A., 1987. About some principal issues of the use of the criteria of similarity in modelling of fractures and faults. Russian Geology and Geophysics (4), 36-42 (in Russian) [Бабичев А.А. О некоторых принципиальных вопросах использования критерия подобия при моделировании трещин и разрывов // Геология и геофизика. 1987. № 4. С. 36-42].

Bondarenko P.M., 1989. Modelling of tectonic stress fields of elementary deformation structures. In: Experimental tectonics. methods, results, and prospects. Nauka, Moscow, p. 126-163 (in Russian) [Бондаренко П.М. Моделирование тектонических полей напряжений элементарных деформационных структур // Экспериментальная тектоника. Методы, результаты, перспективы. М.: Наука, 1989. С. 126-163].

Bornyakov S.A., 1981. Tectonophysical analysis of formation of a transform zone in the elasto-plastic model. In: Problems of fault tectonics. Nauka, Novosibirsk, p. 26-44 (in Russian) [Борняков С.А. Тектонофизический анализ процесса фор- 
мирования трансформной зоны в упруговязкой модели // Проблемы разломной тектоники. Новосибирск: Наука, 1981. C. 26-44].

Bornyakov S.A., 1990. Quantitative analysis of parameters of shear faults varying in scale. Russian Geology and Geophysics (10), 34-42 (in Russian) [Борняков С.А. Количественный анализ параметров разномасштабных сдвигов // Геология и геофизика. 1990. № 10. С. 34-42].

Bornyakov S.A., 2010. Deformation precursors of the Ust-Barguzin earthquake of May 20, 2008. Doklady Earth Sciences 431 (1), 406-408. http://dx.doi.org/10.1134/S1028334X1003030X.

Bornyakov S.A., 2012. Physical modelling of faulting in the lithosphere in the recent stage: review. In: Tectonophysics and top issues of Earth sciences. Proceedings of the 3rd Tectonophysical Conference, 8-12 October 2012. IPE, Moscow, p. 50-56 (in Russian) [Борняков С.А. Физическое моделирование процессов разломообразования в литосфере на современном этапе: обзор // Тектонофизика и актуальные вопросы наук о Земле на современном этапе: Материалы докладов третьей тектонофизической конференции, 8-12 октября 2012 г. М.: ИФ3, 2012. С. 50-56].

Bornyakov S.A., Gladkov A.S., Adamovich A.N., Matrosov V.A., Klepikov V.A., 2003. Informational entropy and fractal dimension as criteria of self-organization of fracture systems in fault zones (based on physical modeling results). Doklady Earth Sciences 391 (5), 766-768.

Bornyakov S.A., Matrosov V.A., Gladkov A.S., 2013. The method for assessment of exploration areas promising for kimberlite bodies within diamond-bearing regions. Patent RU 2492511 C1. (in Russian) [Борняков С.А., Матросов В.А., Гладков А.С. Способ оценки перспективности поисковой площади на обнаружение алмазоносных кимберлитовых тел в пределах алмазоносных районов. Патент RU 2492511 C1. 2013].

Bornyakov S.A., Semenova N.V., 2011. Dissipative processes in fault zones (based on physical modeling results). Russian Geology and Geophysics 52 (6), 676-683. http://dx.doi.org/10.1016/j.rgg.2011.05.010.

Bornyakov S.A., Sherman S.I., 2000. Multilevel self-organization of destruction in a shear zone (data of physical modeling). Fizicheskaya Mezomekhanika 3 (4), 105-112 (in Russian) [Борняков С.А., Шерман С.И. Многоуровневая самоорганизация деструктивного процесса в сдвиговой зоне (по результатам физического моделирования) // Физическая мезомеханика. 2000. Т. 3. № 4. С. 107-115].

Bornyakov S.A., Sherman S.I., 2003. Multistage evolution of strike-slip faults reflected in their displacement-fault length relationship (tectonophysical modeling). Russian Geology and Geophysics 44 (7), 712-718.

Brace W.F., Byerlee J.D., 1966. Stick-slip as a mechanism for earthquake. Science 153 (3739), 990-992. http://dx.doi.org/ 10.1126/science.153.3739.990.

Brillouin L., 1966. Scientific Uncertainty and Information. Mir, Moscow, 271 p. (in Russian) [Бриллюэн Л. Научная неопределенность и информация. М.: Мир,1966. 271 с.].

Buddo V.Yu., Truskov V.A., 1982. Stress fields inside models. In: Experimental tectonics in solution of problems of applied and theoretical geology. Abstracts of the All-Union Symposium. Novosibirsk, p. 39-40 (in Russian) [Буддо В.Ю., Трусков В.А. Поля напряжений внутри модели // Экспериментальная тектоника в решении задач практической и теоретической геологии: Тезисы докладов Всесоюзного симпозиума. Новосибирск, 1982. С. 39-40].

Byerlee J., 1978. Friction of rocks. Pure and Applied Geophysics 116 (4-5), 615-626. http://dx.doi.org/10.1007/BF0087 6528.

Cheremnykh A.V., 2005. Active stress field in the Baikal rift zone: laboratory modeling. Russian Geology and Geophysics 46 (10), 1071-1080.

Cheremnykh A.V., 2010. Fault-block structure and the stress state of the upper crust of Lake Baikal's eastern coast (field observations and modeling). Izvestiya, Physics of the Solid Earth 46 (5), 404-411. http://dx.doi.org/10.1134/S10693513100 50058.

Cheremnykh A.V., Gladkov A.S., Afon'kin A.M., Potekhina I.A., Serebryakov E.V., Kuz'min I.V., 2014. Modelling of the strain-and-stress state in the vicinity of the fault conjunction in the area of the Mir kimberlite pipe (Yakutian diamondbearing province). Izvestiya Sibirskogo otdeleniya sektsii nauk o Zemle RAEN. Geologiya, poiski i razvedka rudnykh mestorozhdeniy (1 (44)), 35-43 (in Russian) [Черемных А.В., Гладков А.С., Афонькин А.М., Потехина И.А., Серебряков E.В., Кузьмин И.В. Моделирование напряженно-деформированного состояния в окрестностях разломного узла района кимберлитовой трубки «Мир» (Якутская алмазоносная провинция) // Известия Сибирского отделения секции наук о Земле РАЕН. Геология, поиски и разведка рудных месторождений. 2014. № 1 (44). С. 35-43].

Courtillot V., Tapponier P., Varet J., 1974. Surface features associated with transform faults: a comparison between observed examples and an experimental model. Tectonophysics 24 (4), 317-329. http://dx.doi.org/10.1016/0040-1951(74)90015-8.

Dooley T.P., Schreurs G., 2012. Analogue modelling of intraplate strike-slip tectonics: A review and new experimental results. Tectonophysics 574-575, 1-71. http://dx.doi.org/10.1016/j.tecto.2012.05.030.

Durelli J., Riley W.F., 1970. Introduction to Photomechanics (Polarization Optical Method). Translated from English. Mir, Moscow, 488 p. (in Russian) [Дюрелли А., Райли У. Ведение в фотомеханику (поляризационно-оптический метод): Пер. с англ. М.: Мир, 1970. 488 c].

Gladkov A.S., Manakov A.V., Bornyakov S.A., Matrosov V.A., 2008. Tectonophysical Studies in Diamond Prospecting. Nauchny Mir, Moscow, 175 p. (in Russian) [Гладков А.С., Манаков А.В., Борняков С.А., Матросов В.А. Тектонофизические исследования при алмазопоисковых работах. М.: Научный мир, 2008. 175 c]. 
Graveleau F., Malavieille J., Dominguez S., 2012. Experimental modelling of orogenic wedges: A review. Tectonophysics 538-540, 1-66. http://dx.doi.org/10.1016/j.tecto.2012.01.027.

Grigoriev A.S., Osokina D.N. (Eds.), 1979. Stress and Strain Fields of the Lithosphere. Nauka, Moscow, 256 p. (in Russian) [Поля напряжений и деформаций в литосфере / Ред. А.С. Григорьев, Д.Н. Осокина. М.: Наука, 1979. 256 с.].

Gzovsky M.B., 1970. Development of new directions in tectonophysics. Izvestia AN SSSR. Fizika Zemli (5), 51-84 (in Russian) [Гзовский М.В. Развитие новых направлений в тектонофизике // Известия АН СССР. Физика Земли. 1970. № 5. С. 51-84].

Gzovsky M.V., 1975. Fundamentals of Tectonophysics. Nauka, Moscow, 536 p. (in Russian) [Гзовский М.В. Основы тектонофизики. М.: Наука, 1975. 536 c].

Gzovsky M.V., Osokina D.N., Lomakin A.A., Kudryashova V.V., 1974. Stresses, faults, and earthquakes foci (modelling results). In: Regional studies of seismic regime. Shtinitsa, Kishinev, p. 113-124 (in Russian) [Гзовский М.В., Осокина Д.Н. Ломакин А.А., Кудряшова В.В. Напряжения, разрывы, очаги землетрясений (результаты моделирования) // Региональные исследования сейсмического режима. Кишинёв: «Штиница», 1974. С. 113-124].

Haken H., 1980. Synergetics. Mir, Moscow, 404 p. (in Russian) [Хакен Г. Синергетика. М.: Мир, 1980. 404 с.].

Haken H., 1985. Synergetics: Instability Hierarchies of Self-Organizing Systems and Devices. Mir, Moscow, 19 p. (in Russian) [Хакен Г. Синергетика: Иерархия неустойчивости в самоорганизующихся системах и устройствах. М.: Мир, 1985. 419 c.].

Hubbert M.K., 1937. Theory of scale models as applied to the study of geologic structures. Geological Society of America Bulletin 48 (10), 1459-1520. http://dx.doi.org/10.1130/GSAB-48-1459.

Klimontovich Yu.L., 1989. Problems in the statistical theory of open systems: Criteria for the relative degree of order in selforganization processes. Soviet Physics Uspekhi 32 (5), 416-433. http://dx.doi.org/10.1070/PU1989v032n05ABEH00 2717.

Kostrov B.V., 1975. Mechanics of Tectonic Earthquake Focus. Nauka, Moscow, 174 p. (in Russian) [Костров Б.В. Механика очага тектонического землетрясения. М.: Наука, 1975. 174 с.].

Kuznetsov O.L., 1981. Nonlinear geophysics. In: Issues of nonlinear geophysics. VNIIYaGG, Moscow, p. 5-20 (in Russian) [Кузнецов О.Л. Нелинейная геофизика // Вопросы нелинейной геофизики. М.: ВНИИЯГГ, 1981. С. 5-20].

Letnikov F.A., 1992. Synergetics of Geological Systems. Nauka, Moscow, 228 р. (in Russian) [Летников Ф.А. Синергетика геологических систем. Новосибирск: Наука, 1992. 228 с.]

Levi K.G., Sherman S.I., 1991. Neotectonic Movements in Seismically Active Zones of the Lithosphere. Tectonophysical Analysis. Nauka, Novosibirsk, 166 p. (in Russian) [Леви К.Г., Шерман С.И. Неотектонические движения земной коры в сейсмоактивных зонах литосферы: тектонофизический анализ. Новосибирск: Наука, 1991. 166 с.].

Lobatskaya R.M., 2003. Infrastructure of fault zone of the lithosphere and seismicity. In: Stress-and-Strain State and Seismicity of the Lithosphere. GEO Branch, Publishing House of SB RAS, Novosibirsk, p. 92-95 (in Russian) [Лобацкая P.M. Инфраструктура разломных зон литосферы и сейсмичность // Напряженно-деформированное состояние и сейсмичность литосферы. Новосибирск: Изд-во СО РАН, филиал «Гео», 2003. С. 92-95].

Lukhnev A.V., San'kov V.A., Miroshnichenko A.I., Ashurkov S.V., Calais E., Déverchère J., 2008. Recent movements, deformation and rotation of blocks in the Mongol-Baikal regions according to GPS data. In: All-Russia Conference "Tectonophysics and Topical Problems in Earth Sciences. To the 40th anniversary of M.V. Gzovsky Laboratory of Tectonophysics, Institute of Physics of the Earth RAS”. IPE RAS, Moscow, Vol. 1, p. 264-266 (in Russian) [Лухнев А.В., Саньков B.А., Мирошниченко А.И., Ашурков, С.В., Кале Э., Девершер Ж. Современные движения, деформации и вращения блоков Монголо-Байкальского региона по данным GPS // Всероссийская конференция «Тектонофизика и актуальные вопросы наук о Земле. К 40-летию создания М.В. Гзовским лаборатории тектонофизики в ИФЗ РАН». М.: ИФЗ РАН, 2008. Т. 1. С. 264-266].

Mandelbrot B.B., 1982. The fractal geometry nature. Freeman, New York, 480 p.

Matrosov V.A., Bornyakov S.A., Gladkov A.S., 2004. A new approach to optimization of prognostic prospecting for diamondiferous kimberlites. Doklady Earth Sciences 395 (2), 192-195.

Melnikova V.I., Radziminovich N.A., 1998. Mechanisms of action of earthquake foci in the Baikal region over the period 1991-1996. Geologiya i Geofizika 39 (11), 1598-1607.

Mikhailova A.V., 1971. The method of quantitative analysis of displacements, deformation and strain in plastic nontransparent models. In: Tectonophysics and mechanical properties of rocks. Nauka, Moscow, p. 38-48 (in Russian) [Muхайлова А.В. Методика количественной оценки перемещений, деформаций и напряжений в пластических непрозрачных моделях // Тектонофизика и механические свойства горных пород. М.: Наука, 1971. С. 38-48].

Miroshnichenko A.I., 1989. Conditions of Activation and Stress Fields of Fault Jointing Zones. Synopsis of the Author's Thesis for Candidate of Geology and Mineralogy Degree. Novosibirsk, 16 p. (in Russian) [Мирошниченко А.И. Условия активизации и поля напряжений зон сочленения разломов: Автореф. дис. ... канд. геол.-мин. наук. Новосибирск, 1989. 16 с.].

Miroshnichenko A.I., Adamovich A.N., 1990. Modelling of the state of stresses of fault jointing zones. In: Baikal rift seismicity. Nauka, Novosibirsk, p. 3-7 (in Russian) [Мирошниченко А.И., Адамович А.Н. Моделирование напряженного состояния зон сочленения разломов // Сейсмичность Байкальского рифта. Новосибирск: Наука, 1990. С. 3-7]. 
Miroshnitchenko A.I., San'kov V.A., Parfeevets A.V., Lukhnev A.V., 2007. State of stress and strain of the Earth crust of the basins of North Mongolia from the model results. In: Conference commemorating the 50th Anniversary of the 1957 Gobi-Altay earthquake. Ulaanbaatar, p. 138-143.

Myachin V.N., 1978. Earthquake Preparation Processes. Nauka, Moscow, 231 p. (in Russian) [Мячкин В.Н. Процессы подготовки землетрясений. М.: Наука, 1978. 231 с.].

Naylor M.A., Mandl G., Superteijn C.H.K., 1986. Fault geometries in basement-induced wrench faulting under different initial stress states. Journal of Structural Geology 8 (7), 737-752. http://dx.doi.org/10.1016/0191-8141(86)90022-2.

Nesmeyanov S.A., 2004. Engineering Geotectonics. Nauka, Moscow, 780 p. (in Russian) [Несмеянов С.А. Инженерная геотектоника. М.: Наука, 2004. 780 с.].

Noselli G., Dal Corso F., Bigoni D., 2010. The stress intensity near a stiffener disclosed by photoelasticity. International Journal of Fracture 166 (1-2), 91-103. http://dx.doi.org/10.1007/s10704-010-9502-9.

Osokina D.N., 1963. Plastic and Elastic Low-Module Optically Active Materials in Studies of Crustal Stresses by the Modelling Method. The USSR Acad. Sci. Publishing House, Moscow, 196 p. (in Russian) [Осокина Д.Н. Пластичные и упругие низкомодульные оптически-активные материалы для исследования напряжений в земной коре методом моделирования. М.: Изд-во АН СССР, 1963. 196 с.].

Osokina D.N., 1989. Modeling of tectonic stress fields caused by discontinuities and inhomogeneities in the Earth's crust. In: Experimental tectonics. Methods, results, and prospects. Nauka, Moscow, p. 163-196 (in Russian) [Осокина Д.Н. Моделирование тектонических полей напряжений, обусловленных разрывами и неоднородностями в земной коре // Экспериментальная тектоника. Методы, результаты, перспективы. М.: Наука, 1989. С. 163-196].

Osokina D.N., Bondarenko P.M., 1989. Application issues of polarization optical method in experimental tectonics for modelling of tectonic stress fields. In: Experimental tectonics. Methods, results, and prospects. Nauka, Moscow, p. 78-125 (in Russian) [Осокина Д.Н., Бондаренко П.М. Вопросы применения поляризационно-оптического метода в экспериментальной тектонике для моделирования тектонических полей напряжений // Экспериментальная тектоника. Методы, результаты, перспективы. М.: Наука, 1989. С. 78-125].

Osokina D.N., Tsvetkova N.Y., 1979. Modeling method of local stress fields in the vicinity of tectonic fractures and in earthquake foci. In: Stress and strain fields of the lithosphere. Nauka, Moscow, p. 139-162 (in Russian) [Осокина Д.Н., Цветкова Н.Ю. Метод моделирования локальных полей напряжений в окрестностях тектонических разрывов и в очагах землетрясений // Поля напряжений и деформаций в литосфере. М.: Наука, 1979. С. 139-162].

Panin V.E., 1998. Foundations of physical mesomechanics. Fizicheskaya Mezomekhanika 1 (1), 5-22 (in Russian) [Панин E.B. Основы физической мезомеханики // Физическая мезомеханика. 1998. Т. 1. № 1. С. 5-22].

Panin V.E., Egorushkin V.E., Makarov P.V., Grinyayev Yu.V., Zuyev L.B., Syryamkin V.I., Kolobov Yu.R., 1995. Physical Mesomechanics and Computer Design of Materials. Nauka, Novosibirsk, 297 p. (in Russian) [Панин В.Е., Егорушкин В.Е., Макаров П.В., Гриняев Ю.В., Зуев Л.Б., Сырямкин В.И., Колобов Ю.Р. Физическая мезомеханика и компьютерное конструирование материалов. Новосибирск: Наука, 1995. 297 с.].

Prigozhin I., Kondepudi D., 2002. Modern Thermodynamics: From Heat Engines to Dissipative Structures. Mir, Moscow, 460 p. (in Russian) [Пригожин И., Кондепуди Д. Современная термодинамика: от тепловых двигателей до диссипативных структур. М.: Мир, 2002. 460 с.].

Pushcharovsky Yu.M. (Ed.), 1994. Nonlinear Geodynamics. Nauka, Moscow, 192 p. (in Russian) [Нелинейная геодинамика / Под ред. Ю.М. Пущаровского. М.: Наука, 1994. 192 с.].

Pushcharovsky Yu.M., 1998. Geologic expression of nonlinear geodynamic processes. Geotectonics 32 (1), 3-14.

Ramberg H., 1981. The role of gravity in orogenic belts. In: K.R. McClay, N.J. Price (Eds.), Thrust and Nappe Tectonics. Geological Society, London, Special Publications, Vol. 9, p. 125-140. http://dx.doi.org/10.1144/GSL.SP.1981.009.01.11.

Rats M.V., Chernyshev S.N., 1970. Fracturing and Properties of Fractured Rocks. Nedra, Moscow, 160 p. (in Russian) [Pau M.В., Чернышев С.Н. Трещиноватость и свойства трещиноватых горных пород. М.: Недра, 1970. 160 с.].

Rebetsky Yu.L., 2007. Tectonic Stresses and Strength of Natural Massifs. Akademkniga, Moscow, 407 p. (in Russian) [Ребецкий Ю.Л. Тектонические напряжения и прочность природных массивов. М.: ИКЦ «Академкнига», 2007. 407 с.].

Ruzhich V.V., 1977. Relationships between parameters of faults and their practical value. In: Mechanisms of formation of tectonic structures in East Siberia. Nauka, Moscow, p. 41-48 (in Russian) [Ружич B.В. Зависимости между параметрами разрывных нарушений и их практическое значение // Механизмы формирования тектонических структур Восточной Сибири. Новосибирск: Наука, 1977. С. 41-48].

Sadovsky M.A., 1979. Natural lumping of rocks. Doklady AN SSSR 247 (4), 829-832 (in Russian) [Садовский М.A. Естественная кусковатость горной породы // Доклады АН СССР. 1979. Т. 247. № 4. С. 829-832].

Sadovsky M.A., Pisarenko V.F., 1991. Seismic Process in Block Medium. Nauka, Moscow, 97 p. (in Russian) [Садовский М.А., Писаренко В.Ф. Сейсмический процесс в блоковой среде. М.: Наука, 1991. 97 с.].

San'kov V.A., Miroshnichenko A.I., Parfeevets A.V., Arzhannikova A.V., Lukhnev A.V., 2004. Late Cenozoic state of stress in the Earth's crust of the Khubsugul region (Northern Mongolia): Field and experimental evidence. Geotectonics 38 (2), $142-152$. 
Seminsky K.Zh., 1986. Structural and Mechanical Properties of Clayey Pastes as Model Material in Tectonic Experiments. IEC SB of the USSR Acad. Sci., Irkutsk, 130 p. VINITI 13.08.86. 5762-B86 (in Russian) [Семинский К.Ж. Структурно-механические свойства глинистых паст как модельного материала в тектонических экспериментах. Иркутск: ИЗК СО АН СССР, 1986. 130 с. ВИНИТИ 13.08.86. № 5762-В86].

Seminsky K.Zh., 2003. The Internal Structure of Continental Fault Zones. Tectonophysical Aspect. GEO, Novosibirsk, 244 p. (in Russian) [Семинский К.Ж. Внутренняя структура континентальных разрывных зон: тектонофизический аспект. Новосибирск: Изд-во «ГЕО», 2003. 244 с.].

Shemenda A.I., 1983. Criteria of similarity in mechanical modelling of tectonic processes. Russian Geology and Geophysics (10), 10-19 (in Russian) [Шеменда А.И. Критерии подобия при механическом моделировании тектонических процессов // Геология и геофизика. 1983. № 10. С. 10-19].

Sherman S.I., 1977. Physical Regularities of Faulting in the Earth's Crust. Nauka, Siberian Branch, Novosibirsk, 102 p. (in Russian) [Шерман С.И. Физические закономерности развития разломов земной коры. Новосибирск: Наука. Сиб. отд-ние, 1977. 102 с.].

Sherman S.I., 1984. Physical experiment in tectonics and the theory of similarity. Russian Geology and Geophysics (3), 8-18 (in Russian) [Шерман С.И. Физический эксперимент в тектонике и теория подобия // Геология и геофизика. 1984. № 3. C. 8-18].

Sherman S.I., 1996. Destructive zones of the lithosphere, their state of stresses and seismicity. In: Neotectonics and recent geodynamics of continents and oceans. MTK, RAS, Moscow, p. 157-158 (in Russian) [Шерман С.И. Деструктивные зоны литосферы, их напряженное состояние и сейсмичность // Неотектоника и современная геодинамика континентов и океанов. М.: РАН, МТК, 1996. С. 157-158].

Sherman S.I., Bornyakov S.A., Buddo V.Yu., 1983. Areas of Dynamic Influence of Faults (Modelling Results). Nauka, Novosibirsk, 112 p. (in Russian) [Шерман С.И., Борняков С.А., Буддо В.Ю. Области динамического влияния разломов (результаты моделирования). Новосибирск: Наука, 1983. 112 с.].

Sherman S.I., Bornyakov S.A., Buddo V.Yu., 1985. Recommendations on Evaluation of Widths of Near-Fault Structural Changes. IEC SB RAS, Irkutsk, 42 p. (in Russian) [Шерман С.И., Борняков С.А., Буддо В.Ю. Рекомендации по оценке ширины приразломных структурных изменений. Иркутск: ИЗК СО РАН, 1985. 42 с.].

Sherman S.I., Cheremnykh A.V., Bornyakov S.A., Gladkov A.S., Shishkina L.P., 2002. Dynamics of major faulting in extension zones of the lithosphere (Physical modeling results). Fizicheskaya Mezomekhanika 5 (2), 79-86 (in Russian) [Шеpман С.И., Черемных А.В., Борняков С.А., Гладков А.С., Шишкина Л.П. Динамика формирования генеральных разломов в зонах растяжения литосферы (результаты физического моделирования) // Физическая мезомеханика. 2002. T. 5. № 2. С. 79-86].

Sherman S.I., Cheremnykh A.V., Miroshnichenko A.I., 2005. New data on stress field structure in the Baikal rift system: Modeling Results. Doklady Earth Sciences 401 (2), 249-252.

Sherman S.I., Seminsky K.Zh., Bornyakov S.A. et al., 1991. Faulting in the Lithosphere. Shear Zones. Nauka, Novosibirsk, 261 p. (in Russian) [Шерман С.И., Семинский К.Ж., Борняков С.А. и др. Разломообразование в литосфере: зоны сдвига. Новосибирск: Наука, 1991. 261 с.].

Sherman S.I., Seminsky K.Zh., Bornyakov S.A. et al., 1992. Faulting in the Lithosphere. Extension Zones. Nauka, Novosibirsk, 227 p. (in Russian) [Шерман С.И., Семинский К.Ж., Борняков С.А. и др. Разломообразование в литосфере: зоны растяжения. Новосибирск: Наука, 1992. 227 с.].

Sherman S.I., Seminsky K.Zh., Bornyakov S.A. et al., 1994. Faulting in the Lithosphere. Compression Zones. Nauka, Novosibirsk, 262 p. (in Russian) [Шерман С.И., Семинский К.Ж., Борняков С.А. и др. Разломообразование в литосфере: зоны сжатия. Новосибирск: Наука, 1994. 262 с.].

Solonenko A., Solonenko N., Melnikova V., Shteiman E., 1997. The seismicity and earthquake focal mechanisms of the Baikal rift zone. Bulletin des Centres de Recherches Exploration-Production Elf Aquitaine 21 (1), 207-231.

Stoyanov S.S., 1977. Fault Zone Formation Mechanisms. Nedra, Moscow, 114 p. (in Russian) [Стоянов C.C. Механизмы формирования разрывных зон. М.: Недра, 1977. 114 с.].

Tchalenko J.S., 1970. Similarities between shear zones of different magnitudes. Geological Society of America Bulletin 81 (6), 1625-1640. http://dx.doi.org/10.1130/0016-7606(1970)81[1625:SBSZOD]2.0.CO;2.

Turcotte D., Schubert J., 1985. Geodynamics. Applications of Continuum Physics to Geological Problems. Mir, Moscow, 727 p. (in Russian) [Теркот Д., Шуберт Дж. Геодинамика. Геологические приложения физики сплошных сред. М.: Мир, 1985. 727 с.].

Velde B., Dubois J., Touchard G., Badri A., 1990. Fractal analysis of fractures in rocks: the Cantor's Dust method. Tectonophysics 179 (3), 345-352. http://dx.doi.org/10.1016/0040-1951(90)90300-W.

Ventcel E.S., Ovcharov L.A., 2000. Theory of Random Processes and Its Engineering Applications. Vysshaya Shkola, Moscow, 383 p. (in Russian) [Вентцель E.С., Овчаров Л.А. Теория случайных процессов и ее инженерные приложения. М.: Высшая школа, 2000. 383 с.].

Vstovsky G.V., Bornyakov S.A., 2010. First experiences of seismodeformation monitoring of Baikal rift zone (by the example of South-Baikal earthquake of August 27, 2008). Natural Hazards and Earth System Science 10 (4), 667-672. http://dx. doi.org/10.5194/nhess-10-667-2010.

Wilcox R.E., Harding T.P., Seely D.R., 1973. Basic wrench tectonics. AAPG Bulletin 57 (1), 74-96. http://dx.doi.org/10. 1306/819A424A-16C5-11D7-8645000102C1865D. 


\section{S.A. Bornyakov et al.: Main regularities of faulting in lithosphere...}

Yin Xiu-Ian, Ma Yin-Sheng et al., 2002. Photoelastic modeling of the tectonic stress field in the central part of the Bozhong depression. Journal of Geomechanics 8 (3), 219-228.

Zubarev D.N., Morozov V.G., Repke G., 2002. Statistical Mechanics of Non-Equilibrium Processes. Fizmatlit, Moscow, 431 р. (in Russian) [Зубарев Д.Н., Морозов В.Г., Репке Г. Статистическая механика неравновесных процессов. М.: Физматлит, 2002. 431 с.].

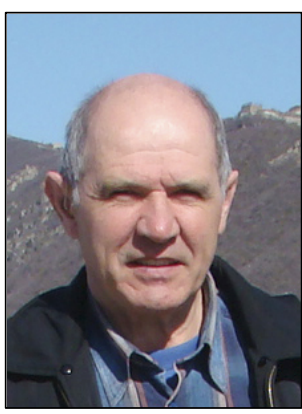

Борняков Сергей Александрович, канд. геол.-мин. наук, с.н.с.

Институт земной коры СО РАН

664033, Иркутск, ул. Лермонтова, 128, Россия

\e-mail: bornyak@crust.irk.ru

Bornyakov, Sergei A., Candidate of Geology and Mineralogy, Senior Researcher

Institute of the Earth's Crust SB RAS

128 Lermontov street, Irkutsk 664033, Russia

\e-mail: bornyak@crust.irk.ru

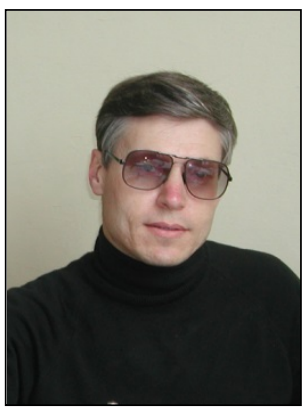

Семинский Константин Жанович, докт. геол.-мин. наук, зав. лабораторией тектонофизики

Институт земной коры СО РАН

664033, Иркутск, ул. Лермонтова, 128, Россия

Тел.: 8(3952)423027; e-mail: seminsky@crust.irk.ru

Seminsky, Konstantin Zh., Doctor of Geology and Mineralogy, Head of Laboratory of Tectonophysics Institute of the Earth's Crust SB RAS

128 Lermontov street, Irkutsk 664033, Russia

Tel.: 8(3952)423027; e-mail: seminsky@crust.irk.ru

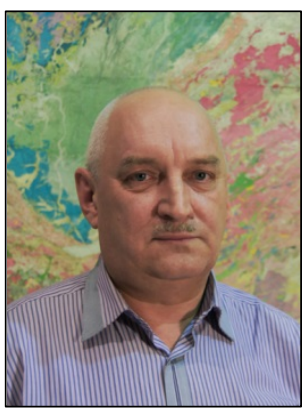

Буддо Владимир Юрьевич, канд. геол.-мин. наук

Институт земной коры СО РАН

664033, Иркутск, ул. Лермонтова, 128, Россия

Buddo, Vladimir Yu., Candidate of Geology and Mineralogy

Institute of the Earth's Crust SB RAS

128 Lermontov street, Irkutsk 664033, Russia

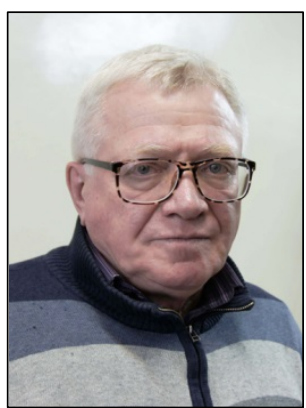

Мирошниченко Андрей Иванович, канд. геол.-мин. наук, с.н.с.

Институт земной коры СО РАН

664033, Иркутск, ул. Лермонтова, 128, Россия

e-mail: mai@crust.irk.ru

Miroshnichenko, Andrei I., Candidate of Geology and Mineralogy, Senior Researcher Institute of the Earth's Crust SB RAS

128 Lermontov street, Irkutsk 664033, Russia

e-mail:mai@crust.irk.ru 


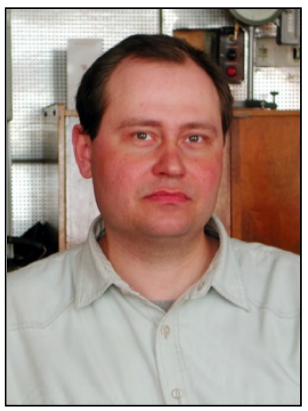

Черемных Александр Викторович, канд. геол.-мин. наук, с. н. с.

Институт земной коры СО РАН

664033, Иркутск, ул. Лермонтова, 128, Россия

Тел.: 89501404851; e-mail: cherem@crust.irk.ru

Cheremnykh, Alexander V., Candidate of Geology and Mineralogy, Senior Researcher Institute of the Earth's Crust SB RAS

128 Lermontov street, Irkutsk 664033, Russia

Tel.: 89501404851; e-mail: cherem@crust.irk.ru

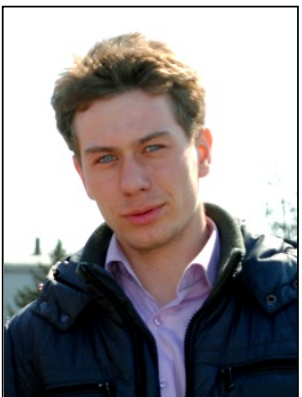

Черемных Алексей Сергеевич, аспирант

Институт земной коры СО РАН

664033, Иркутск, ул. Лермонтова, 128, Россия

e-mail: acherem@crust.irk.ru

Cheremnykh, Alexei S., PhD student

Institute of the Earth's Crust SB RAS

128 Lermontov street, Irkutsk 664033, Russia

e-mail: acherem@crust.irk.ru

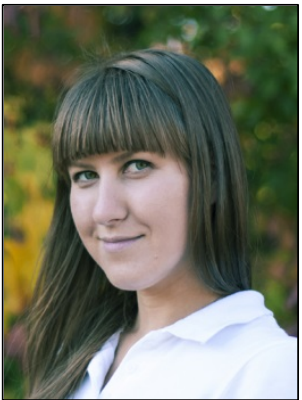

Тарасова Анастасия Алексеевна., аспирант Институт земной коры СО РАН

664033, Иркутск, ул. Лермонтова, 128, Россия

Tarasova, Anastassia A., PhD student

Institute of the Earth's Crust SB RAS

128 Lermontov street, Irkutsk 664033, Russia 